\title{
\#USGS
}

science for a changing world

Prepared in cooperation with the Missouri River Recovery Program

\section{Overview and Progress of the Pallid Sturgeon Assessment Framework Redesign Process}

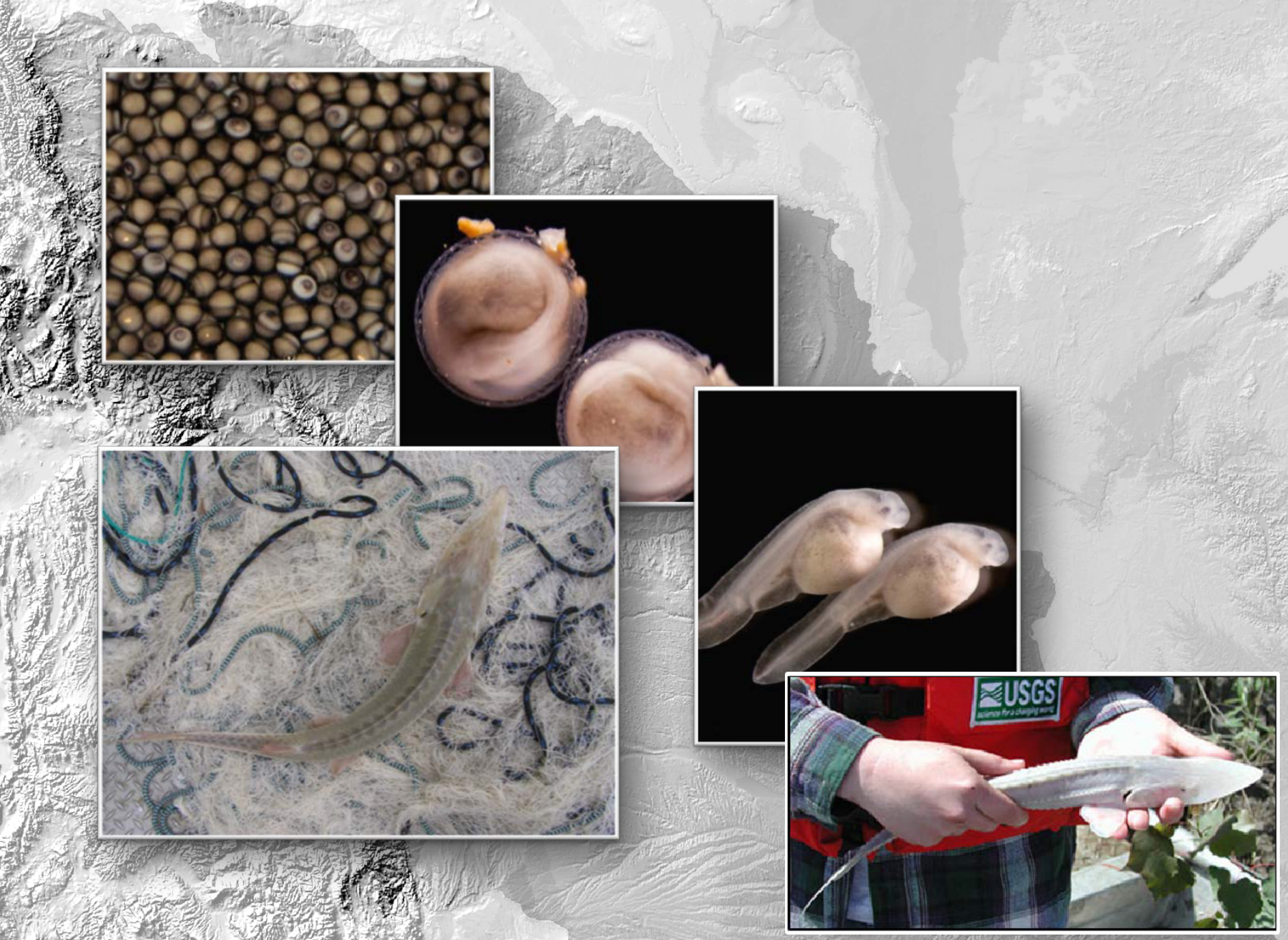

Open-File Report 2018-1166

U.S. Department of the Interior U.S. Geological Survey 
Cover photograph index:

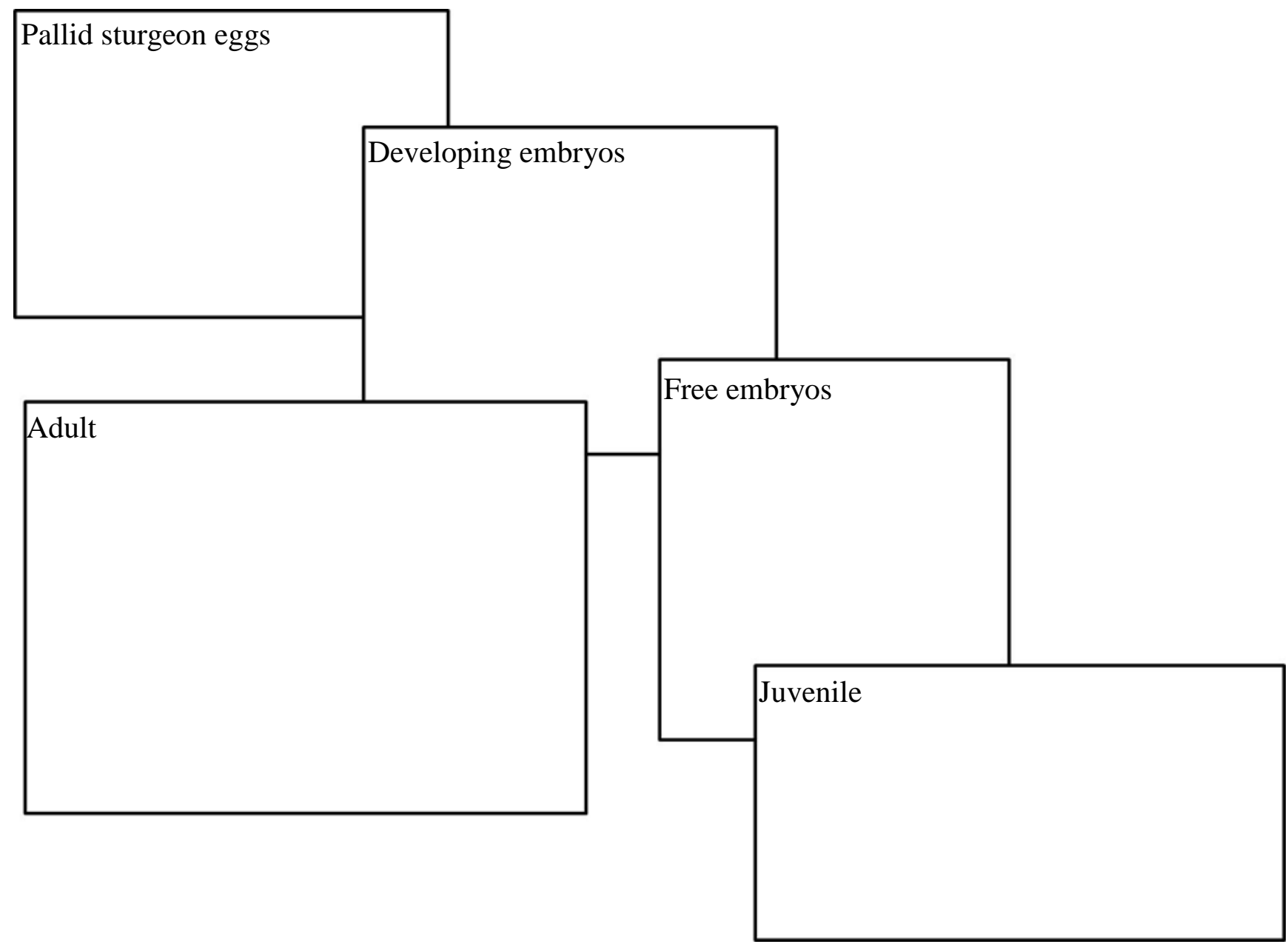

Background image: shaded relief map of the Missouri River drainage basin, US Geological Survey, EROS Data Center.

Photographs by U.S. Geological Survey personnel 


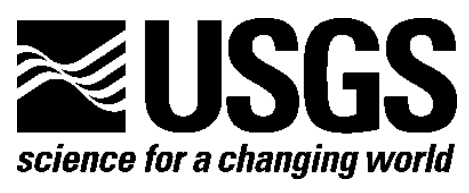

\section{Overview and Progress of the Pallid Sturgeon Assessment Framework Redesign Process}

By Michael E. Colvin, Sara Reynolds, Robert B. Jacobson, Landon L. Pierce, Kirk D. Steffensen, Timothy L. Welker

Open-File Report 2018-1166 


\section{U.S. Department of the Interior RYAN K. ZINKE, Secretary}

\section{U.S. Geological Survey James F. Reilly II, Director}

U.S. Geological Survey, Reston, Virginia: 2018

For more information on the USGS - the Federal source for science about the Earth, its natural and living resources, natural hazards, and the environment-visit https://www.usgs.gov/ or call 1-888-ASK-USGS (1-888-275-8747).

For an overview of USGS information products, including maps, imagery, and publications, visit https://store.usgs.gov/.

Any use of trade, firm, or product names is for descriptive purposes only and does not imply endorsement by the U.S. Government.

Although this information product, for the most part, is in the public domain, it also may contain copyrighted materials as noted in the text. Permission to reproduce copyrighted items must be secured from the copyright owner.

Suggested citation:

Colvin, M.E., Reynolds, S., Jacobson, R.B., Pierce, L.L., Steffensen, K.D., and Welker, T.L., 2018, Overview and progress of the pallid sturgeon assessment framework redesign process: U.S. Geological Survey Open-File Report 2018--1166, 87 p., https://doi.org/10.3133/ofr20181166.

ISSN 2331-1258 (online) 


\section{Contents}

Acknowledgments …..............................................................................................................

Abstract ……

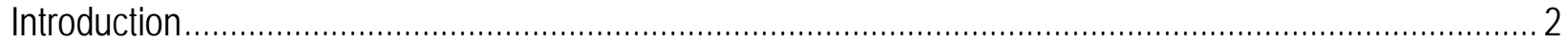

Context of the Pallid Sturgeon Population Assessment Program in the Adaptive Management Program ..... 4

The Need to Initiate a Pallid Sturgeon Population Assessment Program Redesign .................................... 6

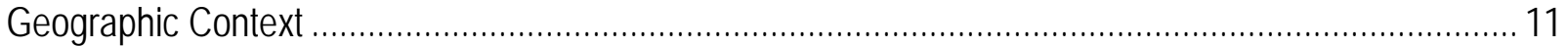

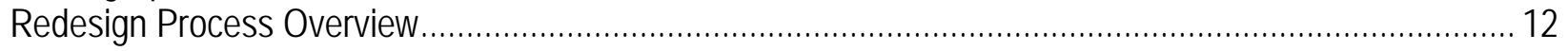

Identify Stakeholder Views on Objectives for the Monitoring Program ................................................... 13

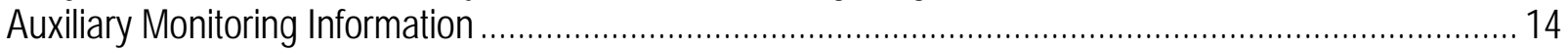

Calculate Performance Metrics Given Alternative Monitoring Designs .................................................... 21

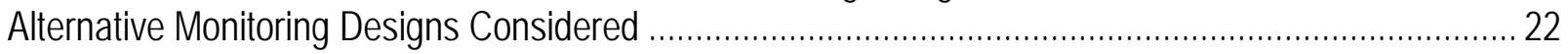

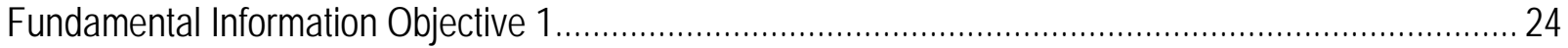

Basin-Level Survey Design, Bend-Level Sampling Effort, and Gears ........................................... 24

Simulating Recruitment to Valuate Fundamental Information Objective 1 ........................................ 25

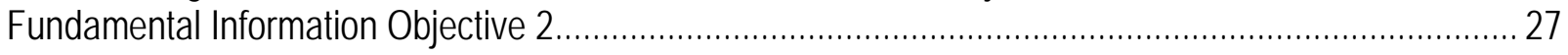

Basin-Level Survey Design, Bend-Level Sampling Effort, and Gears............................................. 28

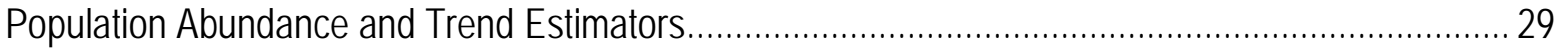

Abundance Estimators .............................................................................................. 30

Minimum Known Alive ............................................................................................ 30

Closed Capture-Recapture Estimators............................................................................ 30

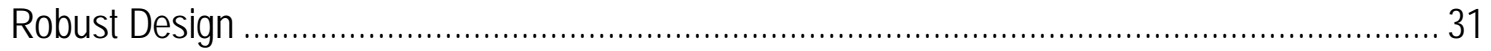

Estimating Minimum Known Alive, $\mathrm{M}_{0}$, and $\mathrm{M}_{\mathrm{t}}$ Segment-Level Abundance .............................. 33

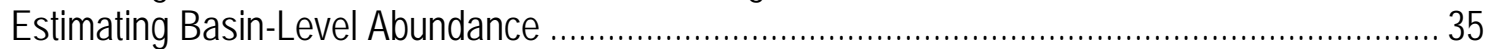

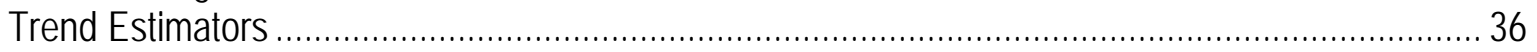

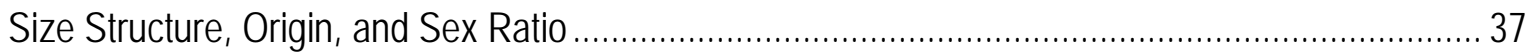

Simulating Monitoring Design Fundamental Objective 2 Performance Metrics_An Overview............ 38

Generation of Reference Populations with Known Dynamics ........................................................ 39

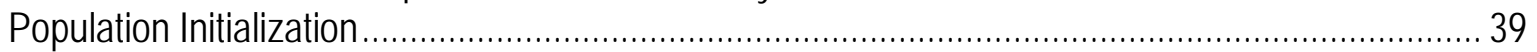

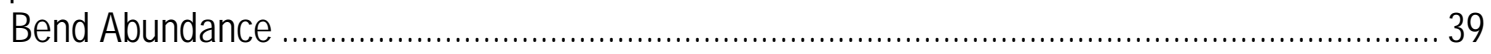

Assign Demographic Attributes...................................................................................... 40

Initialize Individual Length and Growth Parameters ........................................................ 41

Simulating Annual Transitions ........................................................................................ 42

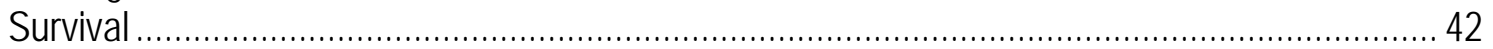

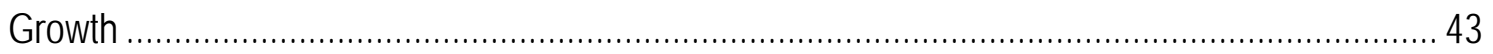

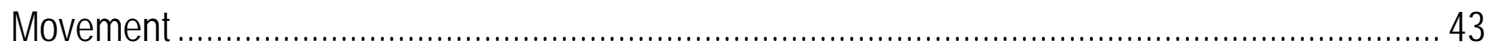

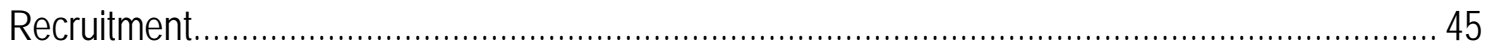

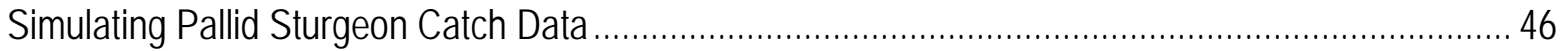

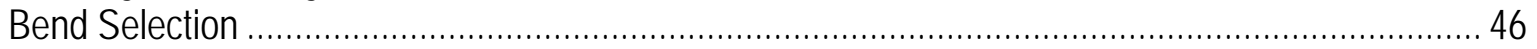

Pallid Sturgeon Captures........................................................................................................ 47

Calculating Performance Metrics Given Catch Data and Associated Monitoring Design .................... 50

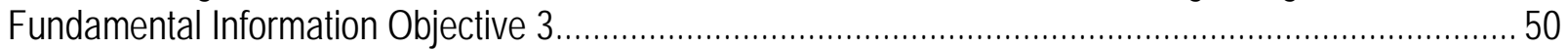

Fundamental Information Objective 4............................................................................... 51

Fundamental Information Objective 5.................................................................................. 54

Synthesize Outputs and Develop a Decision-Support Tool to Compare Alternative Monitoring Designs .... 55

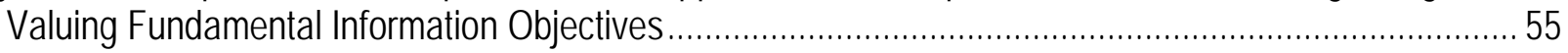


Linking Performance Metrics and Fundamental Information Objectives............................................... 55

Weighting Fundamental Information Objectives and Subobjectives.................................................. 58

Preliminary Design Outputs............................................................................................ 59

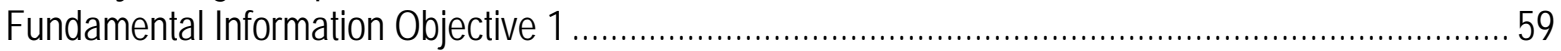

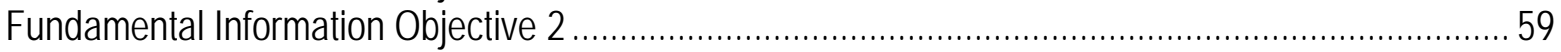

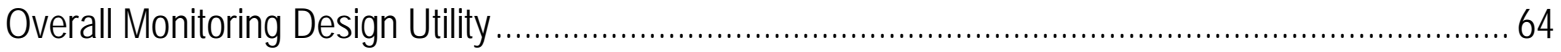

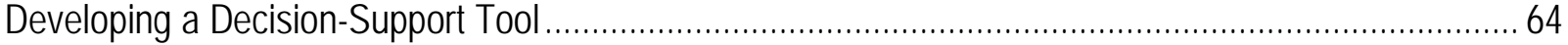

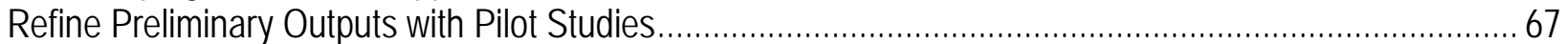

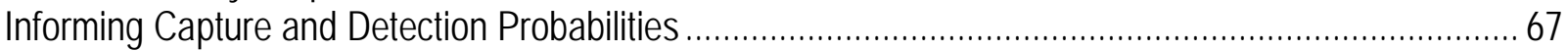

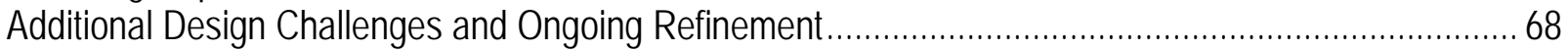

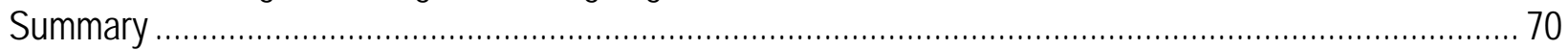

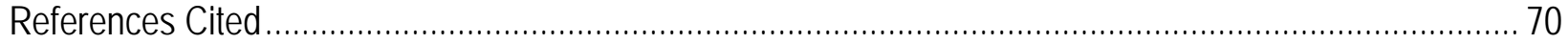

Appendix 1. Recruitment-Detection Simulation Parameters …………….......................................... 75

Appendix 2. Arithmetic Mean Compared to Weighted Mean Aggregation Approaches ...............................76

Appendix 3: Reference Population and Catch-Data Simulation Parameters ............................................ 80

\section{Figures}

Figure 1. Map of the Missouri River highlighting segments of the upper and lower basins, and relevant sections of the Yellowstone and Mississippi Rivers............................................................................... 3

Figure 2. Information monitoring framework illustrating the integration of the four information

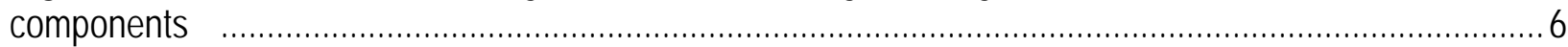

Figure 3. Fundamental objective and subobjectives for pallid sturgeon recovery................................ 8 Figure 4. Segment-specific initial length distributions used to initialize individual pallid sturgeon before simulating population dynamics............................................................................................. 42

Figure 5. Probability of a pallid sturgeon moving to an upstream or downstream bend or remaining at bend 78 located at river kilometer (rkm) 1,453........................................................................... 44

Figure 6. Example gamma distribution fit to effort data for trotline deployed in the upper basin, where effort is measured as minutes per gear deployment. ..................................................................... 49

Figure 7. Utility functions used to scale the fundamental objective 2 performance metrics calculated for pallid sturgeon abundance and trend......................................................................................5

Figure 8. Boxplots of the probability of detecting a recruit at the basin level with increasing number of trawls within a bend.

Figure 9. Boxplots of the performance metrics associated with fundamental objective 2 for varying sturgeon-season designs...

Figure 10. Boxplots of scaled utility values for each of the performance metrics in figure 9 relating to fundamental objective 2 .

Figure 11. Boxplots of the overall utility value for fundamental objective 2, calculated as the combined utility for trend and abundance estimates assuming equal weighting of subobjectives.

Figure 12. Plots of median monitoring design utility versus cost for each of the 270 analyzed alternative monitoring designs (the sturgeon-season sampling designs illustrated by boxplots in figure 11 plus recruitment-detection sampling design) that were simulated for trotlines and the given estimators...

Figure 13. Zoomed in version of figure 12 to show the estimators associated with the highest utilities that cost approximately $\$ 0.9$ million.

Figure 14. Illustration of a decision-support model developed for fundamental objective 1...................67 
Figure 2.1. Plots comparing the outcomes of the performance metrics associated with fundamental objective 2 (as calculated for the 1,600 catch-data replicates) of the arithmetic mean (AM) aggregation method and the weighted mean (WM) aggregation method.

Figure 3.1. Occasion-level capture probability distributions resulting from various mean and standard deviation inputs to the logit-normal distribution defining deployment-level catchability in the catch-data simulations.

Figure 3.2. Occasion-level capture probability distributions resulting from various mean and standard deviation inputs to the logit-normal distribution defining deployment-level catchability in the catch-data simulations.

Figure 3.3. Occasion-level capture probability distributions resulting from various mean and standard deviation inputs to the logit-normal distribution defining deployment-level catchability in the catch-data simulations.

Figure 3.4. Occasion-level capture probability distributions resulting from various mean and standard deviation inputs to the logit-normal distribution defining deployment-level catchability in the catch-decision data simulations.

\section{Tables}

Table 1. Information objectives of the Pallid Sturgeon Population Assessment Program, v. 1.0 (Welker and others, 2017).

Table 2. Fundamental management and information objectives for pallid sturgeon under the Missouri River Recovery Program.

Table 3. Objectives and subobjectives elicited during PSPAP v. 2.0 workshops and webinars with actions and recommended program routing to address the information need. ................................................. 15

Table 4. Alternative monitoring designs compared in the current analyses. .......................................2 23

Table 5. Summary of bends within Pallid Sturgeon Population Assessment Program Missouri river segments and number of segments sampled within segment. .......................................................... 29

Table 6. Segment and river level densities by origin............................................................... 40

Table 7. Collaborative population model inputs. ………...............................................................53

Table 1.1. Recruitment-detection simulations: currently simulated parameter values and the full distributions under analysis (proposed future work).

Table 2.1. Known bend abundance, length, and density for each of the four bends within the segment of interest.

Table 3.1. Reference population parameter inputs and distributions.

Table 3.2. Summary of effort data by gear and basin, where effort is measured in minutes of gear use per deployment.

Table 3.3. Catch data simulation parameter inputs and distributions. 


\section{Conversion Factors}

International System of Units to U.S. customary units

\begin{tabular}{|c|c|c|}
\hline \multicolumn{3}{|c|}{$\begin{array}{rrr}\text { Multiply } & \text { By } & \text { To obtain }\end{array}$} \\
\hline \multicolumn{3}{|c|}{ Length } \\
\hline millimeter (mm) & 0.03937 & inch (in.) \\
\hline kilometer (km) & 0.6214 & mile (mi) \\
\hline kilometer (km) & 0.5400 & mile, nautical (nmi) \\
\hline
\end{tabular}

Temperature in degrees Celsius $\left({ }^{\circ} \mathrm{C}\right)$ may be converted to degrees Fahrenheit $\left({ }^{\circ} \mathrm{F}\right)$ as ${ }^{\circ} \mathrm{F}=\left(1.8 \times{ }^{\circ} \mathrm{C}\right)+32$.

\section{Abbreviations}

CPUE catch per unit effort

IRC interception-rearing complex

MCLFS main-channel larval flux sampling

MKA minimum known alive

MRRP Missouri River Recovery Program

MRSAMP Missouri River Science and Adaptive Management Plan

PSPAP Pallid Sturgeon Population Assessment Program

USACE U.S. Army Corps of Engineers

USFWS U.S. Fish and Wildlife Service 


\section{Acknowledgments}

This report benefitted from technical review from Dr. Carl Schwarz (Simon Fraser University), Dr. Drew Tyre (University of Nebraska), and Dr. Mark Wildhaber (U.S. Geological Survey). The research has been funded through the U.S. Army Corps of Engineers Missouri River Recovery_Integrated Science Program and the U.S. Geological Survey. The authors gratefully acknowledge the collaboration of dozens of pallid sturgeon and river experts (Pallid Sturgeon Population Assessment Program stakeholders), from many agencies, who participated in workshops and discussions. We also gratefully acknowledge multiple discussions and feedback from the Missouri River Recovery Implementation Committee's Independent Science Advisory Panel. 


\title{
Overview and Progress of the Pallid Sturgeon Assessment Framework Redesign Process
}

By Michael E. Colvin, ${ }^{1}$ Sara Reynolds, ${ }^{1}$ Robert B. Jacobson, ${ }^{2}$ Landon L. Pierce, ${ }^{3}$ Kirk D. Steffensen, ${ }^{4}$ Timothy L. Welker ${ }^{5}$

\begin{abstract}
The Pallid Sturgeon Population Assessment Program (PSPAP) was initiated in 2003, and full implementation began in 2006, to monitor the trend of Scaphirhynchus albus (pallid sturgeon) and native fish communities in the Upper and Lower Missouri River Basins. The original PSPAP (v. 1.0) was a catch-effort based monitoring program where population abundance and trend were monitored using a relative index, catch per unit effort. In 2013, the Missouri River Recovery Program (MRRP), led by the U.S. Army Corps of Engineers (USACE) and the U.S. Fish and Wildlife Service (USFWS), began a reassessment of science and monitoring approaches to support a new river management plan. The need to redesign the PSPAP was triggered by the recognition that the PSPAP v. 1.0 would not be optimally effective in contributing information needed to make decisions about the pallid sturgeon fundamental management objective- to avoid jeopardizing the continued existence of the pallid sturgeon from USACE actions in the Missouri River-identified in the Missouri River Science and Adaptive Management Plan. The fundamental management objective includes two management subobjectives: (1) increase pallid sturgeon recruitment to age 1 and (2) maintain or increase numbers of pallid sturgeon as an interim measure until sufficient and sustained natural recruitment occurs. These two management subobjectives motivated the development of two fundamental information objectives for PSPAP v. 2.0: (1) to provide information needed to quantify recruitment to age 1 and (2) to quantify pallid sturgeon population abundance and trend. The charge to the authors of this report was to develop an approach to monitoring the pallid sturgeon population in the Missouri River that would contribute information toward gauging overall performance of management actions to achieve the fundamental objectives of the MRRP and to potentially improve understanding of linkages from the management activities to population responses. We used transparent and robust processes to identify alternative monitoring designs that meet the fundamental objectives for managing pallid sturgeon in the MRRP, with a focus on simulation models to evaluate the performance of varying monitoring. This report documents the process of comparing potential alternative monitoring design abilities to provide decision-relevant information for management of the species. The process includes
\end{abstract}

\footnotetext{
${ }^{1}$ Mississippi State University.

${ }^{2}$ U.S. Geological Survey.

${ }^{3}$ U.S. Fish and Wildlife Service.

${ }^{4}$ Nebraska Game and Parks Commission.

${ }^{5}$ U.S. Army Corps of Engineers.
} 
evaluation of information content and attendant uncertainties and considers tradeoffs in types of information valued by stakeholders. The anticipated end product of this process will be synthesized in a decision-support tool that can be used to facilitate learning and iterative revisions of the monitoring roadmap.

\section{Introduction}

The Pallid Sturgeon Population Assessment Program (PSPAP) was initiated in 2003, with full implementation beginning in 2006, to monitor the trend of Scaphirhynchus albus (pallid sturgeon) and native fish communities in the Upper and Lower Missouri River basins (table 1, fig. 1; for a brief history, see Welker and others [2017]). The original PSPAP (referred to as "v. 1.0") is a catch-effort based monitoring program where population abundance is monitored using a relative index, catch per unit effort (CPUE). The main stem Missouri River was organized into segments of differing length, and bends within those segments were the fundamental sampling units. A predetermined number (about 25 percent) of bends within each segment was randomly selected each year under a rigorous sampling protocol (Welker and others, 2017).

Table 1. Information objectives of the Pallid Sturgeon Population Assessment Program, v. 1.0 (Welker and others, 2017).

\begin{tabular}{cl}
\hline Number & \multicolumn{1}{c}{ Objective } \\
\hline 1 & $\begin{array}{l}\text { Evaluate annual and long-term trends in pallid sturgeon population abundance and geographic } \\
\text { distribution throughout the Missouri River System. }\end{array}$ \\
2 & $\begin{array}{l}\text { Evaluate annual results and long-term trends of habitat usage of pallid sturgeon and hatchery stocked } \\
\text { pallid sturgeon by season and life stage. }\end{array}$ \\
3 & $\begin{array}{l}\text { Evaluate population structure and dynamics of pallid sturgeon in the Missouri River system. } \\
\text { Evaluate annual results and long-term trends in native target species population abundance and } \\
\text { geographic distribution throughout the Missouri River system. }\end{array}$ \\
5 & $\begin{array}{l}\text { Evaluate annual results and long-term trends of habitat usage of the target native species by season } \\
\text { and life stage. } \\
\text { Evaluate annual results and long-term trends in all remaining species (minimum of } 50 \text { fish } \\
\text { collected/species) population abundance and geographic distribution throughout the Missouri River } \\
\text { system. }\end{array}$ \\
\end{tabular}

Throughout its implementation, PSPAP v. 1.0 has provided a wealth of data related to pallid sturgeon in the Missouri River and has facilitated various analyses that have aided in system and species understanding. As management objectives for pallid sturgeon in the Missouri River have evolved, however, expectations for the PSPAP have also evolved. In 2013, the Missouri River Recovery Program (MRRP), led by the U.S. Army Corps of Engineers (USACE) and the U.S. Fish and Wildlife Service (USFWS), began a reassessment of science and monitoring approaches to support a new river management plan. The reassessment indicated that PSPAP monitoring could be revised to be more effective in providing decision-relevant information for the new management plan. 


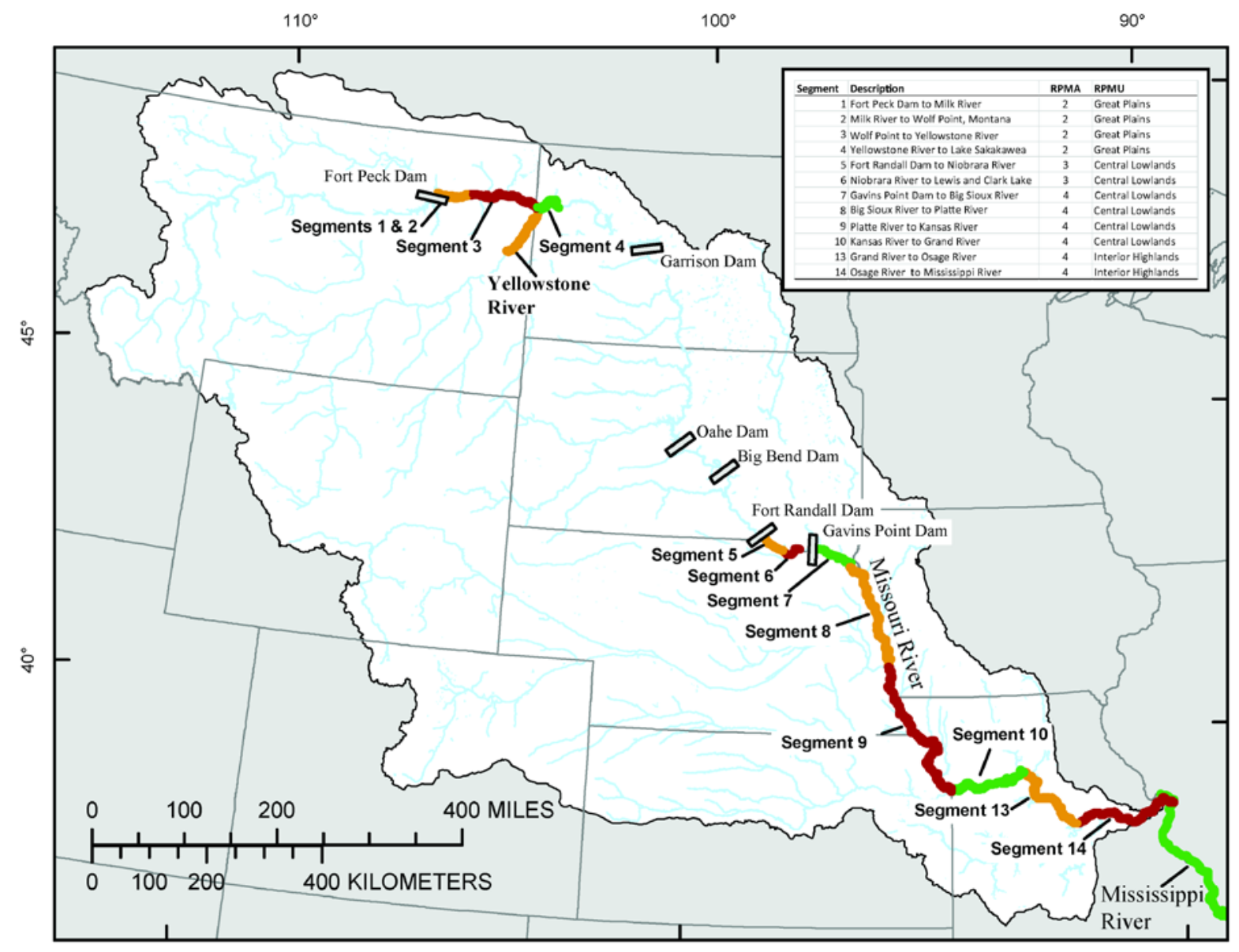

Figure 1. Map of the Missouri River highlighting segments of the upper and lower basins, and relevant sections of the Yellowstone and Mississippi Rivers. Relations among segments, recovery priority management areas (RPMAs), and recovery plan management units (RPMUs) are indicated in the upper right. Simulations included sampling bends within segments $2-4$ of the upper basin and segments $7-10$, 13 , and 14 of the lower basin under various monitoring designs.

This report documents the process of comparing potential alternative monitoring design abilities to provide decision-relevant information for management of the species. The process includes evaluation of information content and attendant uncertainties and considers tradeoffs in types of information valued by stakeholders. It follows the roadmap for developing a monitoring program described by Reynolds and others (2016), in which the primary components follow an iterative decision-making approach of (1) frame the problem, (2) design the program, (3) implement and learn, and (4) learn and revise. The first component contains several steps including identifying the problem and defining the objectives of the monitoring program. The design component focuses on monitoring type and how system understanding is quantified and estimated. The last components are where periods of adjustment and modification occur from postimplementation learning. This report is an initial documentation of a work in progress. Additional reports are anticipated as we refine and adapt the monitoring program given new information from analyses and pilot implementation.

We used a transparent and robust process to identify alternative monitoring designs that meet the fundamental objectives for managing pallid sturgeon in the MRRP. We used a 
purposely thorough process, examining estimators that would not likely meet objectives, such that the value of varying monitoring designs could be demonstrated. Through this process, we elicited stakeholder inputs on ancillary objectives, system understanding, and development of performance metrics that represent fundamental management objectives. The end product of this process will be synthesized in a decision-support tool that can be used to facilitate learning and iterative revisions of the monitoring framework.

The redesign process thus far has led to the consideration of PSPAP v. 2.0 monitoring designs that retain much of the original PSPAP v. 1.0 monitoring approaches. PSPAP v. 2.0 differs from v. 1.0 in that it considers sampling designed to specifically target age- 0 and age- 1 naturally produced pallid sturgeon. It also places a stronger emphasis on obtaining absolute abundance estimates, resulting in the consideration of monitoring designs that include markrecapture sampling. Additionally, the redesign process led to the de-emphasis of sampling of the native fish community (Welker and others, 2017). Fish-community sampling was characterized as an ancillary subobjective, and it will be analyzed in future work. This deemphasis does not imply the elimination of fish-community sampling; however, its inclusion will ultimately be determined by relevance to decision making and budget constraints.

\section{Context of the Pallid Sturgeon Population Assessment Program in the Adaptive Management Program}

Redesign of the PSPAP v. 1.0 to PSPAP v. 2.0 is intended to update population assessment to support adaptive management of the MRRP. PSPAP v. 2.0 builds from the strengths of the original PSPAP v. 1.0 and provides a complementary component of an overall monitoring framework. PSPAP v. 2.0 is considered a necessary part of the pallid sturgeon monitoring framework on the Missouri River, but it is not considered sufficient for all monitoring needs. Instead, the PSPAP v. 2.0 is designed to complement three additional monitoring and assessment components:

1. effectiveness monitoring of management actions,

2. focused research studies, and

3. a collaborative, integrative population model.

Together, the four components consist of the pallid sturgeon monitoring and assessment framework needed to understand and forecast population responses to management actions (fig. 2). The four components include the following:

1. PSPAP v. 2.0.-Akin to the original PSPAP v. 1.0, the fundamental objective of PSPAP v. 2.0 is to provide essential population-level information needed for the MRRP to make decisions about its fundamental management objectives, including, but not limited to, the following:

- Discern abundance and trends of the pallid sturgeon population and serve as calibration and validation of model forecasts.

- Complement and enhance understanding of the effect of system-level management actions to population responses. PSPAP v. 2.0, under the proposed structure, cannot provide direct linkages to all management actions but will be especially important in evaluating population responses, population augmentation, and stocking actions. 
2. Effectiveness monitoring.-Each MRRP action has an associated monitoring plan that is designed to provide insights into whether or not the action has the intended ecological effect. Effectiveness monitoring plans have been defined for flow cues, passage around Intake Dam on the Lower Yellowstone River in Montana (fig. 1), spawning-habitat construction, interception-rearing complex (IRC) construction, and rehabilitation of shallow-water habitat projects. These effectiveness monitoring plans focus on implementation monitoring (that is, was the management action implemented as intended?) and process-based monitoring (that is, did the management action achieve desired changes to ecological processes thought to lead to increased growth and survival?). They do not address population-level responses to the actions directly. Instead, they provide information complementary to PSPAP v. 2.0, the collaborative population model, and focused research studies, which will be needed to link the management actions to the population-level effect. An overview of the effectiveness monitoring approach for each of the MRRP actions, with IRCs presented as a more detailed example, is provided by the Missouri River Science and Adaptive Management Plan (MRSAMP; Fischenich, and others, 2018b).

3. Focused research studies. - The MRSAMP defines four levels of implementation of actions for pallid sturgeon. Level 1 is foundational research, level 2 is field experimentation, level 3 is implementation of a management action at a level expected to create measurable population responses, and level 4 is full implementation of the action. Levels 1 and 2 comprise focused research and experimental studies, described in appendix C of the MRSAMP Fischenich, and others, 2018a). The focused studies are designed to provide a fundamental understanding of pallid sturgeon ecology in the Missouri River and to develop quantitative response models. For example, level-1 mesocosm studies on foraging bioenergetics of age-0 sturgeon are meant to translate changes in habitat characteristics in IRCs (depths, velocities, and bottom conditions) into changes in growth and survival. Other level-1 studies are intended to develop technologies that can be used to measure responses, such as improvements in telemetry systems and direct measurements of habitat conditions and egg survival. Level-2 experimentation evaluates an action by implementing it in the field. An example would be occasional pulsed flow releases from a dam to quantify reproductive migration responses. Level-3 implementation occurs at a scale for which it is expected that population-level responses would be measurable. Effectiveness monitoring of level-3 actions will determine if population-level effects actually occur. Contingent on documentation of successful level-3 actions, level-4 actions are defined as implementation at the full level, determined to be a level necessary and sufficient to maintain the pallid sturgeon population at USFWS-determined targets.

4. Collaborative, integrative population model.-The collaborative, integrative population model documented in Jacobson and others (2016) serves as the framework to integrate understanding from effectiveness monitoring, focused research, and PSPAP v. 2.0. Changes in model parameter values associated with actions (for example, increases in age-0 survival associated with IRCs or increases in viable gametes associated with flow cues or spawning habitats) will be incorporated into the model to provide a predictive understanding of population-level responses and uncertainties associated with management actions. PSPAP v. 2.0 may provide additional parameter estimates (for example, gender ratios, fecundity, age at first reproduction, and recrudescent intervals). 
Importantly, PSPAP v. 2.0 will provide the empirical data on population status and trends needed to validate population model results.

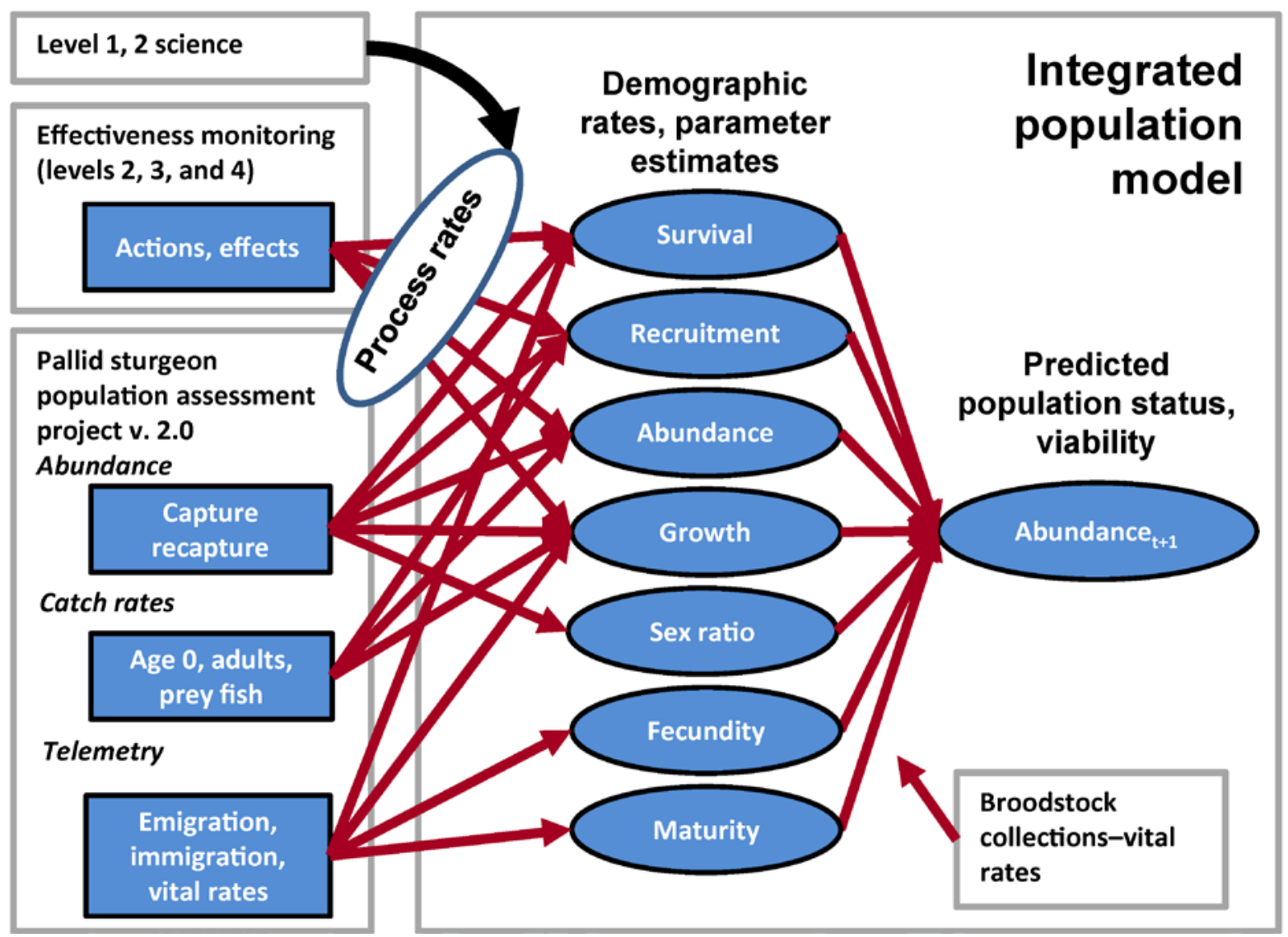

Figure 2. Information monitoring framework illustrating the integration of the four information components.

The remainder of this report focuses on the design process for PSPAP v. 2.0. The redesign process and possible changes may potentially affect many stakeholders. Stakeholders in this sense include State and Federal resource-management agencies, agencies contracted to collect data, consulting groups working on the adaptive management plan, and the USACE, which provides most of the resources to conduct the assessments. Our process is intended to provide a transparent and rigorous approach to compare alternative monitoring designs in the context of a wide range of stakeholder objectives and considerable uncertainty.

\section{The Need to Initiate a Pallid Sturgeon Population Assessment Program Redesign}

The central assumption of the redesign process is that "the value of monitoring in adaptive management is derived from its contribution to adaptive decision making, and monitoring efforts should be designed with that goal in mind." (Williams and others, 2009, p. 32). The desire to redesign the PSPAP was triggered by the recognition that the original PSPAP v. 1.0 would not be optimally effective in contributing information needed to make 
decisions about the pallid sturgeon fundamental objectives identified in the MRSAMP. The charge to the Technical Team (authors of this report) was to develop an approach to monitoring the pallid sturgeon population in the Missouri River that would contribute information toward gauging overall performance of management actions to achieve the fundamental objectives of the MRRP and to improve understanding of linkages from the management activities to population responses. As discussed in the previous section, the population assessment program is intended to be an essential, complementary part of a multicomponent monitoring and assessment framework and, therefore, is not expected to be successful without the complementary parts. The charge to the team was not necessarily to replace the PSPAP v. 1.0 but to refocus so it would be more effective and integrated within the monitoring and assessment framework.

The fundamental pallid sturgeon management objectives of the MRRP were defined and provided by the USFWS (fig. 3, table 2). The fundamental management objective-to avoid jeopardizing the continued existence of the pallid sturgeon from USACE actions in the Missouri River-is a broad statement compatible with development of the MRRP management plan. The two management subobjectives are more specific and focused on measurable outcomes. Specifically, the subobjectives prescribed by the USFWS are (1) to increase pallid sturgeon recruitment to age 1 and (2) to maintain or increase numbers of pallid sturgeon as an interim measure until sufficient and sustained natural recruitment occurs (fig. 3). These two management subobjectives motivated the development of two fundamental information objectives for PSPAP v. 2.0; we use the term information objective to describe information needed to quantify understanding and progress toward the management objectives: (1) to provide information needed to quantify recruitment to age 1 and (2) to quantify pallid sturgeon population abundance and population abundance trend

Management subobjective 1 (increase pallid sturgeon recruitment to age 1) is based on the understanding that bottlenecks for pallid sturgeon populations are likely in age-0 survival and that after the first year of life, survival increases substantially (Jacobson and others, 2015; Rotella, 2015; Steffensen and others, 2015; DeLonay and others, 2016). Assessing this subobjective is particularly challenging because of the rarity of the species, lack of captures of naturally produced age-0 through age- 3 fish, and difficulties in accurately determining ages past 4 years of age to know when a fish was recruited (Killgore and others, 2007; Koch and others, 2011; Hamel and others, 2014; Braaten and others, 2015). Three metrics to assess whether management subobjective 1 is achieved were specified in the MRSAMP (fig. 3). Metric 1.1 is specified as catch rates (that is, CPUE or unit area) of age- 0 and age- 1 naturally produced pallid sturgeon (sturgeon reproduced in the wild with either wild or hatchery parentage). As directly assessing recruitment through metric 1.1 is unlikely because of the rarity of capturing naturally produced age- 0 and age- 1 pallid sturgeon, two additional recruitment metrics were specified in the MRSAMP. The second metric, metric 1.2, is the use of model-based estimates of abundance of age- 0 and age- 1 naturally produced fish using data on abundance of age- 0 to age- 4 fish. The third metric, metric 1.3, is model-based estimates of survival of age- 0 and age- 1 naturally produced fish using data for age- 0 to age- 4 fish. These two metrics of recruitment will need to be assessed through estimates of abundance and trend of older fish, determination of hatchery or natural origin, and back calculation of age- 1 recruitment rates through a well-calibrated and validated population model. 
Missouri River Recovery Program goal: Develop a suite of actions that meets Endangered Species Act responsibility for pallid sturgeon while continuing to operate the Missouri River system to meet its authorized purposes.

U.S. Fish and Wildlife Service fundamental objective for pallid sturgeon: Avoid jeopardizing the continued existence of the pallid sturgeon from U.S. Army Corps of Engineers actions on the Missouri River.

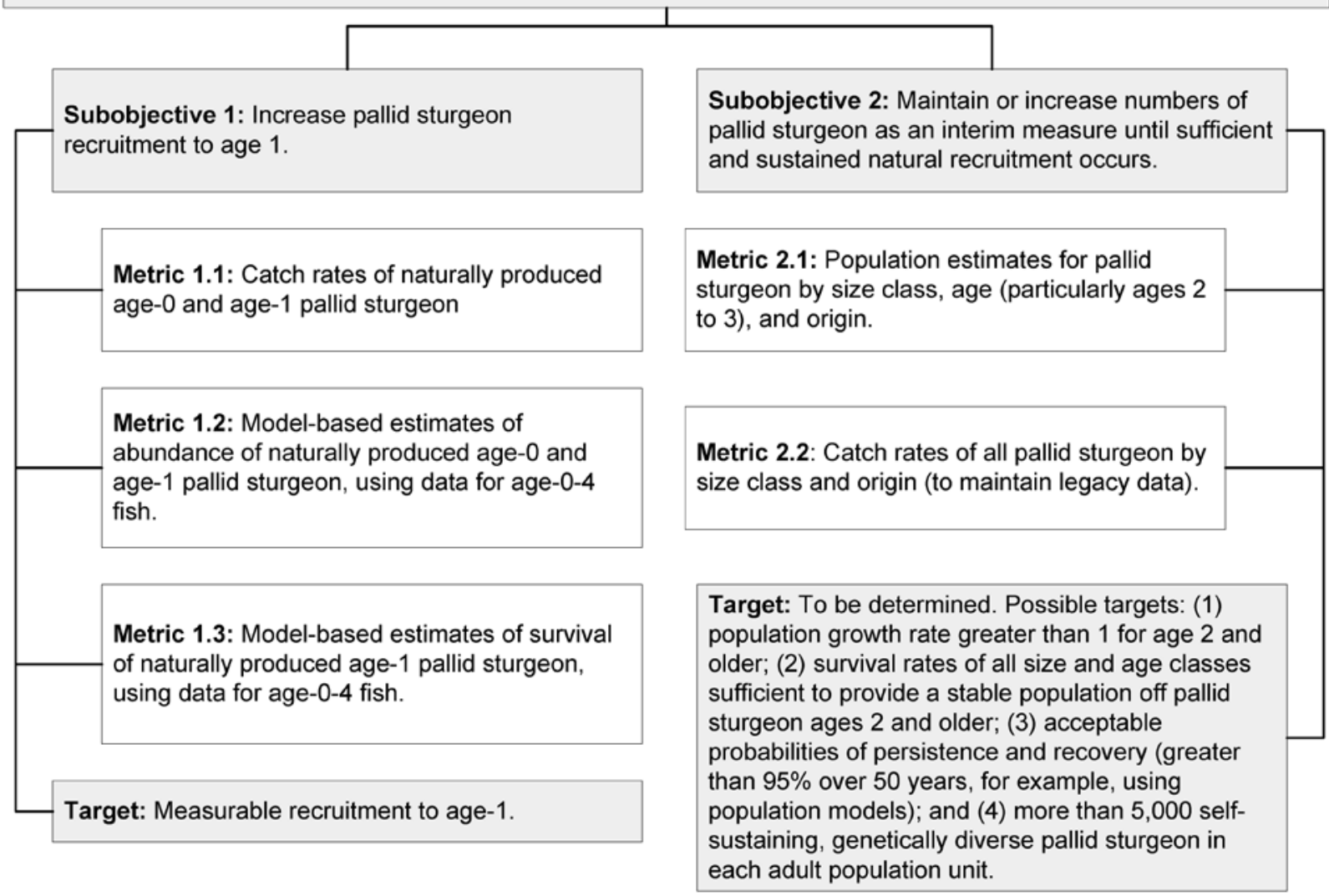

Figure 3. Fundamental objective and subobjectives for pallid sturgeon recovery. Quantifiable metrics 1.1, 2.1, and 2.2 could be estimated as part of a status and trend monitoring program. Here, metrics 1.1-1.3 refer to naturally produced age-0 and age-1 pallid sturgeon.

Success of management subobjective 2 (maintain or increase numbers of pallid sturgeon as an interim measure until sufficient and sustained natural recruitment occurs) is quantified by two metrics (fig. 3), as specified in the MRSAMP: metric 2.1 is pallid sturgeon population estimates for all size and age classes and by origin, and metric 2.2 is catch rates of all pallid sturgeon by size class and origin. Known-age hatchery-origin capture data will contribute to population estimates by age class; nonetheless, evaluating metric 2.1 with respect to all age classes is challenging due to difficulties in accurately determining pallid sturgeon ages (Killgore and others, 2007; Koch and others, 2011; Hamel and others, 2014; Braaten and others, 2015). Unknown ages (for example, ages of natural-origin fish) are expected to be estimated by the population model, which has been informed by known-age hatchery fish data, or potentially, other validated growth models that account for length-age relationship differences between hatchery and natural-origin pallid sturgeon. Additionally, the direct evaluation of metric 2.1 and metric 2.2 with respect to all size classes will be affected by the size selectivity of the gears used. 
Table 2. Fundamental management and information objectives for pallid sturgeon under the Missouri River Recovery Program. [--, not applicable]

Missouri River Recovery Program pallid sturgeon management objectives

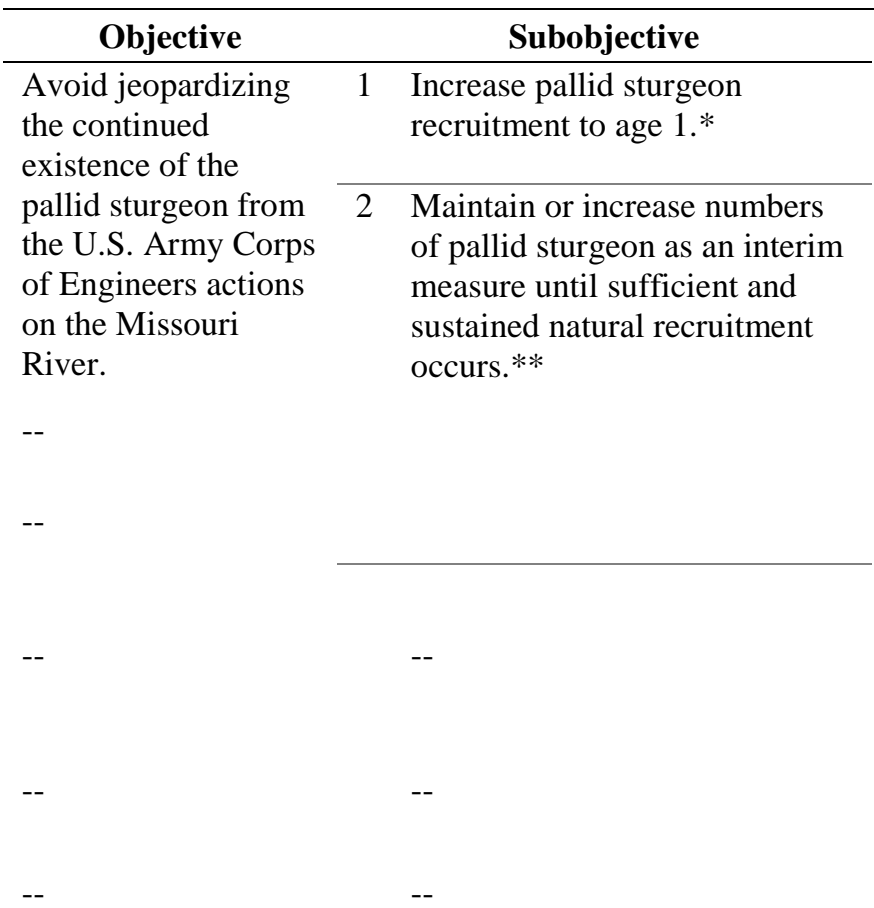

Pallid Sturgeon Population Assessment Program v. 2.0 information fundamental objectives

\begin{tabular}{|c|c|c|c|}
\hline & \multicolumn{2}{|c|}{ Objective } & Performance metric \\
\hline 1 & \multicolumn{2}{|c|}{$\begin{array}{l}\text { Quantify pallid sturgeon recruitment to age } 1 \\
\text { (from natural reproduction). }\end{array}$} & $\begin{array}{l}\text { Power to detect } \\
\text { recruitment if recruitment } \\
\text { occurs. }\end{array}$ \\
\hline \multirow[t]{4}{*}{2} & \multirow{4}{*}{$\begin{array}{c}\text { Quantify pallid } \\
\text { sturgeon population } \\
\text { status and trends, } \\
\text { natural and hatchery } \\
\text { origin. }\end{array}$} & \multirow[t]{2}{*}{$\begin{array}{l}\text { Population } \\
\text { abundance }\end{array}$} & $\begin{array}{l}\text { Bias of abundance } \\
\text { estimates. }\end{array}$ \\
\hline & & & $\begin{array}{l}\text { Precision of abundance } \\
\text { estimates. }\end{array}$ \\
\hline & & \multirow[t]{2}{*}{$\begin{array}{l}\text { Population } \\
\text { abundance trend }\end{array}$} & $\begin{array}{l}\text { Bias of population trend } \\
\text { estimates. }\end{array}$ \\
\hline & & & $\begin{array}{l}\text { Precision of population } \\
\text { trend estimates. }\end{array}$ \\
\hline 3 & \multicolumn{2}{|c|}{$\begin{array}{l}\text { Maintain compatibility with PSPAP v. } 1.0 \\
\text { data to extent possible }\end{array}$} & $\begin{array}{l}\text { Proportion of randomly } \\
\text { selected bends within } \\
\text { segment; completeness of } \\
\text { sampling. }\end{array}$ \\
\hline 4 & \multicolumn{2}{|c|}{$\begin{array}{l}\text { Provide relevant demographic data for pallid } \\
\text { sturgeon population model inputs. }\end{array}$} & $\begin{array}{l}\text { Proportion of possible } \\
\text { population model inputs. }\end{array}$ \\
\hline 5 & \multicolumn{2}{|c|}{$\begin{array}{l}\text { Evaluate monitoring information in a } \\
\text { benefit:cost framework. }\end{array}$} & Estimated costs. \\
\hline
\end{tabular}

*Metrics for management subobjective 1 include metric 1.1, catch rates of naturally produced age-0 and age- 1 pallid sturgeon; metric 1.2 , modelbased estimates of abundance of naturally produced age- 0 and age-1 pallid sturgeon; and metric 1.3, model-based estimates of survival of naturally produced pallid sturgeon to age 1 .

**Metrics for management subobjective 2 are metric 2.1, population estimates of all pallid sturgeon by size class, age, and origin; and metric 2.2, catch rates of all pallid sturgeon by size class and origin. 
Just as the two management subobjectives are directly linked to the first two PSPAP v. 2.0 fundamental information objectives (table 2), so are the metrics that assess these objectives. Metric 2.1 and metric 2.2 provided by the MRSAMP for management subobjective 2 (fig. 3) motivated the definition of the performance metrics for fundamental information objective 2 to provide the information needed to quantify pallid sturgeon population abundance and trends by origin. Metric 2.1 and metric 2.2 depend on population estimates and catch of pallid sturgeon. To assess the information value provided by these population estimates, PSPAP v. 2.0 evaluates the estimate's bias (accuracy) and precision. Therefore, PSPAP v. 2.0 fundamental information objective 2 is assessed by four performance metrics: abundance estimate bias, abundance estimate precision, trend estimate bias, and trend estimate precision (table 2).

The performance metric for the first PSPAP v. 2.0 fundamental information objective (to provide information needed to quantify recruitment to age 1) was primarily dependent on metric 1.1 because metric 1.2 and metric 1.3 are model-based estimates that can be indirectly linked to the performance metrics of fundamental information objective 2. Estimation of metric 1.2 and metric 1.3 will likely be dependent on the integrative population model, which, in turn, will be dependent on the ability of the pallid sturgeon data collected to provide realistic abundance and parameter estimates.

Metric 1.1 is the CPUE of naturally produced age- 0 and age- 1 pallid sturgeon. Expected low catch of naturally produced age- 0 and age- 1 pallid sturgeon poses challenges in assessing the information value of age- 0 and age- 1 CPUE. Few captures of age- 0 and age- 1 fish could result from little to no spawning, low numbers of recruits due to low early life history survival (Hadley and Rotella, 2009; Steffensen and others, 2010, 2013a; Rotella, 2015, 2017), insufficient effort, or varying capturing probability for age- 0 and age- 1 fish. Moreover, the reasons for low catch of age-0 and age-1 natural-origin fish may vary by geographic location; for example, in the Lower Missouri River, young stocked fish are often not recaptured at high rates until about age 4, whereas in the Upper Missouri River, crews have recaptured age-1, age-2, and age-3 stocked fish. Additionally, for broadcast spawners like pallid sturgeon, naturally low levels of age-0 survival could result in years with little to no recruitment even in the absence of anthropogenic stressors - especially given the present reduced size of the population, which can result in low numbers of spawning individuals. Given these challenges and uncertainties, it may be likely that catch of age- 0 and age- 1 pallid sturgeon will be zero even if recruitment occurs. Data with a high proportion of zeros have been shown to have decreased power in detecting population trends (Wildhaber and others, 2011). Therefore, as a first approach to linking the performance metric for information objective 1 to metric 1.1 (catch rates of age- 0 and age- 1 fish), it is important to determine if sampling efforts will have the power to detect recruitment when it does occur. Hence, the PSPAP v. 2.0 process has moved forward with assessing this metric (power to detect recruitment given it occurs) for fundamental information objective 1.

Together, the PSPAP v. 2.0 performance metrics described above are a first approach in assessing the ability of a monitoring design to provide decision-relevant information as defined in the MRRP. As with PSPAP v. 1.0 (table 1), these metrics aim to provide an overall understanding of pallid sturgeon trends in population abundance. Additionally, they emphasize providing an understanding of pallid sturgeon absolute abundance and the power to detect recruitment while deemphasizing fish-community data collection. Links from management actions to population responses will require additional understanding acquired through research, effectiveness monitoring, and the collaborative population model (fig. 2). 
In addition to the two information objectives that align directly to the MRRP management subobjectives, the Technical Team included three information objectives supported by the USFWS that follow logically to support MRRP program needs (table 2).

- Maintain compatibility with PSPAP v. 1.0 data to the extent possible.-This information objective is based on the desire to continue those parts of the PSPAP v. 1.0 dataset that are useful for documenting long-term (multidecade) abundance and trends in pallid sturgeon populations.

- $\quad$ Provide relevant demographic data for pallid sturgeon population model inputs.-This information objective is based on the rationale that adaptive management of the pallid sturgeon population requires a population-modeling framework that can be used to test sensitivity, and eventually to provide predictions, of population responses to management actions. The collaborative integrative model (Jacobson and others, 2015) depends on many input parameters, some of which are likely to be efficiently collected during PSPAP v. 2.0 deployments, whereas others may be routed to other data collection efforts (that is, as ancillary objectives discussed below).

- Analyze monitoring information in a benefit:cost framework. - Costs are clearly a practical constraint on information acquisition. Consideration of costs allows the MRRP to examine tradeoffs of investments in monitoring information content within the PSPAP, among all pallid sturgeon monitoring and assessment efforts, and among all MRRP management actions.

The five information objectives of PSPAP v. 2.0 are refocused from the information objectives of the preexisting PSPAP v. 1.0 (Welker and others, 2017), which also included assessments of pallid sturgeon habitat selection and population abundance and trends of other native fish species (table 1).

\section{Geographic Context}

The PSPAP v. 2.0 is designed to address pallid sturgeon populations in the Upper Missouri River from Fort Peck Dam to the headwaters of Lake Sakakawea, including the Lower Yellowstone River up to the Intake Dam, and the Lower Missouri River from Gavins Point Dam to the confluence with the Mississippi River (fig. 1). This geography defines two functionally independent population zones, typically referred to as the "upper basin" and the "lower basin." Designation of "basin" is somewhat misleading as the assessment focuses on the main stems and does not include all tributaries. Nevertheless, we retain the terms upper basin and lower basin in this report for compatibility with previous documents.

We use a general hierarchical framework for river classification originally published by Frissell and others (1986). Within these parts of the Upper Missouri, Lower Yellowstone, and Lower Missouri Rivers, segments are defined where major tributaries enter the main stem or other independent geologic or engineering structures control the nature of the river's flow regime or morphology. In the next level of the spatial hierarchy, bends are identified as geomorphic units with repeatable sequences of macrohabitats, typically crossover-bend-crossover, equivalent to riffle-pool-riffle sequences in smaller rivers. This spatial framework is retained from the PSPAP v. 1.0, which was developed based on the spatial breakdown of the Missouri River Benthic Fishes Study (Wildhaber and others, 2012). As with PSPAP v. 1.0, the bend serves as the basic sampling unit (or replicate) for the redesign (Welker and others, 2017). At times, we refer to aggregations of similar bends as "reaches," a flexible term denoting lengths of rivers 
longer than bends and shorter than segments. Within bends, macro-, meso-, and microhabitat units are defined at increasingly finer scales, following Welker and others (2017).

Adult pallid sturgeon have been documented migrating hundreds of kilometers upstream, and age- 0 pallid sturgeon are thought to disperse comparable distances downstream (DeLonay and others, 2016). As a result, it is possible that spawning or recruitment is taking place outside the sampling segments designated as part of the MRRP (for example, in tributaries or the Mississippi River; fig. 1). The closed robust design multistate model can account for temporary immigration to and emigration from an unobservable state, which would include fish that move beyond the sampling frame (for example, into the Mississippi River) as well as fish that move into unsampled Missouri River bends. Data that allow for the estimation of immigration and emigration parameters (for example, telemetry, microchemistry, and genetics data) may provide additional information that would allow PSPAP v. 2.0 to better distinguish between these movement cases. Additionally, migration parameters could be used to inform a Bayesian estimator, which, given some extra assumptions, may be able to account for temporary and permanent migration, allowing for an estimate of actual (versus apparent) survival. PSPAP v. 2.0 has been designed from the assumption that migration rates will be parameterized with monitoring data provided by these other data streams (telemetry, microchemistry, and genetics data); telemetry, in particular, is likely to be included as a component of PSPAP v. 2.0 monitoring in coordination with effectiveness monitoring (Fischenich and others, 2018a) but is not covered in the scope of this report.

\section{Redesign Process Overview}

The objective of the redesign effort is to quantify the tradeoffs in cost and utility of alternative monitoring designs in achieving monitoring information objectives. Moreover, the approach must be transparent and reproducible and must produce a practical design that can be carried out within budget constraints. The process used to compare alternative monitoring designs and estimators was developed to be rigorous and transparent because of the many stakeholders affected by potential modifications to the PSPAP v. 1.0 program. Our approach is to use simulation studies to calculate performance metrics representing the monitoring program objectives. Where available, simulation parameters are informed by data obtained from the PSPAP v. 1.0. In subsequent steps, the simulations will be synthesized, if possible, to a decisionsupport tool like a Bayesian Decision Network to compare alternative PSPAP v. 2.0 monitoring designs and provide a decision-making framework that accounts for uncertainty (Marcot and others, 2001; Nyberg and others, 2006). Moreover, the approach developed here will provide a tool for the USACE and USFWS to make decisions in the face of uncertain future funding levels that could result in a need to assess the relative values of investments among monitoring objectives, or between monitoring and management objectives. Additionally, because of the simulation approach used, estimators are already developed and can easily be updated and implemented to provide estimates for annual reporting of metrics for adaptive management progress reports as data are received. Lastly, it should be noted that calculating alternative monitoring design performance metrics was not trivial and, at times, required weeks of computing time to run some estimators with sufficient stochastic replicates to characterize uncertainty in outcomes; therefore, analysis is continually ongoing to improve results. This report provides details necessary to evaluate the redesign process, but results are considered provisional because changes are likely as more monitoring design outcomes are calculated and as 
uncertainty is reduced through pilot projects. In brief, the design process includes four components:

1. Identify stakeholder objectives, subobjectives, and metrics for the monitoring program;

2. Calculate performance metrics given alternative monitoring designs;

3. Synthesize outputs and develop a decision-support tool to compare alternative monitoring designs and estimators; and

4. Refine preliminary outputs with pilot studies.

The following sections detail the above components used for the design process.

\section{Identify Stakeholder Views on Objectives for the Monitoring Program}

From March 2017 through March 2018, we convened 2 formal workshops and 3 webinars to elicit input from PSPAP stakeholders on their views about objectives, metrics, and logistical data. We also instituted an online blog for input and presented details on design progress at multiple planning meetings. Although the fundamental objectives and subobjectives for the MRRP, and therefore PSPAP v. 2.0, were already determined, elicitation of views on objectives served to test whether critical monitoring aspects had been overlooked and to examine the extent to which ancillary objectives could be accommodated within PSPAP v. 2.0. We used the term "ancillary objectives" to denote monitoring objectives with combinations of the following characteristics:

- the contribution to informing the fundamental management objectives was indirect or had high uncertainty;

- may serve to mitigate risk, anticipate surprises;

- may support other agencies’ management objectives;

- may provide large marginal benefit for low marginal cost.

As the result of the workshops, quantifiable metrics were identified for each of the five fundamental information objectives and organized into an objectives hierarchy, which can be used to compare how alternative monitoring designs achieve the fundamental information objectives (table 2). Four of the five fundamental information objectives were mapped to single quantifiable metrics that were used to compare how well a monitoring design achieved these objectives. The second fundamental information objective, quantify pallid sturgeon population abundance and trend, is specified as two information subobjectives representing the abundance and trend components of the fundamental objective. Measures of bias and precision of pallid sturgeon population abundance and trend estimates were used to quantify how a monitoring design achieved this fundamental information objective. Future analyses may combine the bias and precision of an estimate into a single quantity by using the root square mean error of the estimate as the metric.

Far-ranging discussions during the workshops resulted in numerous suggestions for ancillary objectives, subobjectives, and related metrics. Ancillary objectives included sampling for varying population metrics to monitor and approaches needed to quantify the metrics. Metrics identified during the objectives elicitation were organized into eight overarching objective categories, each with several subobjectives. Specifically, stakeholders identified metrics relating to population structure (for example, age and size structure, sex ratio), reproductive status (for example, fecundity, reproductive cycling, size at sexual maturity), health status (for example, stress, condition, diet, contaminant load), population augmentation, movement (for example, 
spawning, seasonal), demographic rates (for example, recruitment, survival), fish community (for example, competition, invasive species), and genetic status (for example, effective population size, hybridization, local adaptation) (table 3). The elicited objectives were arranged into a network that served two purposes. First, it clarified stakeholders' views about fundamental and means objectives, thereby assuring a broad understanding of interests and concerns. Second, the objectives network highlighted the interdependency of objectives and the conditional nature of metrics (for example, one metric may be required to estimate another metric). Many of the elicited objectives qualified as ancillary according to our definition and so are considered beyond the scope of the current PSPAP v. 2.0 analysis.

The ancillary objectives were pruned from the objectives network and corresponding routings, and actions were proposed for each subobjective (table 3). The proposed routings generally fall into four classes:

1. ancillary subobjectives that should be considered as part of the core PSPAP v. 2.0,

2. ancillary subobjectives that may be efficiently addressed in coordination with PSPAP v. 2.0 but not necessarily with the long-term commitment of core PSPAP v. 2.0 sampling,

3. ancillary subobjectives that may be more efficiently addressed through other existing sampling programs (such as effectiveness monitoring or broodstock collection programs), and

4. ancillary subobjectives that should presently be addressed with stand-alone level-1 or level-2 science efforts.

Decisions about prioritizing ancillary objectives and subobjectives are not within the scope of this report but will be addressed in subsequent reports as their benefits and costs are considered in more detail.

\section{Auxiliary Monitoring Information}

We recognize two additional sources of monitoring information as being auxiliary to the PSPAP v. 2.0 - telemetry and larval flux sampling. These two sources may contribute substantial value to PSPAP v. 2.0, but they also overlap considerably with effectiveness monitoring under the MRSAMP (Fischenich and others, 2018a). Although monitoring efforts for these sources will probably be housed in the PSPAP v. 2.0, considerably more design work is needed to optimize how the effort will contribute to population assessment and effectiveness monitoring.

1. Telemetry of adult pallid sturgeon is fundamental to assessments of effectiveness for flow-management, passage, and spawning-habitat actions (Fischenich and others, 2018a). At the same time, assessment of adult presence/absence and movements through telemetry can contribute critical understanding of population dynamics through evaluations of immigration/emigration, reproductive migrations, and site fidelity. Telemetry can also contribute to assessment of capture probabilities and can serve as ancillary information for mark-recapture. It will be a logistical challenge to design an overarching strategy that optimizes telemetry information for both effectiveness monitoring and population assessment. 
Table 3. Objectives and subobjectives elicited during PSPAP v. 2.0 workshops and webinars with actions and recommended program routing to address the information need.

[PSPAP v. 2.0, Pallid Sturgeon Population Assessment Program, version 2.0; CPUE, catch per unit effort; --, not applicable]

\begin{tabular}{|c|c|c|c|c|c|}
\hline Subobjective & Metric & Action & Recommended program routing & $\begin{array}{l}\text { Duration or } \\
\text { frequency }\end{array}$ & Comments \\
\hline \multicolumn{6}{|c|}{ Objective-Population structure } \\
\hline Age structure & $\begin{array}{l}\text { Age distribution, } \\
\text { mean age }\end{array}$ & $\begin{array}{l}\text { NONE- continue } \\
\text { current sampling }\end{array}$ & Presently included in PSPAP v. 2.0 & Annually & From known age fish \\
\hline $\begin{array}{l}\text { Size structure } \\
\text { (RSD) }\end{array}$ & RSD values & $\begin{array}{l}\text { NONE- continue } \\
\text { current sampling }\end{array}$ & Presently included in PSPAP v. 2.0 & Annually & -- \\
\hline Maximum size & Maximum size & $\begin{array}{l}\text { NONE- continue } \\
\text { current sampling }\end{array}$ & Presently included in PSPAP v. 2.0 & Annually & -- \\
\hline Sex ratio & $\begin{array}{l}\text { Ratio of } \\
\text { males:females }\end{array}$ & $\begin{array}{l}\text { Analyze blood for } \\
\text { hormone profiles }\end{array}$ & $\begin{array}{l}\text { Ancillary, collect as part of } \\
\text { broodstock sampling or } \\
\text { longitudinal studies of tagged fish. }\end{array}$ & Annually & $\begin{array}{l}\text { Need female and other reproductive rates } \\
\text { to estimate effective population size. Role } \\
\text { in management hypotheses }\end{array}$ \\
\hline \multicolumn{6}{|c|}{ Objective-Reproductive status } \\
\hline Egg quality & $\begin{array}{l}\text { Egg volume, egg } \\
\text { diameter, fat } \\
\text { content }\end{array}$ & Take egg sample & $\begin{array}{l}\text { Ancillary, collect as part of } \\
\text { broodstock sampling. }\end{array}$ & Annually & -- \\
\hline $\begin{array}{l}\text { Reproductive } \\
\text { cycling of mature } \\
\text { fish }\end{array}$ & $\begin{array}{l}\text { Number of years } \\
\text { between } \\
\text { reproductive } \\
\text { events }\end{array}$ & Take blood, ultrasound & $\begin{array}{l}\text { Ancillary, collect as part of } \\
\text { broodstock sampling or } \\
\text { longitudinal studies of tagged fish. }\end{array}$ & Annually & -- \\
\hline Age at maturity & $\begin{array}{l}\text { Probability a } \\
\text { pallid sturgeon is } \\
\text { mature given } \\
\text { length or age }\end{array}$ & Take blood & $\begin{array}{l}\text { Ancillary, collect as part of } \\
\text { broodstock sampling or } \\
\text { longitudinal studies of tagged fish. }\end{array}$ & Annually & $\begin{array}{l}\text { Use blood work to build function for } \\
\text { known age hatchery origin fish }\end{array}$ \\
\hline $\begin{array}{l}\text { Spawning } \\
\text { aggregation and } \\
\text { synchrony of } \\
\text { reproductive fish }\end{array}$ & $\begin{array}{l}\text { Mapped areas of } \\
\text { relatively high } \\
\text { numbers of } \\
\text { reproductive pallid } \\
\text { sturgeon }\end{array}$ & $\begin{array}{l}\text { Identify high use } \\
\text { locations }\end{array}$ & $\begin{array}{l}\text { Ancillary, conduct as part of } \\
\text { effectiveness monitoring for } \\
\text { spawning cues and spawning } \\
\text { habitats. }\end{array}$ & Annually & $\begin{array}{l}\text { Can be covered through planned level-1 } \\
\text { and -2 science efforts to understand } \\
\text { reproductive migrations, responses to } \\
\text { pulsed flows, and constructed spawning } \\
\text { habitats. }\end{array}$ \\
\hline $\begin{array}{l}\text { Fecundity of } \\
\text { mature females }\end{array}$ & $\begin{array}{l}\text { Number of eggs } \\
\text { produced by a } \\
\text { female pallid } \\
\text { sturgeon }\end{array}$ & $\begin{array}{l}\text { Record volume of eggs } \\
\text { released, number of } \\
\text { eggs per volume, } \\
\text { estimation with } \\
\text { ultrasound }\end{array}$ & $\begin{array}{l}\text { Ancillary, collect as part of } \\
\text { broodstock sampling or } \\
\text { longitudinal studies of tagged fish. }\end{array}$ & Annually & -- \\
\hline
\end{tabular}


Table 3. Objectives and subobjectives elicited during PSPAP v. 2.0 workshops and webinars with actions and recommended program routing to address the information need. - Continued

[PSPAP v. 2.0, Pallid Sturgeon Population Assessment Program, version 2.0; CPUE, catch per unit effort; --, not applicable]

\begin{tabular}{|c|c|c|c|c|c|}
\hline Subobjective & Metric & Action & Recommended program routing & $\begin{array}{l}\text { Duration } \\
\text { or } \\
\text { frequency }\end{array}$ & Comments \\
\hline \multicolumn{6}{|c|}{ Objective_Fish health status } \\
\hline Stress & $\begin{array}{l}\text { RNA stress markers for } \\
\text { pallid sturgeon. }\end{array}$ & Take blood & $\begin{array}{l}\text { Ancillary. Conduct as limited-term } \\
\text { coordinated sampling coordinated } \\
\text { with PSPAP v. } 2.0 \text { and (or) } \\
\text { broodstock sampling. }\end{array}$ & Annually & -- \\
\hline Contaminants & $\begin{array}{l}\text { Proportion of pallid } \\
\text { sturgeon population with } \\
\text { contaminant } \\
\text { accumulations and } \\
\text { magnitude. }\end{array}$ & Take blood & $\begin{array}{l}\text { Ancillary. Conduct as limited-term } \\
\text { coordinated sampling coordinated } \\
\text { with PSPAP v. } 2.0 \text { and (or) } \\
\text { broodstock sampling. }\end{array}$ & Annually & $\begin{array}{l}\text { Contaminant levels may vary among } \\
\text { individuals, binary or continuous. } \\
\text { Detection threshold? }\end{array}$ \\
\hline Fish condition & $\begin{array}{l}\text { Relative weight of pallid } \\
\text { sturgeon. }\end{array}$ & $\begin{array}{l}\text { NONE- continue } \\
\text { current sampling }\end{array}$ & Presently included in PSPAP v. 2.0 & Annually & -- \\
\hline Abnormalities & $\begin{array}{l}\text { List of externally } \\
\text { identified abnormalities } \\
\text { present in pallid sturgeon }\end{array}$ & $\begin{array}{l}\text { Record external } \\
\text { abnormalities }\end{array}$ & Presently included in PSPAP v. 2.0 & Annually & -- \\
\hline \multicolumn{6}{|c|}{ Objective-Demographic rates } \\
\hline Predation & $\begin{array}{l}\text { Predation rates of age- } 0 \\
\text { pallid sturgeon. }\end{array}$ & $\begin{array}{l}\text { Diets of } \\
\text { predators }\end{array}$ & $\begin{array}{l}\text { Presently included as level } 1 \text { science } \\
\text { component. }\end{array}$ & $\begin{array}{l}\text { Annually, } \\
\text { 3-5 years }\end{array}$ & $\begin{array}{l}\text { mDNA being explored as a tool. } \\
\text { Turbidity-mediated predation of free } \\
\text { embryos is already a level } 1 \text { component. }\end{array}$ \\
\hline Survival & $\begin{array}{l}\text { Probability an invidual } \\
\text { pallid sturgeon survives } \\
\text { to the next year or other } \\
\text { time interval }\end{array}$ & $\begin{array}{l}\text { NONE-Continue } \\
\text { mark recapture } \\
\text { of fish }\end{array}$ & Presently included in PSPAP v. 2.0 & Annually & $\begin{array}{l}\text { Falls under trend: trend = survival }+ \\
\text { recruitment. For fish that have recruited to } \\
\text { gear and maintain tags. }\end{array}$ \\
\hline Growth & $\begin{array}{l}\text { Change in pallid } \\
\text { sturgeon length over } \\
\text { time at large }\end{array}$ & $\begin{array}{l}\text { NONE-Continue } \\
\text { mark recapture } \\
\text { of fish }\end{array}$ & Presently included in PSPAP v. 2.0 & Annually & -- \\
\hline
\end{tabular}


Table 3. Objectives and subobjectives elicited during PSPAP v. 2.0 workshops and webinars with actions and recommended program routing to address the information need. - Continued

[PSPAP v. 2.0, Pallid Sturgeon Population Assessment Program, version 2.0; CPUE, catch per unit effort]

\begin{tabular}{ll}
\multicolumn{1}{c}{ Subobjective } & \multicolumn{1}{c}{ Metric } \\
\hline $\begin{array}{l}\text { Drift and } \\
\text { dispersal }\end{array}$ & $\begin{array}{l}\text { Areas where age-0 pallid } \\
\text { sturgeon are encountered. }\end{array}$ \\
& \\
Use of & \\
Mississippi & $\begin{array}{l}\text { Proportion or number of pallid } \\
\text { River and } \\
\text { tributaries }\end{array}$ \\
& $\begin{array}{l}\text { Mississippi River or Missouri } \\
\text { River tributaries; proportion of } \\
\text { pallids that return to Missouri } \\
\text { that recruited to age } 1 \text { in the } \\
\text { Mississippi. }\end{array}$
\end{tabular}

Habitat

selection,

undifferentiated

by life stage.

$\begin{array}{ll}\text { Spawning } & \text { Ratio of pallid sturgeon } \\ \text { habitat } & \text { probability of use and habitat } \\ \text { availability and } & \text { availability. }\end{array}$

selection.

Movement Movements of pallid sturgeon among bends within segment.

\section{Action \\ Recommended program}

routing

Ojective-Movement and habitat selection

Sample areas in the Presently included as level

river for age- 0 pallid sturgeon

1 and 2 science

components. Potential to

institute main channel

larval flux sampling.

Use microchemistry, genetics, telemetry to evaluate movements

Presently included as level 1 science components, effectiveness monitoring; suggest some limited coordinated sampling with PSPAP v. 2.0.

Use telemetry and trawling data to identify habitat use and habitat mapping to define availability

Use telemetry to identify spawning areas and habitat mapping to define availability

Use telemetry program to identify movement and estimate movement parameters 1 science components, effectiveness monitoring. 1 science components, effectiveness monitoring.

Presently included as level 1 science components, effectiveness monitoring.

Duration
or
frequency Comments

frequency

Annually, Part of IRC or HAMP in Lower Basin.

3-5 years Level 1 CSRP studies. In Upper River, level 1 and level 2 science related to Fort Peck flow pulses, Yellowstone spawning. Potential to institute main channel larval flux sampling.

Annually Existing level 1 microchemistry. Existing comparison of genetics with Mississippi River catches (need to solidify protocol for submission of data). Effectiveness monitoring for cues (upper and lower) and spawning habitats (lower).

Presently included as level Annually

Level 1 studies exist for spawning habitat use and availability (see below). Level 1 and effectiveness monitoring in IRCs will allow for some habitat selection for age 0 .

Presently included as level Annually

Level 1 studies exist for spawning habitat use and availability (upper and lower river). Effectiveness monitoring in constructed spawning habitats will allow for detailed assessment of spawning habitat selection.
Annually Level 1 studies exist for responses to hydrologic cues (upper and lower river). 
Table 3. Objectives and subobjectives elicited during PSPAP v. 2.0 workshops and webinars with actions and recommended program routing to address the information need. - Continued

[PSPAP v. 2.0, Pallid Sturgeon Population Assessment Program, version 2.0; CPUE, catch per unit effort; --, not applicable]

\begin{tabular}{|c|c|c|c|c|c|}
\hline Subobjective & Metric & Action & $\begin{array}{c}\text { Recommended program } \\
\text { routing }\end{array}$ & $\begin{array}{l}\text { Duration } \\
\text { or } \\
\text { frequency }\end{array}$ & Comments \\
\hline \multicolumn{6}{|c|}{ Ojective-Movement and habitat selection-Continued } \\
\hline IRC habitat & $\begin{array}{l}\text { Areas of sturgeon free- } \\
\text { embryo interception and } \\
\text { larval rearing habitats. }\end{array}$ & $\begin{array}{l}\text { Hydrodynamic modeling to } \\
\text { identify interception } \\
\text { hydraulics, quantified with } \\
\text { validated particle tracking. }\end{array}$ & $\begin{array}{l}\text { Presently included as level } \\
1 \text { science components, } \\
\text { effectiveness monitoring. }\end{array}$ & $\begin{array}{l}\text { Annually, } \\
3-5 \text { years }\end{array}$ & Part of IRC or HAMP in Lower Basin. \\
\hline $\begin{array}{l}\text { Foraging } \\
\text { habitat }\end{array}$ & $\begin{array}{l}\text { Areas of habitat conforming } \\
\text { to pallid sturgeon age- } 0 \\
\text { foraging definition. }\end{array}$ & $\begin{array}{l}\text { Hydrodynamic modeling in } \\
\text { IRCs, controls combined } \\
\text { with trawling data for age } \\
0 \text {, to refine foraging } \\
\text { definition }\end{array}$ & $\begin{array}{l}\text { Presently included as level } \\
1 \text { science components, } \\
\text { effectiveness monitoring. }\end{array}$ & $\begin{array}{l}\text { Annually, } \\
3-5 \text { years }\end{array}$ & -- \\
\hline \multicolumn{6}{|c|}{ Objective-Genetics } \\
\hline $\begin{array}{l}\text { Local } \\
\text { adaptation }\end{array}$ & Local sturgeon adaptation & Collect genetic samples. & $\begin{array}{l}\text { Presently included in } \\
\text { PSPAP v. } 2.0\end{array}$ & Annually & $\begin{array}{l}\text { Note that understanding of genetic } \\
\text { diversity and hybridization will improve } \\
\text { with information from existing level-1 } \\
\text { studies that focus on improving } \\
\text { understanding of the pallid sturgeon } \\
\text { genome. }\end{array}$ \\
\hline Hybridization & $\begin{array}{l}\text { Proportion of sturgeon } \\
\text { population composed of } \\
\text { hybrids }\end{array}$ & Collect genetic samples. & $\begin{array}{l}\text { Presently included in } \\
\text { PSPAP v. } 2.0\end{array}$ & Annually & $\begin{array}{l}\text { Note that understanding of genetic } \\
\text { diversity and hybridization will improve } \\
\text { with information from existing level-1 } \\
\text { studies that focus on improving } \\
\text { understanding of the pallid sturgeon } \\
\text { genome. }\end{array}$ \\
\hline $\begin{array}{l}\text { Effective } \\
\text { population size }\end{array}$ & $\begin{array}{l}\text { Estimates of effective pallid } \\
\text { sturgeon population size }\end{array}$ & $\begin{array}{l}\text { Collect genetic samples, } \\
\text { estimate sex ratio, estimate } \\
\text { survival }\end{array}$ & $\begin{array}{l}\text { Presently included in } \\
\text { PSPAP v. } 2.0\end{array}$ & Annually & $\begin{array}{l}\text { Note that understanding of genetic } \\
\text { diversity and hybridization will improve } \\
\text { with information from existing level-1 } \\
\text { studies that focus on improving } \\
\text { understanding of the pallid sturgeon } \\
\text { genome. Also need estimates of survival, } \\
\text { sex ratio and inbreeding. }\end{array}$ \\
\hline
\end{tabular}


Table 3. Objectives and subobjectives elicited during PSPAP v. 2.0 workshops and webinars with actions and recommended program routing to address the information need. - Continued

[PSPAP v. 2.0, Pallid Sturgeon Population Assessment Program, version 2.0; CPUE, catch per unit effort; --, not applicable]

\begin{tabular}{|c|c|c|c|c|c|}
\hline Subobjective & Metric & Action & $\begin{array}{l}\text { Recommended } \\
\text { program routing }\end{array}$ & $\begin{array}{l}\text { Duration } \\
\text { or } \\
\text { frequency }\end{array}$ & Comments \\
\hline \multicolumn{6}{|c|}{ Other objectives } \\
\hline $\begin{array}{l}\text { Trends in } \\
\text { native forage } \\
\text { fish }\end{array}$ & $\begin{array}{l}\text { Species-specific CPUE } \\
\text { for native species that } \\
\text { serve as forage for } \\
\text { pallid sturgeon. }\end{array}$ & Sample fish community & $\begin{array}{l}\text { Ancillary, maybe } \\
\text { added in coordination } \\
\text { with PSPAP v. } 2.0 .\end{array}$ & Annually & $\begin{array}{l}\text { This would be contingent on level } 1 \text { studies that would } \\
\text { refine understanding of diets, bioenergetic requirements } \\
\text { of juvenile and adult fish. }\end{array}$ \\
\hline Diet & $\begin{array}{l}\text { Species-specific } \\
\text { contribution to pallid } \\
\text { sturgeon diet, as } \\
\text { proportions. }\end{array}$ & $\begin{array}{l}\text { Perform lavage on captured } \\
\text { pallid sturgeon, identify } \\
\text { food items }\end{array}$ & $\begin{array}{l}\text { Ancillary, level-1 } \\
\text { type studies that } \\
\text { would provide basis } \\
\text { for contingent } \\
\text { decisions. }\end{array}$ & $\begin{array}{l}\text { Annually, } \\
3-5 \text { years }\end{array}$ & $\begin{array}{l}\text { The foundation for this level- } 1 \text { type study is being } \\
\text { established independent of the MRRP. }\end{array}$ \\
\hline $\begin{array}{l}\text { Fish } \\
\text { community }\end{array}$ & Species richness & Sample fish community & $\begin{array}{l}\text { Ancillary, maybe } \\
\text { added in coordination } \\
\text { with PSPAP v. } 2.0 .\end{array}$ & Annually & $\begin{array}{l}\text { This would be contingent on determination of pallid } \\
\text { sturgeon population dependency on fish community } \\
\text { metrics. }\end{array}$ \\
\hline $\begin{array}{l}\text { Competition } \\
\text { with native } \\
\text { species }\end{array}$ & $\begin{array}{l}\text { Competition } \\
\text { coefficients }\end{array}$ & -- & $\begin{array}{l}\text { Ancillary, level-1 } \\
\text { type studies that } \\
\text { would provide basis } \\
\text { for contingent } \\
\text { decisions. }\end{array}$ & $\begin{array}{l}\text { Annually, } \\
3-5 \text { years }\end{array}$ & $\begin{array}{l}\text { Not possible directly; would need to estimate } \\
\text { competition coefficients (for example, Lotka Volterra } \\
\text { model). Contingent on development of evidence that } \\
\text { competition is limiting to pallid sturgeon. }\end{array}$ \\
\hline $\begin{array}{l}\text { Zooplankton } \\
\text { densities }\end{array}$ & $\begin{array}{l}\text { Zooplankton per cubic } \\
\text { meter }\end{array}$ & $\begin{array}{l}\text { Do zooplankton trawls at } \\
\text { locations within segments }\end{array}$ & $\begin{array}{l}\text { Ancillary, level-1 } \\
\text { type studies that } \\
\text { would provide basis } \\
\text { for contingent } \\
\text { decisions. }\end{array}$ & $\begin{array}{l}\text { Annually, } \\
3-5 \text { years }\end{array}$ & $\begin{array}{l}\text { Likely that time integrated estimates of zooplankton } \\
\text { production are more informative. Contingent of } \\
\text { development of information that lower trophic levels of } \\
\text { food web are limiting to pallid sturgeon. }\end{array}$ \\
\hline
\end{tabular}


Table 3. Objectives and subobjectives elicited during PSPAP v. 2.0 workshops and webinars with actions and recommended program routing to address the information need. - Continued

[PSPAP v. 2.0, Pallid Sturgeon Population Assessment Program, version 2.0; CPUE, catch per unit effort; --, not applicable]

\begin{tabular}{|c|c|c|c|c|c|}
\hline Subobjective & Metric & Action & Recommended program routing & $\begin{array}{l}\text { Duration } \\
\text { or } \\
\text { frequency }\end{array}$ & Comments \\
\hline & & & Objective: Hatchery records & & \\
\hline $\begin{array}{l}\text { Stocking } \\
\text { locations } \\
\text { and } \\
\text { numbers }\end{array}$ & $\begin{array}{l}\text { Location-specific } \\
\text { pallid sturgeon } \\
\text { stocking numbers and } \\
\text { fish sizes }\end{array}$ & $\begin{array}{l}\text { NONE- continue current } \\
\text { best management } \\
\text { practices, assure accurate, } \\
\text { complete record keeping. }\end{array}$ & $\begin{array}{l}\text { Already conducted as part of broodstock } \\
\text { and hatchery programs. }\end{array}$ & Annually & -- \\
\hline $\begin{array}{l}\text { Broodstock } \\
\text { production }\end{array}$ & $\begin{array}{l}\text { Number of pallid } \\
\text { sturgeon broodstock } \\
\text { moved to hatchery } \\
\text { and reproductive } \\
\text { condition. }\end{array}$ & $\begin{array}{l}\text { NONE- continue current } \\
\text { best management } \\
\text { practices, assure accurate, } \\
\text { complete record keeping. }\end{array}$ & $\begin{array}{l}\text { Already conducted as part of broodstock } \\
\text { and hatchery programs. }\end{array}$ & Annually & Some are reproductive, some are not. \\
\hline $\begin{array}{l}\text { Hatchery } \\
\text { production }\end{array}$ & $\begin{array}{l}\text { Number of pallid } \\
\text { sturgeon produced by } \\
\text { the hatchery system }\end{array}$ & $\begin{array}{l}\text { NONE- continue current } \\
\text { best management } \\
\text { practices, assure accurate, } \\
\text { complete record keeping. }\end{array}$ & $\begin{array}{l}\text { Already conducted as part of broodstock } \\
\text { and hatchery programs. }\end{array}$ & Annually & -- \\
\hline $\begin{array}{l}\text { Fin curl or } \\
\text { other } \\
\text { diseases }\end{array}$ & $\begin{array}{l}\text { Proportion of pallid } \\
\text { sturgeon lots with fin } \\
\text { curl, proportion of } \\
\text { outplants with fin curl } \\
\text { (or other diseases). }\end{array}$ & $\begin{array}{l}\text { NONE- continue current } \\
\text { best management } \\
\text { practices, assure accurate, } \\
\text { complete record keeping. }\end{array}$ & $\begin{array}{l}\text { Production data collection already } \\
\text { conducted as part of broodstock and } \\
\text { hatchery programs. External evidence of } \\
\text { disease (for example, fin curl) should be } \\
\text { standard operating practice for PSPAP v. } \\
2.0 \text {. }\end{array}$ & Annually & -- \\
\hline
\end{tabular}


2. Main-channel larval flux sampling (MCLFS) has been introduced to address questions related to abundance and condition of age-0 sturgeon that are not intercepted in IRCs. MCLFS would assess the relative flux and condition of free embryos that bypass IRCs to evaluate the fate of nonintercepted larvae. MCLFS can also contribute critical information related to population dynamics by quantifying fluxes of age- 0 sturgeon to the Mississippi River (or Lake Sakakawea, in the upper basin) and as an indicator of years with spawning success (table 3). MCLFS may fit within the general umbrella of PSPAP v. 2.0 but would be an entirely different sample design and would require development of specific technology to sample drift with ichthyoplankton nets in the main channel safely and effectively. MCLFS will be discussed in greater detail in a subsequent progress report.

We should also note that although the broodstock sampling conducted by PSPAP stakeholder agencies has provided extremely useful information in the past, the PSPAP v. 2.0 process is proceeding without expectation that it will necessarily continue to do so. Our lack of inclusion of broodstock monitoring recognizes that broodstock sampling is intended fundamentally to support pallid sturgeon population augmentation and stocking efforts, a management action that may be implemented at different levels depending on the status of the population and augmentation decisions. As a result, it would not be prudent to plan PSPAP v. 2.0 based on assumed continuation of broodstock sampling. The remainder of this report will focus on the core PSPAP v. 2.0 metrics related to the fundamental information objectives.

\section{Calculate Performance Metrics Given Alternative Monitoring Designs}

Fundamental information objectives 1 and 2 each required simulation to calculate performance metrics. For fundamental information objective 1, we simulated recruitment at varying levels and interception at varying locations to account for uncertainty. We then simulated catch of recruits with varying capture probabilities and efforts (for example, number of replicate trawls). Lastly, we analyzed the simulated data, calculating the proportion of simulations where one or more recruits were detected and using this proportion as the performance metric.

Calculating performance metrics for fundamental information objective 2 was more complicated due to the computational time component involved with estimating abundance. In short, we simulated capture of pallid sturgeon from simulated reference populations over a 10year period to compare alternative monitoring designs. For each combination of reference population and monitoring design, we simulated catch data by first selecting which bends to sample over the 10 years and then selecting which individual fish (of those located in the sampled bends during sampling) were captured during each occasion. We then used the simulated catch datasets and the associated monitoring design estimators to estimate population abundance and trend, which, in turn, were compared to the true values for the reference population. Using this approach, we were able to calculate the bias and precision of basin-level abundance and trend estimates, the performance metrics for fundamental information objective 2 . We then scaled metric values to vary on a scale ranging from 0 to 1 . In a subsequent step in this process, we plan to use swing weighting to make a quantitative link to the fundamental objective. Swing weighting is a method for weighting and combining multiple attributes into a single overall utility value. We describe the process in more detail in the "Weighting Fundamental Information Objectives and Subobjectives" section. 
Fundamental information objectives 3 and 4 are partly addressed in this report. We evaluated objective 3-maintain compatibility with sturgeon-season PSPAP v. 1.0 data-with scenarios that assumed nearly all aspects of PSPAP v. 1.0 were retained. Currently, the only differences in sturgeon-season sampling involve limiting the range of gear types used and, in some scenarios, how sampled bends are selected (albeit the number of bends sampled within a segment is maintained). Future assessments will address the information gain and additional costs that would result from expanding the scope to include native fish-community sampling, for example. Components of fundamental information objective 4-provide demographic data relevant to population modeling - were determined to exist, in large part, in complementary science and monitoring efforts, with the possible exception of obtaining blood sampling for gender ratios, which could be completed in coordination with PSPAP v. 2.0.

Lastly, fundamental information objective 5-evaluate monitoring information in a benefit:cost framework - required compilation of historical funding and effort to generate a field-crew-specific cost per bend, which, in turn, was used to estimate the cost of a monitoring design. The details of these steps are provided below.

\section{Alternative Monitoring Designs Considered}

Alternative monitoring designs consisted of varying combinations of a recruitmentdetection sampling design, a sturgeon-season sampling design, and abundance and trend estimators (table 4). Sturgeon-season sampling alternatives resemble PSPAP v. 1.0 sampling with some modifications in order to accommodate more sophisticated absolute abundance estimators and optimal gears. Alternative sampling decisions of interest were identified during the PSPAP workshop at the 2017 Missouri River Natural Resources Committee meeting, as well as during followup input from stakeholders and experts in the system. In short, the basin-scale sampling designs considered maintained the existing PSPAP v. 1.0 sampling framework where each basin was divided into segments, river segments were divided into bends, and sampling occurred within each bend using standard gears. However, using a closed population capturerecapture estimator to estimate demographic rates and abundance will require the modification of including repeated sampling of a bend over a short period (for example, days) to achieve demographic closure. Choice of sturgeon-season sampling design and estimators, whose combination we will refer to as a sturgeon-season design, affect fundamental information objectives 2-5.

Recruitment-detection sampling is a new type of sampling additional to the sturgeonseason and fish-community season sampling that occurred in PSPAP v. 1.0. It is a slight modification to the PSPAP v. 1.0 that would likely overlap with the end of sturgeon season and continue into what has been fish-community season under PSPAP v. 1.0. As currently simulated, recruitment-detection sampling occurs in the same set of bends determined by the sturgeonseason sampling component of the monitoring design; however, each bend is sampled on only 1 day by several trawls, where the number of trawls does not have to match the number of gear deployments used during sturgeon-season sampling. Instead, alternative recruitment-detection sampling designs vary in the number of trawls per bend, which has an effect on the outcomes of fundamental information objectives 1 and 5. Additionally, there is potential for recruitmentdetection sampling to contribute to fish-community sampling, an ancillary subobjective (table 3) that will be assessed in future work. 
Table 4. Alternative monitoring designs compared in the current analyses.

[Monitoring designs consist of a recruitment-detection design and a sturgeon-season design, each with an associated set of monitoring decisions. Each decision can be combined with any other decision (with the exceptions noted for the abundance and trend estimators), for a total of 1,458 alternative monitoring designs. Currently, simulations for 1,350 monitoring designs have been completed, because the closed robust design multistate model (CRDMS) estimator has only been analyzed for fixed sampling with 2 and 3 occasions. Including 0 trawls in the recruitment-detection decisions allows for an examination of monitoring designs that do not include the additional recruitment-detection sampling (a decision that may be optimal given very low detection probabilities).]

\begin{tabular}{|c|c|c|c|}
\hline \multicolumn{4}{|c|}{ Alternative monitoring decisions } \\
\hline \multicolumn{2}{|c|}{$\begin{array}{l}\text { Recruitment- } \\
\text { detection } \\
\text { decisions }\end{array}$} & \multicolumn{2}{|r|}{ Sturgeon-season decisions } \\
\hline \multirow{14}{*}{$\begin{array}{l}\text { Number } \\
\text { of trawls } \\
\text { per } \\
\text { sampled } \\
\text { bend }\end{array}$} & 0 & \multirow{2}{*}{ System-level sampling strategy } & Randomly chosen bends (Random) \\
\hline & 2 & & Randomly chosen fixed bends (Fixed) \\
\hline & 3 & \multirow{4}{*}{$\begin{array}{l}\text { Number of within year sampling } \\
\text { occasions }\end{array}$} & 1 \\
\hline & 4 & & 2 \\
\hline & $5-9$ & & 3 \\
\hline & $10-19$ & & 4 \\
\hline & $20-29$ & \multirow{3}{*}{ Gear } & Trotlines \\
\hline & 30-39 & & Gill nets (lower basin)/trammel nets (upper basin) \\
\hline & $40-49$ & & Combination of trotlines and gill nets/trammel nets \\
\hline & & \multirow{5}{*}{ Abundance and trend estimator } & Catch effort (CPUE) \\
\hline & & & Minimum Known Alive (MKA_AM \& MKA_WM) \\
\hline & & & $\mathrm{M}_{0}$ (AM \& WM, given 2 or more occasions) \\
\hline & & & $\mathrm{M}_{\mathrm{t}}$ (AM \& WM, given 2 or more occasions) \\
\hline & & & Multistate robust design (CRDMS, given 2 or more occasions) \\
\hline
\end{tabular}


Recruitment-detection and sturgeon-season sampling designs were mainly independent of one another, allowing them to be analyzed separately with their results combined in the overall monitoring design utility calculation. In total, 9 alternative recruitment-detection sampling designs and 24 alternative sturgeon-season sampling designs were simulated (table 4). Combining the 24 sturgeon-season sampling designs with each feasible abundance and trend estimator yields a possible 162 sturgeon-season designs. As of the date of this progress report (March 2018), 150 of the sturgeon-season designs have been analyzed - the multistate robust design estimator has only been examined for a portion of the catch datasets. Each sturgeonseason design can be paired with any 1 of the 9 recruitment-detection sampling designs for a current total of 1,350 alternative monitoring designs analyzed (table 4). Monitoring designs are detailed in the following two sections with a discussion of the recruitment-detection sampling under "Fundamental Information Objective 1" and a discussion of the sturgeon-season sampling and associated abundance and trend estimators in "Fundamental Information Objective 2.”

\section{Fundamental Information Objective 1}

Power to detect recruitment for a brood year-given it occurred-was the performance metric provided for fundamental information objective 1. Challenges of sampling recruits may lead to no or little recruitment data (age-0 and age- 1 captures), even when recruitment occurs, and therefore, directly assessing the annual number of recruits within a basin is extremely unlikely; however, sampling efforts may be able to detect if recruitment is occurring. Therefore, a simulation analysis was conducted to calculate the probability of detecting recruitment, given it occurs. As a first approach, we focused on the detection of naturally produced age- 0 pallid sturgeon, given they are present somewhere in the basin (upper or lower) The analysis involved several steps including (1) simulating age-0 recruitment at varying levels; (2) assigning recruits to a location within the basin, allowing for uncertainty in interception location; (3) repeated sampling within a bend to capture an age-0 recruit, allowing for uncertainty in capture probability; and (4) synthesis of simulation results to calculate the probability of detecting a recruit at the basin level.

\section{Basin-Level Survey Design, Bend-Level Sampling Effort, and Gears}

The decision space for this objective was limited to trawling with otter trawls with 4-mm mesh (OT04) because that gear was identified by experts as most effective for capturing age-0 (and age-1) pallid sturgeon, if present. Basin-level recruitment detection was supported as potentially achievable by experts in the system, and therefore, basin was chosen as the spatial unit for this analysis. Simulations were used to identify how much effort is needed to detect recruitment within a basin by a monitoring program across a range of recruitment levels, interception locations, and capture probabilities. Specifically, given some probability of capturing an age-0 pallid sturgeon in a trawl haul, how many trawls need to be conducted in a bend to achieve a reasonable probability of detecting a recruit at the basin level? To answer this question, we compared alternative monitoring designs with recruitment-detection sampling that ranged from 2 to 49 trawls per sampled bend (table 4), as well as those that did not include the recruitment-detection sampling efforts (0 trawls). Simulations run to date have assumed bends were selected under the same stratified random sampling approach used for sturgeon-season sampling and in PSPAP v. 1.0. In this approach, about 25 percent of all bends within each segment were randomly chosen to be sampled for naturally produced age-0 pallid sturgeon. However, future analyses could explore more targeted recruitment-detection sampling (for 
example, in the lower one-third of the basin) that may provide adequate (or even increased) detection at lower costs.

\section{Simulating Recruitment to Valuate Fundamental Information Objective 1}

Given naturally produced age-0 fish are recruited to a basin, it is uncertain at what level and where recruits are intercepted within the basin. Additionally, age-0 recruitment levels and interception locations are likely to vary between basins. We accounted for these uncertainties by simulating age- 0 recruitment within the upper and lower basins separately and calculating the power of alternative sampling efforts (number of trawls per bend) to detect recruits given different recruitment levels and interception locations.

Recruitment levels varied from 5 to 1,000 naturally produced age-0 pallid sturgeon per basin. Interception locations - represented by a vector of bend-specific interception probabilities - varied among three scenarios, which were designed to represent the uncertainty in interception. The three scenarios were (1) intercepted anywhere in the basin, (2) intercepted in the lower two-thirds of the basin, and (3) intercepted in the lower one-third of the basin. In each scenario, the probability a free embryo settles in a particular bend within a basin is calculated as the ratio of that bend's length to the length of the entire interception region, where lengths were measured in river kilometers and lengths of interception regions were rounded to eliminate cases of interception in only a portion of a bend.

For each combination of the three simulated interception scenarios and basin-specific recruitment levels considered (appendix 1, table 1.1), the given number of recruits were allocated among bends within the basin assuming a multinomial distribution as

$$
N_{\text {basin,bend }} \sim \text { Multinomial }\left(\text { Recruits }_{\text {basin }}, \pi_{\text {basin }}\right)
$$

where

$N_{\text {basin,bend }}$

Recruits $_{\text {basin }}$ within the basin;

$\pi_{\text {basin }}$

is the number of naturally produced age-0 pallid sturgeon in the given bend is the total number of naturally produced age- 0 fish in the basin; is a vector of bend-specific interception probabilities that sums to 1; that is, each entry represents the probability that a drifting free embryo settles in the particular bend within the basin;

bend $\quad$ indexes the bend within the upper or lower basin; and

basin indexes the upper or lower Missouri River basin.

This allocation method determines age- 0 location by assuming pallid sturgeon recruits remain in the same bend they were intercepted in and the survival of intercepted free embryos is equal among interception locations.

The capture probability of each individual trawl was randomly drawn from a basinspecific truncated logit-normal probability distribution:

$$
p_{\text {basin,bend }, k} \sim P\left(\text { TruncatedNormal }\left(\operatorname{logit}\left(p_{\text {basin }}\right), 0.2,-\infty, \operatorname{logit}(0.1)\right),\right.
$$

where

$$
\begin{array}{r}
p_{\text {basin,bend }, k} \\
p_{\text {basin }}
\end{array}
$$$$
\text { is the capture probability of the } k \text { th trawl in the given bend within basin, }
$$$$
\text { is the median capture probability for the basin, }
$$ 
$\operatorname{logit}(x)=\log \left(\frac{x}{1-x}\right)$ is the log-odds function,

$P(x)=\frac{1}{1+e^{-x}} \quad$ is the logistic function,

$k \quad$ indexes trawl within bend,

bend indexes the bend within the upper or lower basin, and

basin indexes the upper or lower Missouri River basin.

The logit-normal distribution was truncated above to prevent capture probabilities from exceeding 0.1 - while pallid sturgeon capture probabilities of OT04 have not been estimated, juvenile pallid sturgeon detection probabilities (an upper bound for capture probability) were found to be less than 0.1 for OT16 otter trawls (Schloesser and others, 2012). To further incorporate uncertainty in OT04 capture probability, basin-level median capture probabilities $\left(p_{\text {basin }}\right)$ were analyzed at various levels ranging between 0.00001 and 0.1 (appendix 1 ). The standard deviation of the truncated normal distribution was fixed at 0.2 to allow for variation among trawls but also to allow for the evaluation of clear differences in capture probability distributions for each value of $p_{\text {basin }}$ considered. Future analyses may look at the effects of additionally varying the standard deviation value and eliminating the truncation of the logitnormal distribution.

Deployment-level age-0 captures were simulated assuming a binomial distribution conditional on capture probability as

$$
C_{\text {basin,bend,k }} \sim \operatorname{Binomial}\left(p_{\text {basin,bend }, k}, N_{\text {basin,bend }}\right)
$$

where

$C_{\text {basin,bend,k }}$

is the number of naturally produced age-0 pallid sturgeon caught in the given bend within basin by trawl $k$,

$p_{\text {basin,bend, },}$ is the capture probability of the $k$ th trawl in the given bend within basin,

$N_{\text {basin,bend }}$ is the number of naturally produced age-0 pallid sturgeon in the given bend within basin,

$k \quad$ indexes trawl within bend,

bend indexes the bend within the upper or lower basin, and

basin indexes the upper or lower Missouri River basin.

Basin-level detection is then calculated as a 0 (not detected) if all trawls within the basin captured no age- 0 fish or a 1 (detected) if at least one naturally produced age- 0 is detected by any of the trawls within the basin:

$$
D_{\text {basin }}=\left\{\begin{array}{ll}
0, & \sum_{\text {bend }} \sum_{k} C_{\text {basin, bend }, k}=0 \\
1, & \sum_{\text {bend }} \sum_{k} C_{\text {basin, bend }, k}>0
\end{array},\right.
$$

where 


$\begin{array}{cl}D_{\text {basin }} & \text { is the detection status of the given basin upon completion of recruitment- } \\ & \text { detection sampling, } \\ C_{\text {basin,bend,k }} & \text { is the number of naturally produced age-0 pallid sturgeon caught in the given } \\ \text { bend within basin by trawl } k, \\ \text { bend } & \text { indexes the bend within the upper or lower basin, } \\ k & \text { indexes trawl within bend, and } \\ \text { basin } & \text { indexes the upper or lower Missouri River basin. }\end{array}$

For each combination of age- 0 recruitment level, interception location, median basinlevel capture probability, and number of recruitment-detection trawls per bend currently analyzed (appendix 1, table 1.1), 50,000 age-0 basin-level detections were simulated. The probability of detecting a recruit within the basin $\left(\right.$ Success $_{\text {basin }}$ ) under the given recruitment scenario and sampling effort (number of trawls per sampled bend) was calculated as the mean of $D_{\text {basin }}$ (taken over the 50,000 replicates). Because each value of $D_{\text {basin }}$ is either a 0 (not detected) or 1 (detected), Success $_{\text {basin }}$ gives the proportion of the 50,000 replicates in which detection was successful. Additional analyses examining criteria for when we have reached a sufficient number of replicates, as well as further analyses on a larger set of parameter values (table 1.1), will allow for a fuller characterization of Success $_{\text {basin }}$ in future reports. Further details of the simulation are discussed in appendix 1. The uncertainties examined in varying scenarios of recruitment level and interception are expected to be evaluated during a potential pilot study in 2018.

The power to detect naturally produced age-0 pallid sturgeon, given they are present within the basin, is a first approach to addressing the utility of sampling for age- 0 fish. If detection power is low, the costs of sampling may outweigh the benefits. However, even if detection power is high under certain scenarios, the power of detecting a recruit in any given year can still be low because these simulations have assumed the presence of age- 0 pallid sturgeon. If the probability that age-0 pallid sturgeon are present within the basin is very low, then detection will also be unlikely. For example, even if we know drifting free embryos exist, there may be a high probability they drift out of the system (for example, drift into Lake Sakakawea or the Mississippi River) or do not survive long enough to be captured as age 0sscenarios that would lead to a detection power of zero. Consequently, the probability that recruitment is detected given the presence of drifting free embryos is lower than the power presented here. Analysis of the probability of detecting age-0 recruits, given drifting free embryos are present, can be conducted using results from the current simulations and accounting for uncertainties in interception location (within or outside of the basin) and survival probability. Additionally, if survival from age 0 to age 1 is extremely low, then the detection of age- 0 recruits this year does not guarantee an increase in the number of age-1 recruits the following year. These simulations did not include an analysis of age- 1 recruits; however, including simulation of naturally produced age-1 captures may be useful in future analyses.

\section{Fundamental Information Objective 2}

Bias and precision of trend and abundance estimates are the four performance metrics provided for fundamental objective 2-quantify pallid sturgeon population trend and abundance (table 2). Simulation was required to calculate these metrics for the various alternative sturgeonseason designs. Alternative sturgeon-season designs consisted of varying combinations of 
sampling decisions and abundance and trend estimators (table 4), in the context of maintaining compatibility with legacy PSPAP v. 1.0 data (fundamental objective 3). In total, bias and precision metrics were calculated for 150 sturgeon-season designs, a process that required simulation and multiple steps. Steps were repeated hundreds of times (for each alternative monitoring design considered) in order to generate a large number of stochastic replicates to characterize uncertainty. Details of the process used to calculate the four performance metrics follow the indepth description, given below, of the various sturgeon-season sampling decisions and estimators used to build the 150 analyzed alternative sturgeon-season monitoring designs.

\section{Basin-Level Survey Design, Bend-Level Sampling Effort, and Gears}

Alternative sturgeon-season sampling decisions of interest were identified during the PSPAP workshop at the 2017 Missouri River Natural Resources Committee meeting, as well as during followup webinars with stakeholders and experts in the system. The underlying PSPAP v. 1.0 sampling grain (river bends) and extent will, thus far, remain the same for the redesign. Since river bend was the only spatial grain recommended during meetings or followup input with stakeholders, there has been no reason to modify this aspect of the sampling design. Instead, maintaining the sampling grain will allow for comparisons with the significant amount of data that have been collected using the current spatial grain, as well as aid in satisfying the fundamental objective of maintaining compatibility with legacy PSPAP v. 1.0 data.

In addition to maintaining the bend as the sampling unit, the number of bends to be sampled within a particular segment has also remained the same (Welker and others, 2017) for all monitoring designs considered; however, for this analysis, we have explored two different methods of bend selection. Some monitoring designs were simulated using randomly selected bends within segment according to the PSPAP v. 1.0 protocol (random bends; table 5). Other monitoring designs analyzed used a modification of the standard PSPAP v. 1.0 bend selection protocol where bends were randomly selected in the first year, and those initially selected bends were used as sampling bends over the next several years (fixed bends). Fixed bends were originally considered for one reason: to allow a well-defined "observable area" for multistate estimators. We have included fixed bends as a survey design in the analysis of other estimators merely for comparison purposes. Fixed survey designs are not recommended as an overall monitoring strategy because inferring information about the entire system from data collected from a fixed survey design will require the assumption that the fixed bends are representative of the overall system. It is for this reason that a fixed bend sampling was discontinued as part of the Missouri River Benthic Fishes Study (Gutreuter and others, 1995), not included in PSPAP v. 1.0, and heavily discounted in our utility analysis (see the "Fundamental Information Objective 3" section). For transparency and thoroughness, we report simulation results of fixed bend sampling here; however, we caution that these results will not be robust to simulation modifications (for example, alternative population spatial distributions). Catch data simulated under both random and fixed bend approaches can contribute to analyses of additional survey designs under consideration. For example, future analyses will likely include a rotating panel design and designs that combine randomly selected and fixed targeted bends.

Sturgeon-season sampling designs also varied in the number of secondary sampling occasions. Abundance estimates from capture-recapture estimators require two or more sampling occasions over a short period (for example, several days) to assume demographic closure. This is a departure from the PSPAP v. 1.0, which is catch-effort based and therefore only requires a single visit to each bend, although a crew can visit the bend multiple times to deploy varying 
gears. We examined the performance of sturgeon-season designs that use two, three, and four occasions (that is, a crew repeatedly sampling a bend over 2, 3, or 4 days). Additionally, we analyzed sampling a bend on a single occasion to mimic the PSPAP v. 1.0.

Table 5. Summary of bends within Pallid Sturgeon

Population Assessment Program Missouri river segments and number of segments sampled within segment.

[km, kilometer; no., number]

\begin{tabular}{cccccc}
\hline Segment & $\begin{array}{c}\text { Number } \\
\text { of } \\
\text { bends }\end{array}$ & $\begin{array}{c}\text { Minimum } \\
\text { length } \\
\mathbf{( k m )}\end{array}$ & $\begin{array}{c}\text { Mean } \\
\text { length } \\
\mathbf{( k m )}\end{array}$ & $\begin{array}{c}\text { Maximum } \\
\text { length } \\
\mathbf{( k m )}\end{array}$ & $\begin{array}{c}\text { No. of } \\
\text { sampled } \\
\text { bends }\end{array}$ \\
\hline 1 & 1 & 7.89 & 7.9 & 7.9 & 0 \\
2 & 40 & 0.64 & 2.2 & 3.9 & 12 \\
3 & 91 & 0.64 & 2 & 7.1 & 21 \\
4 & 24 & 0.97 & 3.3 & 8 & 12 \\
\hline & & Lpper Basin & & \\
\hline 7 & 34 & 0.16 & 2.6 & 7.9 & 12 \\
8 & 61 & 1.13 & 4 & 9.2 & 15 \\
9 & 80 & 1.13 & 4.4 & 11.7 & 20 \\
10 & 39 & 1.61 & 4.7 & 10.3 & 10 \\
13 & 45 & 1.77 & 4.1 & 10.6 & 11 \\
14 & 56 & 1.45 & 3.9 & 19 & 14 \\
\hline
\end{tabular}

Designs examined include a combination of trotlines and gill nets to capture sturgeon in the lower basin and trotlines and trammel nets to capture sturgeon in the upper basin. These gears were selected based on input from experts within the basin and because the continued use of these PSPAP v. 1.0 standard gears will maintain compatibility with existing PSPAP v. 1.0 data. Otter trawls, the remaining PSPAP v. 1.0 sturgeon-season standard gear, were not included in this analysis; however, they may be added into future analyses due to their higher probabilities of capturing smaller fish (Schapaugh and Tyre, 2011).

\section{Population Abundance and Trend Estimators}

Alternative estimators were identified to estimate basin-level population abundance and trend; however, the alternative estimators depend on the number of sampling occasions within a bend. Specifically, if one occasion is used, then only a catch or catch-effort based estimator can be used. Various estimators that rely upon a capture-mark-recapture approach were used to estimate basin-level population abundance and trend if more than one occasion occurs in a bend. In total, 150 alternative designs, which varied in (1) random or fixed bends; (2) one, two, three, or four occasions; (3) trotlines, gill nets (lower basin)/trammel nets (upper basin), or a 50-50 combination of these; and (4) varying estimators, detailed below, conditional on sampling type and number of occasions, have been analyzed (table 4).

Accurately identifying fish age in the field is challenging for naturally produced fish, and the MRSAMP specifies that age classes are to be estimated by the collaborative population 
model; accordingly, the current focus is limited to overall population estimates for pallid sturgeon that can be broken down by size class and origin. Population abundance estimates were made at the bend level and then aggregated to the segment and basin levels for most estimators; however, monitoring designs that used the robust design abundance estimator had difficulty producing estimates at the bend spatial scale. Therefore, all monitoring designs using the robust design estimator directly estimated segment-level abundances, which were then aggregated to the basin level. As varying spatial scales may be of interest to stakeholders, obtaining bend-level estimates (when possible) provided a means to obtaining estimates at all three (bend, segment, and basin) spatial scales. All estimators and aggregation processes are detailed below.

\section{Abundance Estimators}

\section{Minimum Known Alive}

The minimum known alive (MKA) estimator is the most simplistic abundance estimator we considered. It used the number of (unique) individuals captured in a bend as an estimate for the bend abundance, not accounting for capture probability. This estimator was expected to be negatively biased as, given low capture probabilities and reasonable effort, it likely represents only a small portion of the fish living in the bend are caught; however, this estimator has its benefits: (1) it can be used with single-occasion data, and therefore, it can be implemented with the current PSPAP v. 1.0, and (2) it can be used with mark-recapture program data when more

sophisticated estimators fail to produce estimates. Additionally, we included this as a baseline for the comparison of capture-recapture designs.

We ran the MKA estimator under all monitoring program sturgeon-season sampling designs, allowing us to compare it to all other estimators. For single-occasion data, the bendlevel abundance estimate is the same as the number of fish caught in the bend. For multipleoccasion data, the total number of unique fish known to be alive in the bend, as determined from passive integrated transponder (PIT ) tag identification, serves as the estimate for bend-level abundance. Assuming PIT tag identification is always reliable, then the MKA abundance estimate is always clear and estimates standard error is 0 at the bend level; however, nonzero standard errors, representing among bend variability, were calculated when we aggregate bendlevel estimates to the segment and basin levels (see the "Estimating Minimum Known Alive, $\mathrm{M}_{0}$, and $\mathrm{M}_{\mathrm{t}}$ Segment-Level Abundance” section).

\section{Closed Capture-Recapture Estimators}

Closed capture-recapture estimators take advantage of multiple capture occasions within a sampling unit to estimate capture probability and abundance. Several closed population estimators were developed by Otis and others (1978) with many advances occurring over the years (Schwarz and Seber, 1999). Two estimators, $\mathbf{M}_{0}$ and $\mathrm{M}_{\mathrm{t}}$, were considered in our current analyses, and a third estimator, Chao's $\mathrm{M}_{\mathrm{h}}$, is considered for future analyses. The two estimators currently analyzed differ in the way they treat capture probability. Where the $\mathrm{M}_{0}$ estimator assumes that the capture probability $(p)$ is constant across all capture occasions, the $\mathrm{M}_{\mathrm{t}}$ estimator allows capture probability to vary among occasions. Capture probability is likely to vary among occasions due to many factors (for example, water velocity, temperature); however, if variability in capture probability is small, then assuming capture probability is constant (that is, using the $\mathrm{M}_{0}$ estimator) may be sufficient. If different gears are used during each capture occasion and different gears have a large difference in capture probability, then the $\mathrm{M}_{t}$ estimator may be the 
better choice. Since there is a tradeoff between estimating more parameters (multiple capture probabilities) and the bias and precision of these parameter estimates, we implemented both the $\mathrm{M}_{0}$ and the $\mathrm{M}_{\mathrm{t}}$ estimators in all scenarios to compare their performance.

Both the $\mathrm{M}_{0}$ and $\mathrm{M}_{\mathrm{t}}$ estimators rely on the assumption that the population is closed during capture occasions (that is, no fish moves in or out of the bend during sampling). In the analysis of monitoring programs presented here, this assumption will hold as it was one of the assumptions used to generate the reference populations. This allows us to examine the performance of these estimators under circumstances that do not violate model assumptions. If they do not perform well in these circumstances, then it is unlikely they will perform well in others. Given the estimators can reliably perform under the current analysis, it will be important for future analyses to examine the effects of model violations.

The $\mathrm{M}_{0}$ and $\mathrm{M}_{\mathrm{t}}$ estimators estimate bend-level abundance, which is then aggregated to estimate segment and basin-level abundance. Those estimates, in turn, can be used to estimate trend (that is, change in abundance over time). Any estimator results that gave estimates but produced warnings (for example, nonconvergence, extremely large asymptotic bias) were treated as failed estimates, and their values were excluded from the analysis. While failed estimates do not contribute to the population abundance and trend estimates, they do contribute to the assessment of the estimator (as the probability of estimator failure is taken into account when calculating the abundance and trend utilities). We used the closed.t function in the Rcapture package in $\mathrm{R}$ to estimate bend-level abundances and associated uncertainties ( $\mathrm{R}$ Development Core Team, 2010).

\section{Robust Design}

The robust design estimator takes the analysis of capture-recapture data a step further than the closed mark-recapture estimators described above. It uses multiple capture occasions within a year, as well as compares capture data across years, to directly estimate capture probability, abundance, and survival as described by Pollock (1982).

The robust design framework has been applied across a wide range of taxa to estimate demographic rates and population abundance. Its use has been extended to studies of species occurrence (that is, occupancy models [MacKenzie and others, 2002; Tyre and others, 2003]). The robust design provides a rigorous framework that allows for the estimation of relevant demographic rates and abundance using marked individuals. As originally described by Pollock (1982), a robust design consists of primary sampling occasions (for example, years) with secondary sampling occasions nested within each primary occasion. Primary occasions are spaced temporally to capture processes like survival and growth. Secondary occasions occur over a short time frame, short enough that closure of the population from demographic processes (that is, recruitment, mortality, immigration, emigration) can be assumed. The secondary sampling occasions provide multiple opportunities for individuals to be captured, thereby allowing capture probability and abundance to be estimated.

The use of a robust design capture-recapture approach to estimate Missouri River pallid sturgeon abundance and demographic rates is not novel. The first application was Steffensen and others (2012) as part of the annual broodstock collection in segment 9-an analysis that has been recently updated to include new data (Steffensen and others, 2017). Similarly, Winders and Steffensen (2014) used a robust design to estimate abundance and demographic rates for a portion of segment 10 using broodstock collection data. In both studies, pallid sturgeon were captured by setting multiple trotlines at random locations in study reaches (tens of kilometers of 
river length) over a short period. The annual broodstock sampling was the primary occasion and daily capture efforts were the secondary occasions in both studies. Given the study design, survival was estimated over the open period (that is, between annual broodstock collection events). Capture and recapture probabilities, as well as abundance, were estimated within the closed primary period (broodstock collection). Additionally, both studies estimated movement parameters that account for pallid sturgeon leaving or arriving in the study area between closed periods. Although the broodstock program sampling was amenable to opportunistic analysis using robust design, broodstock sampling was not designed for that purpose; our redesign of PSPAP v. 2.0 is intended to evaluate improved designs.

There are variations of the robust design that estimate alternative sets of parameters. The most commonly used version, as well as the version used by Steffensen and others (2012) and Winders and Steffensen (2014), is the version that estimates six parameters. Specifically, these parameters were as follows:
$\varphi \quad$ is the probability of surviving between primary occasions;
$\gamma^{\prime} \quad$ is the probability of being outside the study area and unavailable for capture during the primary occasions, given the animal was not present during the previous primary occasions and given it survives to the current occasion;
$\gamma^{\prime \prime} \quad$ is the probability of being outside the study area and unavailable for capture during the primary occasions, given the animal was present during the previous primary occasions and given it survives to the current occasion; $p \quad$ is the initial capture probability;
$C \quad$ is the recapture probability; and
$f_{0} \quad$ is the number of unobserved individuals.
Depending on the situation, the number of parameters estimated can be reduced by assuming initial capture probability is equal to recapture probability where $p=c$. Similarly, $\gamma^{\prime}$ and $\gamma^{\prime \prime}$ can be specified to represent hypotheses about immigration and emigration processes. For example, random movement (where each fish has the same probability of being outside the sampling reach in a primary occasion independent of its location during the previous primary occasion) can be specified by imposing equality of the movement parameters as $\gamma^{\prime}=\gamma^{\prime \prime}$. Population abundance $(N)$ at each period is a derived parameter calculated as the number of marked fish plus the number of unobserved individuals.

We used what is known as the closed robust design multistate model (CRDMS). Between year movement from bend to bend or segment to segment may lead to individuals being collected in one sampling area (a "state”) one year and another sampling area a future year. A multistate model takes into consideration this movement by looking at and comparing capture histories from all connected states, allowing the estimation of transition probabilities, or the probability that a fish moves from one state to another. In this case, all the parameters listed above are estimated, with the exception of the two gamma parameters ( $\gamma^{\prime}$ and $\gamma^{\prime \prime}$ ), as all movements into and out of the sampling area (or observable area) are now taken into account with the transition probabilities $\psi_{i j}$ (the transition from state $i$ to state $j$ ), where a state is either a sampling unit or the unobservable area outside all sampling units. For example, if we sample segments 7-10, 13, and 14 in the Lower Missouri River, the multistate model will provide transition probabilities from each of these segments to each of the other segments, as well as 
transition probabilities to an unobservable area (for example, temporary migration to the Platte River or Mississippi River).

We attempted to estimate CRDMS model parameters using Program MARK at the bend level to estimate movement among bends with no success. It is likely insufficient recaptures within bends, the computation time needed, or the memory needed prevented obtaining estimates from the estimator. We were, however, able to run the estimator at the segment level, running separate estimates for each basin since basins are assumed unconnected by natural movement. Hence, the CRDMS estimator estimated segment-level population abundances and movement transition probabilities, as well as basin-level annual survival and capture probabilities, where we assumed constant and equal capture and recapture probabilities (that is, $p=c$ ), constant annual survival, and movement transition probabilities that varied by segment but were fixed in time. Some of these simplifying assumptions differ from the assumptions used to generate the reference populations (as well as what we may expect in the real population); nonetheless, they were made to attempt to reduce the number of failed estimates, which can result when fitting a large number of parameters with sparse data. Such simplifications may add to the bias and precision of abundance estimates - the performance metrics we are analyzing - and therefore, could affect how well the CRDMS estimator compares to the other abundance estimators. However, if this simplified estimator performs very well, there may be no need to attempt to fit a more complex model, which may take more computational time or fail to produce estimates more often.

As with the other capture-recapture estimators, it is possible for the CRDMS estimator to fail to produce estimates. Failed estimates are noted in our analyses and, while they do not contribute to the aggregated basin-level abundance and trend estimates, they do contribute to the assessment of the estimator (as the probability of estimator failure is taken into account when calculating the abundance and trend utilities).

\section{Estimating Minimum Known Alive, $M_{0}$, and $M_{t}$ Segment-Level Abundance}

Segment-level abundance estimates were calculated from estimates of segment density (fish per river kilometer). We chose to use the weighted mean bend density as an estimate of segment-level density. It is important to note that this is different from taking the typical (arithmetic) mean of the bend densities. When bends are of different lengths and different densities, the arithmetic mean does not accurately calculate segment-level density, even in the case of known bend-level abundances (appendix 2). However, the weighted mean approach will calculate the true segment-level density under known conditions (appendix 2) and is therefore a better estimator of segment abundance on the Missouri River, where bend lengths and densities vary. For these reasons, we have presented the weighted mean approach here. Additionally, suspecting that the arithmetic mean may be a commonly used alternative, we have also computed segment-level estimates from the arithmetic mean approach. The equations used to compute the arithmetic mean estimates are included in appendix 2 with a comparison of the outcomes from the two aggregation approaches (fig. 2.1).

To account for the different lengths and pallid sturgeon densities of bends in the Missouri River, the weighted mean approach (referred to by Cochran [1977] as the ratio estimator) was used to estimate segment-level density. In particular, the weighted mean approach calculated the weight of a bend as the length of that bend relative to the total length of all sampled bends within the segment, or 


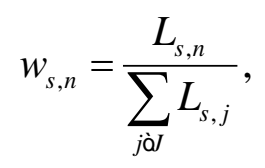

where

$$
\begin{aligned}
w_{s, n} & \text { is the weight of sampled bend } n \text { in segment } S, \\
L_{s, n} & \text { is the length of bend } n \text { in segment } S, \\
J & \text { is the set of indices for all sampled bends in segment } S, \\
n \text { and } j & \text { index sampled bends within a segment, and } \\
S & \text { indexes segment. }
\end{aligned}
$$

The weighted mean density is then calculated as the sum of each bend density multiplied by its weight, or

$$
\hat{d}_{s}=\sum_{j \grave{\partial} J} w_{s, j} \cdot\left(\hat{N}_{s, j} / L_{s, j}\right)
$$

where
$\hat{d}_{s} \quad$ is the estimated segment density of segment $S$;
$w_{s, j} \quad$ is the weight of sampled bend $j$ in segment $S$;
$\hat{N}_{s, j} \quad$ is the estimated pallid sturgeon abundance of bend $j$ in segment $s$;
$L_{s, j} \quad$ is the length, in river kilometers, of bend $j$ in segment $S$;
$J \quad$ is the set of indices for all sampled bends in segment $S$;
j $\quad$ indexes sampled bends within a segment; and
$S \quad$ indexes segment.

Notably, the weighted mean approach for estimating segment density is equivalent to summing the sampled bend abundance estimates together and dividing by the total length of the sampled bends within the river segment (add all within segment sampled bend lengths together), or

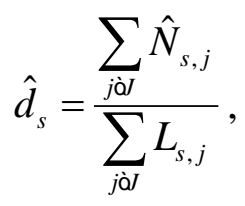

where all variables are as defined in equation 6 above.

The weighted mean estimated segment density is then used to estimate abundance by multiplying the estimated segment density by the length of the segment in river kilometers.

$$
\hat{N}_{s}=\hat{d}_{s} \cdot L_{s}
$$

where

$\hat{N}_{s} \quad$ is the estimated segment abundance of segment $S$, 
$\hat{d}_{s} \quad$ is the estimated segment density of segment $S$ calculated using equation 6 , or equivalently 7 ,

$L_{s} \quad$ is the total length (in river kilometers) of segment $S$, and

$S \quad$ indexes segment.

Relative bend length is a first approach for weighting bend densities when aggregating abundance estimates to the segment level; however, future analyses may additionally incorporate measures of bend area and macrohabitat composition in bend-weight calculations.

For the $\mathrm{M}_{0}$ and $\mathrm{M}_{\mathrm{t}}$ estimators, the segment-level standard error was calculated using the delta method (Powell, 2007; Powell and Gale, 2015) for both aggregation approaches. Since nonzero bend-level standard errors were not available for the MKA estimator (see the "Estimating Minimum Known Alive, $\mathrm{M}_{0}$, and $\mathrm{M}_{\mathrm{t}}$ Segment-Level Abundance" section above), segment-level standard errors were calculated using the variance of the bend-level densities under the given approach:

$$
\operatorname{Var}\left(N_{s}\right)=L_{s}^{2} \cdot \operatorname{Var}\left(d_{s}\right)=L_{s}^{2} \cdot \sum_{j \jmath}\left(\hat{d}_{s, j}-\hat{d}_{s}\right)^{2} \cdot w_{s, j},
$$

where

$$
\begin{aligned}
& \operatorname{Var}\left(N_{s}\right) \quad \text { is the variance of the sampled bend-level abundances in segment } s \text {, } \\
& L_{s} \quad \text { is the total length (in river kilometers) of segment } s \text {, } \\
& \operatorname{Var}\left(d_{s}\right) \quad \text { is the variance of the sampled bend-level densities in segment } s \text {, } \\
& \hat{d}_{s, j} \quad \text { is the estimated density of sampled bend } j \text { in segment } s \text {, } \\
& \hat{d}_{s} \quad \text { is the estimated segment density of segment } S \text { calculated under the chosen } \\
& \text { approach, } \\
& w_{s, j} \quad \text { is the weight of sampled bend } j \text { in segment } s \text { as calculated in equation } 5 \text {, } \\
& J \quad \text { is the set of indices for all sampled bends in segment } s \text {, } \\
& j \quad \text { indexes sampled bends within a segment, and } \\
& S \quad \text { indexes segment. }
\end{aligned}
$$

The segment-level MKA estimator standard error is then calculated as the square root of the variance.

\section{Estimating Basin-Level Abundance}

Basin-level abundances were used to compare monitoring designs. Annual basin-level abundance was estimated by summing annual segment-level abundance estimates within basin. For any years in which one or more segment-level abundances could not be estimated (for example, nonconvergence of an estimator), the weighted means of the available segment-level densities were used as an estimate for basin-level density and then expanded to an abundance estimate (see previous section for details on this approach). Additionally, associated uncertainty around these estimates was calculated using the delta method to combine varying sources of uncertainty (Powell, 2007; Powell and Gale, 2015). The estimates of abundance bias and 
precision for each stochastic replicate were then used, in combination with the performance metrics for trend as calculated below, to parameterize the decision model.

The methods for estimating variance presented here may not accurately reflect the variance of the segment-level and basin-level abundance estimates. When sources of uncertainty are not adequately accounted for, it is possible that the variance is underestimated. The weighted mean approach described here involves the use of the ratio estimator (Cochran, 1977), and therefore, the standard error estimates may be improved in future analyses by using variance estimates for the ratio estimator.

Trend Estimators

Population trend was defined as the population growth rate, $\lambda$, which describes how quickly the population is either growing $(\lambda>1)$ or declining $(\lambda<1)$ each year ( $>$, greater than; $<$ less than). The trend, therefore, is a function of recruitment and survival and can also be quantified as the ratio of abundance from one year to the next. Each abundance estimator allowed for an estimate of the trend, either by comparing abundance from one year to the next or by estimating survival and recruitment.

Population abundance was assumed related to trend, $\lambda$, as $N_{t}=\lambda^{t} N_{0}$, where $N_{t}$ is the population size in year $t$ and $N_{0}$ is the initial population size. Taking the natural logarithm of both sides of this equation yields $\ln \left(N_{t}\right)=\ln (\lambda) \cdot t+\ln \left(N_{0}\right)$. In other words, abundance on a log scale is a linear model with a slope directly related to $\lambda$. Therefore, we fit linear models to the log-transformed segment-level estimated abundances across all 10 years to estimate the average population trend, $\lambda$. In particular, we fit the model

$$
\log \left(N_{s t}\right)=\alpha_{s}+\beta t
$$

where

$N_{s t} \quad$ is the abundance estimate for segment $s$ in year $t$,

$\alpha_{s} \quad$ is the intercept for segment $s$,

$\beta \quad$ is the slope of the linear trend (or coefficient for year) for all segments, and

$t \quad$ is the year $(t=1,2, \ldots, 10)$.

This model was fit to segment-level abundance estimates generated by each of the abundance estimators described above, resulting in 7 abundance based trend estimators ( 2 for each of MKA, $M_{0}$, and $M_{t}$, and 1 for the CRDMS). The estimated slope ( $\hat{\beta}$ ) of the linear model and its standard error were then used to estimate the average trend: $\hat{\lambda}=e^{\hat{\beta}}$ with standard error $e^{\hat{\beta}} \cdot S E(\hat{\beta})$, as calculated using a first-order approximation under the delta method (Powell, 2007), where $S E(\hat{\beta})$ is the standard error of the slope estimate, $\hat{\beta}$. The estimates of trend and the standard error for the trend estimate for each stochastic replicate were then used to parameterize the decision model.

CPUE (or catch per unit area for active gears) has historically been used to estimate population trend (Wildhaber and others, 2011); however, it differs from the abundance estimators above in that it is an estimate of relative abundance. The catch-effort estimator analyzed here assumes that the CPUE is proportional to abundance as 


$$
\frac{C}{f}=q \cdot N
$$

where
C is the number of fish caught,
$q \quad$ is the probability of capturing a single fish per unit effort (Hubert and Fabrizio, 2007),
$f \quad$ is effort (in this case, measured in minutes of gear deployment), and
$N \quad$ is abundance.

Consequently, the log-transformed CPUE also is a linear function of the log-transformed growth rate, $\lambda$, justifying the use of the same approach as in the case of abundance, fitting model 10 with $N_{s t}$ replaced by $C P U E_{s t}$, the segment-level CPUE data. One issue with this approach, however, is that zero CPUE values cannot be log transformed. To avoid problems that arise due to zero-catch values, this trend estimator instead adjusts the CPUE by adding one to the catch before dividing by the effort; that is, $C P U E_{s t}=\left(C_{s t}+1\right) / f_{s t}$ where $C_{s t}$ and $f_{s t}$ are the total catch and effort, respectively, in segment $s$ in year $t$. The estimate for $\lambda$ (that is, $e^{\beta}$ ) and its standard error are calculated from the CPUE version of model 10 in the same manner described for the abundance based trend estimators above. Other approaches for calculating trend from CPUE data avoid zero-catch issues without adding 1 to the catch (for example, Wildhaber and others, 2016) and may prove more useful in future iterations. We include the CPUE trend estimator across all occasion levels to provide a comparison to current PSPAP v. 1.0 metrics.

Size Structure, Origin, and Sex Ratio

Population estimates by size class and origin have been reported utilizing PSPAP v. 1.0 data (for example, Shuman and others, 2011), while estimates of pallid sturgeon sex ratios have been reported using other sources of data, such as that from broodstock collection (Steffensen and others, 2013b). The accuracy and precision of estimators for size structure, origin, and sex ratio have not been currently analyzed in a simulation approach but are included as future work to refine the present analysis and link to ancillary subobjectives. The estimators of size structure, origin, and sex ratio being considered, with caveats for their use, are described in detail below.

Population estimates by length and origin have been identified to be of importance by stakeholders. In particular, MRSAMP subobjective 2 metrics (metric 2.1 and metric 2.2 in fig. 3) include population estimates by size class and origin. Moreover, during meetings with stakeholders, size structure and associated metrics were identified as important subobjectives (table 3). A first approach at estimating population abundance by size class would be to assume that size structure of the catch resembles the size structure of the population, and hence, overall population abundances can be broken down into size classes such that the proportion of each size class matches that seen in the catch. Similarly, abundance estimates can be broken down by origin and sex by assuming that both the hatchery to natural-origin ratio and the sex ratio of the catch resemble those of the population. In this case, determining the sex ratio from catch would be reliant on sampling from other programs, such as the broodstock collection, as determination of sex is currently not part of the PSPAP v. 1.0 sturgeon-season data collection protocols. Trend estimates by size class and origin can then be calculated from the abundance estimates, as described above. This approach relies on the collection of enough data for each size class, origin, 
and sex and does not take into account interactions of these attributes with fish capture. Accounting for interactions between fish size, origin, and sex and fish capture can be done in a capture-recapture framework if capture probability can be modeled as a function of these factors. In particular, fish size has a potential effect on fish capture, and hence, on the performance of this estimation, if the catch from the gear used is size selective.

Size selectivity in gears adds an additional complexity to estimating abundance by size class. Catch from a size-selective gear will not directly reflect the true size structure of the population, as all size classes are not collected with the same probability. Unfortunately, the relationship between capture probability and fish size is uncertain for all gears; however, varying gears do capture different sized fish, indicating that gears are selective (Schapaugh and Tyre, 2011; Wildhaber and others, 2011; Wu and Holan, 2017). Estimating size-specific catch by allowing capture probability to vary with fish length can potentially produce accurate and precise estimates of size class specific abundance. The mark-recapture abundance estimators described above are capable of estimating size class specific abundance in this way, given there are enough captures and recaptures of fish in each size class considered, something that may be difficult to achieve given the rarity of the species and low probabilities of capturing certain size classes. Examination of such estimators is in progress.

\section{Simulating Monitoring Design Fundamental Objective 2 Performance Metrics-An Overview}

At its core, calculating the performance metrics of estimate bias and precision for abundance and trend estimates given a particular monitoring design required simulating estimator outcomes of the monitoring design using three steps:

1. Generate a pallid sturgeon reference population with known dynamics.

2. Simulate catch data given the monitoring design and reference population.

3. Calculate performance metrics given catch data associated with the particular monitoring design and reference population:

A. apply monitoring design estimators to the catch data, and

B. compare abundance and trend estimates to the true reference population values.

Precision estimates for trend and abundance are calculated in step 3A and bias estimates in step 3B. Accounting for uncertainties required the simulation of several stochastic replicates at various steps in the above process. Uncertainties in pallid sturgeon movement and recruitment required generating several pallid sturgeon reference populations; currently, we have simulated 400 replicate populations (appendix 3, table 3.1). Additionally, uncertainties related to capture probability and catchability required that step 2 be repeated several times for each monitoring design and reference population combination; currently, we have simulated four stochastic catchdata replicates per combination for a total of 1,600 ( 400 populations x 4 catch datasets per population) catch-data replicates per monitoring design (appendix 3, table 3.3). The four performance metrics have currently been calculated (step 3) for all 1,600 catch-data replicates for 144 of the 150 analyzed sturgeon-season monitoring designs (table 4) detailed above. The remaining six sturgeon-season monitoring designs are those analyzed with a multistate robust design estimator (paired with fixed sampling, 2 or 3 occasions, and the 3 gear options), and at this time, performance metrics have been calculated for 800 catch-data replicates. Progress on simulations to the present (March 2018) has been constrained by available time, and the other 800 catch-data replicates per monitoring design are underway. 
Calculation of performance metrics for hundreds of replicates simulated under these monitoring designs was not trivial and required weeks of computing time. While the simulation and estimator codes have been parallelized, we have not yet utilized services such as cloud computing or access to a cluster, which would require additional funding. Therefore, as indicated, analysis is continuing to improve results; however, the process detailed in the following three sections will continue to be used as the blueprint for the simulation and analysis of future replicates.

\section{Generation of Reference Populations with Known Dynamics}

A set of reference populations of known pallid sturgeon population dynamics was needed to compare alternative monitoring designs' abilities to achieve monitoring objectives. We simulated 400 replicate reference populations with known dynamics (that is, trend) and abundance using the parameter values described in appendix 3 (table 3.1). Additionally, the replicate reference populations have known size structure, sex structure, origin structure, growth, and movement to facilitate future analysis and optimization of ancillary subobjectives. In short, for each simulated reference population, we (1) populated each river bend with individual pallid sturgeon of known origin, sex, length, and growth parameters; (2) simulated population survival, recruitment, growth, and movement over a 10-year period; (3) simulated several 10-year catch datasets for each alternative monitoring design; and (4) calculated, for each catch dataset, the performance metrics identified in table 2 for fundamental information objective 2 . Here, the methodological details for 1 and 2 are provided below, leaving the details of the catch-data simulation and the performance metric calculations to separate sections.

Population Initialization

Pallid sturgeon reference populations were initialized to represent current conditions by using existing PSPAP v. 1.0 data and relevant pallid sturgeon literature values as needed (table 6). Population initialization required three steps: (1) initialize bend-level abundance, (2) assign demographic attributes (sex and origin) to each individual within each bend, and (3) initialize length and growth parameters for each individual within each bend.

Bend Abundance

Initializing bend-level abundances was constrained to bends within the upper basin (segments 1-4) and lower basin (segments 7-10, 13, and 14) of the Missouri River. We stochastically assigned origin-specific pallid sturgeon abundance to each bend as

$$
N_{\text {segment,bend,origin }} \sim \operatorname{Poisson}\left(\lambda_{\text {segment,origin }} \cdot l_{\text {segment,bend }}\right)
$$

where

$N_{\text {segment,bend,origin }}$
$\lambda_{\text {segment,origin }}$
$I_{\text {segment, bend }}$
segment
bend
origin

is the origin and bend-specific abundance; is the segment and origin-specific density, in fish per river kilometer; is the bend length, in river kilometers; indexes segment; indexes bend within segment; and indexes whether pallid sturgeon were hatchery origin or naturally produced. 
The values of $\lambda_{\text {segment,origin }}$ used to initialize bend-level pallid sturgeon abundance were taken from the literature and are provided in table 6 . While initial segment densities $\left(\lambda_{\text {segment,origin }}\right)$ measure density in fish per bend length (in river kilometers), variation in bend width (among the three different segment groupings indicated in table 6) is indirectly taken into account by simulating initial densities in this manner. In the lower basin, density estimates for small portions of the river were used to calculate the initial segment density values (table 6). Extrapolating these densities to the entire lower basin results in hatchery and natural-origin basin-level abundances that are significantly greater than those presented in Wu and Holan (2017) but comparable to those of Steffensen and others (2017) and Winders and Steffensen (2014). A smaller population size may lead to sparser catch data and decreased estimator performance, something that may be analyzed in more detail in future iterations. Bend- and origin-specific pallid sturgeon abundances were then expanded to represent individual pallid sturgeon with known origin attributes.

Table 6. Segment and river level densities by origin.

[Minimum and maximum mean densities were taken from data across a few recent years (when available), mean densities are those reported in the literature from the most recent

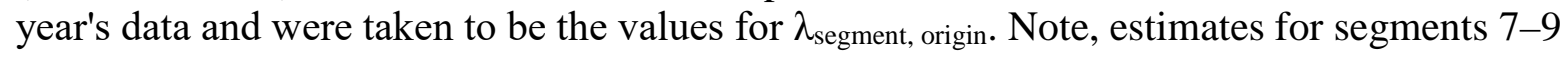
and 10,13,14 were based on sampling and abundance estimates from an 80.5- and a 43.3-rkm reach, respectively, and differ from the lower densities found by Wu and Holan (2017). rkm, river kilometer; $\mathrm{H}$, hatchery; $\mathrm{N}$, natural]

\begin{tabular}{|c|c|c|c|c|c|c|}
\hline Segments & $\begin{array}{l}\text { Fish } \\
\text { Type }\end{array}$ & $\begin{array}{c}\text { Minimum } \\
\text { mean } \\
\text { density } \\
\text { (fish/rkm) }\end{array}$ & $\begin{array}{c}\text { Maximum } \\
\text { mean } \\
\text { density } \\
\text { (fish/rkm) }\end{array}$ & $\begin{array}{c}\text { Mean } \\
\text { density } \\
\text { (fish/rkm) }\end{array}$ & $\begin{array}{c}\text { Most } \\
\text { recent } \\
\text { year of } \\
\text { data }\end{array}$ & References \\
\hline \multicolumn{7}{|c|}{ Upper Basin } \\
\hline \multirow[b]{2}{*}{$1-4$} & $\mathrm{H}$ & 91.57 & 184.45 & 91.57 & 2013 & (Rotella, 2013, 2015) \\
\hline & $\mathrm{N}$ & 0.28 & 0.37 & 0.28 & $2008 *$ & $\begin{array}{l}\text { (Klungle and Baxter, 2005; } \\
\text { Jordan and others, 2016) }\end{array}$ \\
\hline \multicolumn{7}{|c|}{ Lower Basin } \\
\hline \multirow{2}{*}{$7-9$} & $\mathrm{H}$ & 28.62 & 32.3 & 32.3 & 2010 & (Steffensen and others, 2012) \\
\hline & $\mathrm{N}$ & 5.43 & 8.88 & 5.7 & 2010 & (Steffensen and others, 2012) \\
\hline \multirow{2}{*}{$10,13,14$} & $\mathrm{H}$ & 5.53 & 10.17 & 5.53 & 2013 & (Winders and Steffensen, 2014) \\
\hline & $\mathrm{N}$ & 0.56 & 0.93 & 0.93 & 2013 & (Winders and Steffensen, 2014) \\
\hline
\end{tabular}

*Estimated year of data collection based on reference date.

\section{Assign Demographic Attributes}

Pallid sturgeon sex and origin are important attributes to model. In particular, MRSAMP subobjective 2 metrics (fig. 3) include population estimates by origin. Additionally, the population sex ratio plays a role in the calculation of effective population size and was indicated as a subobjective of interest to stakeholders (table 3). Origin (hatchery or natural) was assigned to individual fish in the expansion of the origin-specific bend abundances to individuals. Sex was then assigned to each individual fish, assuming a basin-specific male to female sex ratio of $\gamma_{\text {basin }}$ 
:1, where $1 \leq \gamma_{\text {basin }} \leq 3$ was chosen randomly from a uniform distribution (Jaeger and others, 2009; Steffensen and others, 2013a; Jordan and others, 2016; Wildhaber and others, 2017).

Initialize Individual Length and Growth Parameters

Pallid sturgeon length is an important attribute to model for the purposes of comparing the ability of alternative monitoring designs to achieve fundamental objective 2. In particular, MRSAMP subobjective 2 metrics (metric 2.1 and metric 2.2 in fig. 3) included population estimates by size class. Additionally, size structure and associated metrics were identified as subobjectives important to stakeholders (table 3). Moreover, fish size has a potential effect on monitoring if the catch from a particular gear is size selective. While size-selective catch is an uncertainty, different gears do capture different sized fish (Schapaugh and Tyre, 2011;

Wildhaber and others, 2011; Wu and Holan, 2017), indicating that gears are size selective. Thus, modeling fish length both contributes to the current analysis at hand and - as size-selective gears have yet to be implemented-also opens up potential for future study of gear selectivity and the use of abundance estimators that allow size-specific capture probabilities.

We randomly assigned an initial length to each fish. Initial lengths were generated from a segment-specific distribution constructed from recent (2015 and 2016 sampling season) PSPAP database length data (fig. 4). It should be noted that the PSPAP uses multiple gear types-each with its own size-selectivity curve - to more consistently capture the abundance of all size classes; however, since the size selectivity of each gear is unknown, the PSPAP length data are likely biased by gear selectivity. For each segment, an inverse cumulative distribution function for length was generated by interpolating between the percentiles of the length data for the given segment using the approxfun function in R (R Development Core Team, 2010). Each inverse cumulative distribution function takes a random probability value between 0 and 1 as input and outputs a length value. Therefore, segment-specific initial lengths were assigned stochastically to each pallid sturgeon by randomly sampling the segment-specific inverse cumulative distribution function for length.

We also assigned individual von Bertalanffy growth parameters $L_{\infty}$ and $k$, or the asymptotic length and Brody growth coefficient of a fish's growth trajectory, respectively, to each fish. Growth parameters were generated from a basin-specific bivariate lognormal distribution (appendix 3, table 3.1) fitted to the length data in the PSPAP database. By fitting a bivariate distribution, correlations between $L_{\infty}$ and $k$ were accounted for (that is, variances were not applied to each growth parameter independently). We truncated the basin-specific bivariate lognormal distributions to an 80-percent confidence ellipse using rtruncnorm in R ( R Development Core Team, 2010) to avoid unrealistic growth parameter combinations and randomly assigned basin-specific combinations of $L_{\infty}$ and $k$ to individual pallid sturgeon from the truncated distributions. 


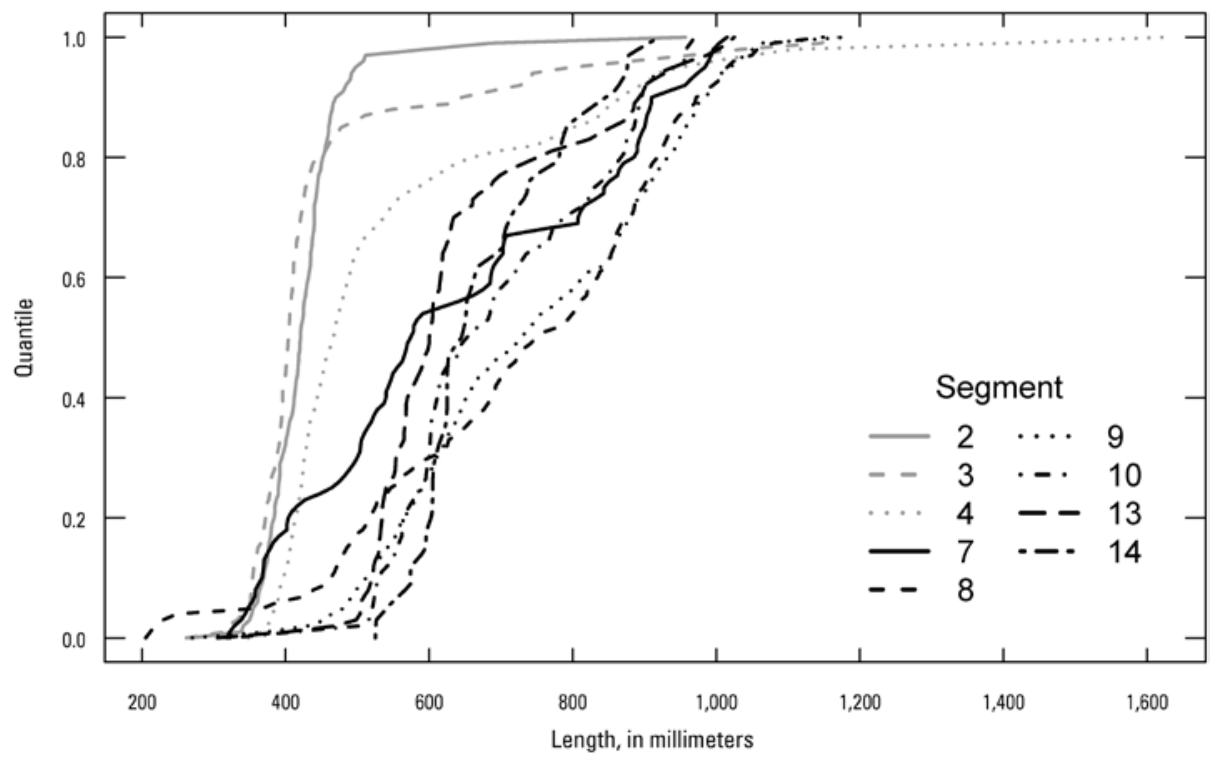

Figure 4. Segment-specific initial length distributions used to initialize individual pallid sturgeon before simulating population dynamics. Upper basin segments $(2,3,4)$ are represented in grey. Lower basin segments $(7,8,9,10,13,14)$ are represented in black. Cumulative distributions were fit to segmentspecific 2015 and 2016 sampling season Pallid Sturgeon Population Assessment Program data. The Pallid Sturgeon Population Assessment Program uses multiple gear types-each with its own size-selectivity curve-to more consistently capture the abundance of all size classes. However, since the size selectivity of each gear is unknown, the Pallid Sturgeon Population Assessment Program length data, and therefore these distributions, are likely biased by gear selectivity.

\section{Simulating Annual Transitions}

After initializing the reference population, we track all individual fish for 10 years, recording individual survival status $\left(Z_{i}\right)$, bend location ( $\left.L o c_{i}\right)$, and length $\left(L_{i}\right)$ on an annual basis. Additionally, recruits may be added to the population and tracked.

Survival

Individual pallid sturgeon survival from year to year was simulated as

$$
Z_{i, t+1} \sim \operatorname{Bernoulli}\left(\phi \cdot Z_{i, t}\right),
$$

where

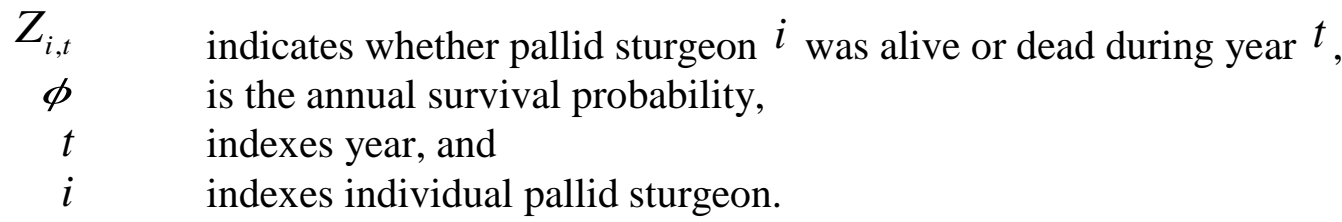

We assumed homogeneous survival probability among basins and years with $\phi$ equal to 0.95 for all simulations (Braaten and others, 2009). Therefore, in the absence of recruitment, the population trend was 0.95 over the 10 -year period simulated. We used a fixed survivalindependent of time, age, length, origin, and sex-so trend could be estimated without the 
confounding of among year variability, assessing whether estimators can estimate trend under some of the least complex conditions (that is, constant trend). Future iterations may assess the performance of trend estimators under more complex conditions that account for temporal or individual differences in survival (Rotella, 2017; Steffensen and others, 2017; Wu and Holan, 2017).

Growth

We additionally modeled individual fish growth so that relevant ancillary subobjectives (for example, size structure) can be analyzed and the effect of fish size on population estimates can be accounted for in future refinements if such a relationship can be estimated. Annual growth, conditional on being alive, was projected by individual von Bertalanffy growth curves (appendix 3, table 3.1) as

$$
L_{i, t+1}=\left(L_{i, t}+\left(L_{\infty, i}-L_{i, t}\right)\left(1-e^{-k_{i}}\right)\right) \cdot Z_{i, t+1}
$$

where

$$
\begin{aligned}
\boldsymbol{L}_{i, t} & \text { is the length of fish } i \text { during year } t, \\
L_{\infty, i} & \text { is the asymptotic length for fish } i, \\
k_{i} & \text { is the Brody growth coefficient for fish } i, \\
Z_{i, t} & \text { indicates whether pallid sturgeon } i \text { was alive (1) or dead (0) during year } t, \\
i & \text { indexes individual fish, and } \\
t & \text { indexes years. }
\end{aligned}
$$

Movement

We simulated within-basin movement occurring between years at the bend level to account for the uncertain influence of movement on monitoring designs. In simulated reference populations, pallid sturgeon can move, outside of the sampling period, to upstream and downstream bends within the same basin or stay within the same bend. In other words, individuals can change bend and segment locations but not basins. Movement probabilities were simulated conditional on current bend location with the probability of being in any given bend the following year decreasing with increasing distance from the current bend or particularly as

$$
\operatorname{mov}(j, n)=\mathrm{P}\left(B_{t+1}=j \mid B_{t}=n\right)=\frac{e^{-\beta \cdot d(j, n)}}{\sum_{\operatorname{mò} M(n)} e^{-\beta \cdot d(m, n)}},
$$

where

$$
\begin{array}{cl}
\operatorname{mov}(j, n) & \text { is the probability of moving to bend } j \text { given current bend location } n \text { and } \\
& \sum_{j \mathrm{o} M(n)} \operatorname{mov}(j, n)=1 ; \\
B_{t} & \text { are bends within the same basin; } \\
\beta & \text { is bend location in year } t ;
\end{array}
$$


$d(m, n) \quad$ is the distance from the center of bend $m$ to the center of bend $n$, in river kilometers; and

$M(n) \quad$ is the set of all bends within a particular Missouri River basin, the basin in which bend $n$ lies.

Individual movement among bends was simulated as

where

$$
\operatorname{Loc}_{i, t+1} \sim \text { Multinomial }\left(\overrightarrow{\operatorname{mov}}\left(\operatorname{Loc}_{i, t}\right) \cdot Z_{i, t+1}\right)
$$

$\operatorname{Loc}_{i, t} \quad$ is the bend location for pallid sturgeon $i$ in year $t$,

$\sim \quad$ denotes that the variable has a probability distribution,

$\overrightarrow{m o v}\left(\operatorname{Loc}_{i, t}\right) \quad$ is a vector of bend-specific probabilities whose entries are $\operatorname{mov}\left(j, L o c_{i, t}\right)$ for each bend $j$ within the appropriate basin as defined in equation 15 ,

$Z_{i, t} \quad$ indicates whether pallid sturgeon $i$ was alive (1) or dead (0) during year $t$,

$i \quad$ indexes individual pallid sturgeon, and

$t \quad$ indexes year.

Currently, reference populations were simulated with very little between year movement ( $\beta=1$; high site fidelity), allowing an examination of whether estimators can perform reasonably in the simplified case of very little between year movement. Additionally, to account for the uncertain nature of movement probabilities, we plan to vary $\beta$, allowing the analysis of populations with movements associated with different levels of site fidelities (fig. 5); auxiliary telemetry data will contribute to this understanding. Movement probabilities that reflect behavioral responses to habitat management actions (for example, preference of modified habitats) could also be simulated. Movement in all these scenarios reflects movements among bends between sampling years and not reproductive migratory movements within sampling year because those types of movement require active telemetry of reproductive fish (DeLonay and others, 2016).

Transitions from bend 78 (rkm 1,453)

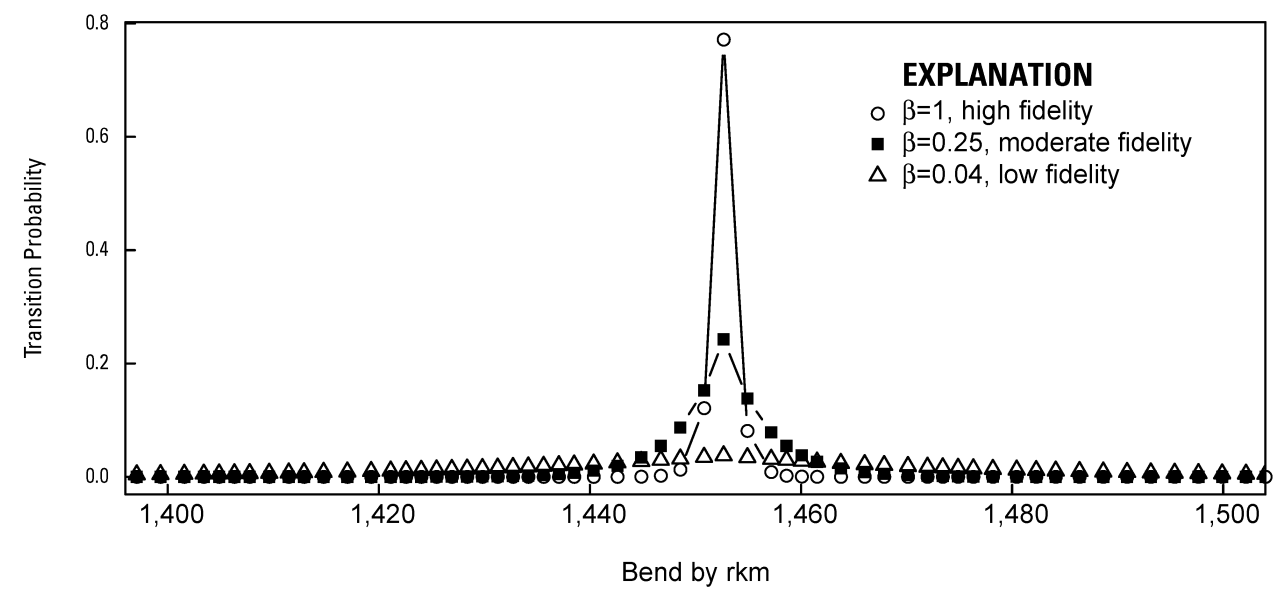

Figure 5. Probability of a pallid sturgeon moving to an upstream or downstream bend or remaining at bend 78 located at river kilometer ( $\mathrm{rkm})$ 1,453. 
Currently, only populations not in violation of estimator movement assumptions have been simulated. Violations to estimator assumptions (for example, within sampling year movement, temporary and permanent migration to and from regions outside of the study area) could affect estimated bias and precision, and smaller scale analyses on this topic have been presented on the PSPAP blog (https://mcolvin.github.io/PSPAP-Reboot/.). Future work should assess violations to estimator assumptions; however, a simulation analysis of model violations on a scale similar to the current undertaking will likely be prohibitively complex, and other methods will need to be explored.

\section{Recruitment}

Basin-specific annual age-1 recruitment was stochastically simulated for each replicate reference population and determined by two factors: (1) whether or not successful recruitment occurred, and (2) given recruitment occurred, how many naturally produced age-1 pallid sturgeon recruited to the population. Both the number of recruits and recruitment frequency (that is, how often recruitment occurred) were simulated at various levels to account for recruitment uncertainties and their effects on a monitoring design's ability to achieve the fundamental objectives. Moreover, varying recruitment frequencies (for example, once every 3 years, once every 5 years, never) accounts for the potential influence of recruitment on trend estimates. In short, recruitment was incorporated into simulated population dynamics by, first, stochastically assigning whether or not any age- 1 pallid sturgeon were recruited to the population; second, stochastically generating how many pallid sturgeon recruited if recruitment occurred; and lastly, assigning spatial location, sex, origin, length, and growth parameters to each individual recruit, as detailed below.

Whether or not recruitment occurred was simulated as

$$
R_{\text {basin,t }} \sim \operatorname{Bernoulli}\left(\psi_{\text {basin, recruitment }}\right)
$$

where

$$
\begin{array}{cl}
R_{\text {basin,t }} & \text { indicates whether recruitment occurred (1) or not (0) in the given basin during } \\
& \text { year } t, \\
\psi_{\text {basin,recruitment }} & \text { is the basin-specific frequency of recruitment, } \\
t & \text { indexes year, and } \\
\text { basin } & \text { indexes the upper or lower basin. }
\end{array}
$$

Basin-specific recruitment period, that is, $1 / \psi_{\text {basin,recruitment }}$, was a randomly drawn integer from 1 to 5 , giving recruitment frequency values of $1,1 / 2,1 / 3,1 / 4$, and 1/5. The number of age- 1 pallid sturgeon recruited to the basin-level population was simulated as

$$
N_{\text {recruits,basin,t }} \sim \operatorname{Poisson}\left(\lambda_{\text {recruits, basin }} \cdot R_{\text {basin, },}\right)
$$

where

$N_{\text {recruits,basin,t }}$ is the number of age-1 pallid sturgeon recruited to the given basin in year $t$,

$\lambda_{\text {recruits,basin }}$ is the basin-specific mean level of recruitment, 


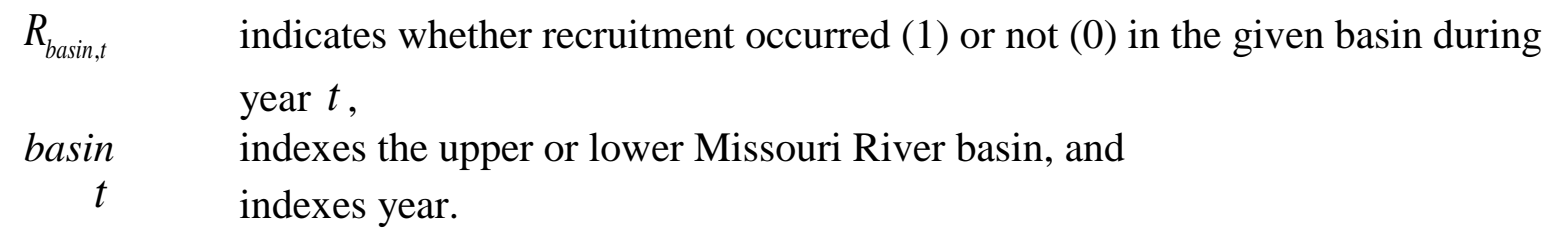

The values for $\lambda_{\text {recruits,basin }}$ were randomly drawn from values ranging from 10 to 100 for the lower basin and 10 to 50 for the upper basin. Recruitment numbers were then expanded to represent individual pallid sturgeon, which were each assigned natural-origin status. Each recruit was also randomly assigned to a bend within the basin of origin. Additionally, individual recruits were assigned a sex, an initial length of 200 millimeters (mm), and individual growth parameters $\left(L_{\infty, i}, k_{i}\right)$. The initial length value was selected to approximate the size of an age- 1 recruit, and the stochastic assignment of growth parameters and sex were as described for the population initialization (see also appendix 3, table 3.1). Recruits were added to reference population in order to analyze how age-1 recruitment would influence trend estimates given that recruits can be detected. For the reference population simulations, we assumed age-1 recruits had an equal probability of being in any bends within basin, described in the recruitment-detection simulations. Other scenarios, or scenarios with increasing recruit numbers over time (for example, in response to IRC construction) may be considered for future simulations.

\section{Simulating Pallid Sturgeon Catch Data}

For each combination of reference population and monitoring design, we simulated catch data by first selecting which bends to sample throughout the 10 years and then selecting which individual fish (of those located in the sampled bends during sampling) were caught during each capture occasion. The sturgeon-season sampling component of the monitoring design, as described earlier, determines how bends are selected, as well as the number of within year sampling occasions per bend. Gear- and basin-specific sampling efforts were simulated using sampling information from the PSPAP database. The capture of individual fish depended on gear- and basin-specific capture probabilities, which are uncertain. Therefore, we varied capture probabilities over a large range, accounting for the effect this uncertainty has on fundamental objective 2 outcomes given a particular monitoring design. The details of this simulation process are given in the subsections below with all parameter values listed in appendix 3 (tables 3.2 and 3.3).

\section{Bend Selection}

All monitoring designs under consideration included sampling bends located within segments $2-4,7-10,13$, and 14 . The number of bends sampled within each segment was chosen to be consistent with past sampling procedures. In particular, we chose the number of sampled bends within the segment to match those given in USACE's 2017 PSPAP Guiding Document (Welker and others, 2017). The way selected bends were generated, however, varied and was determined by the particular choice of sturgeon-season sampling component of the monitoring design. In particular, two alternative system-level sampling designs were considered: a random design and a fixed design. Under the random sampling design, bends within a segment were chosen each year uniformly at random, while under the fixed sampling design, they were chosen uniformly at random for the first year and then fixed to be sampled each of the following 9 years. 
As indicated in the earlier discussion of sturgeon-season designs (see the "Basin-Level Survey Design, Bend-Level Sampling Effort, and Gears” section), a fixed sampling design was implemented to improve sampling area definitions in multistate analyses, and in general, we caution against the use of such a design as it could bias results.

\section{Pallid Sturgeon Captures}

We simulated catch data for monitoring designs that included one, two, three, or four sampling occasions per year for each sampled bend. Additionally, to thoroughly sample a bend during a sampling occasion, eight gear deployments are used to capture fish (Welker and Drobish, 2017; Welker and others, 2017). For a particular sampled bend during a particular year, each fish located in the given bend had a probability, $p_{k}$, of being captured during occasion $\boldsymbol{k}$. This occasion-level capture probability varied from bend to bend and among occasions because it was calculated from individualized deployment catchability and effort values, defined in detail below. If a living fish was located in the given sampled bend during the given year, then capture was simulated as

$$
C_{i, t, k} \sim \operatorname{Bernoulli}\left(p_{t, k} \cdot Z_{i, t}\right)
$$

where

$$
\begin{aligned}
C_{i, t, k} & \text { indicates whether pallid sturgeon } i \text { was captured (1) or not (0) during } \\
& \text { sampling occasion } k \text { during year } t, \\
p_{t, k} & \text { is the bend-specific capture probability for sampling occasion } k \text { in year } t, \\
Z_{i, t} & \text { indicates whether pallid sturgeon } i \text { was alive (1) or dead (0) during year } t, \\
i & \text { indexes individual pallid sturgeon within the given bend, } \\
k & \text { indexes sampling occasion within year, and } \\
t & \text { indexes year. }
\end{aligned}
$$

For each of the eight deployments within occasion $k$, an effort value $f$ was generated from gear- and basin-specific gamma distribution and a catchability value $q$ was generated from a gear-specific distribution (appendix 3). Deployment-specific capture probabilities, $y$, were then calculated as $y=q \cdot f$ (Hubert and Fabrizio, 2007), and the eight within occasion deployment capture probabilities were summed (and bounded at 1) to obtain occasion-level capture probability, or

$$
\begin{aligned}
p_{n, g, t, k} & =\min \left(1, \sum_{j=1}^{8} y_{n, g, t, k, j}\right) \\
& =\min \left(1, \sum_{j=1}^{8} f_{n, g, t, k, j} \cdot q_{n, g, t, k, j}\right),
\end{aligned}
$$

where

$p_{n, g, t, k} \quad$ is the capture probability for gear $g$ during sampling occasion $k$ within year $t$ in bend $n$; 
$y_{n, g, t, k, j} \quad$ is the capture probability for deployment $\boldsymbol{j}$ of gear $\boldsymbol{g}$ made within occasion $\boldsymbol{k}$, year $t$, and bend $n$;

$f_{n, g, t, k, j} \quad$ is the effort (in minutes) for deployment $j$ of gear $g$ made within occasion $\boldsymbol{k}$, year $t$, and bend $n$;

$q_{n, g, t, k, j} \quad$ is the catchability for deployment $j$ of gear $g$ within occasion $k$, year $t$, and bend $n$;

j $\quad$ indexes deployment within sampling occasion;

$k \quad$ indexes sampling occasion within year;

$t \quad$ indexes year;

$g \quad$ indexes gear; and

$n \quad$ indexes the bend.

Basin- and gear-specific gamma distributions for deployment level effort $\left(f_{n, g, t, k, j}\right)$ were estimated using the PSPAP database. We defined effort as the time (in minutes) that a gear was set, dragged, or pulled during a single deployment. This is a general measurement of effort that can be calculated for all gear types. We recognize that gear set time is more relevant to measuring effort for passive gears; however, the distance or area effort metrics typically used for PSPAP v. 1.0 active gears can be assessed as a linear function of time and gear-specific variables (for example, $d=v t$, where $d$ is the distance trawled, $v$ is the average trawl velocity relative to the river bottom and perpendicular to the trawl width, and $t$ is the time duration of the trawl). For simulations of active gears, we have allowed effort to be measured as the time portion of this function while the gear-specific variable(s) and any associated uncertainties are accounted for in the catchability coefficient $\left(q_{n, g, t, k, j}\right)$. Future simulations may further reframe and incorporate effort values based on distance or area metrics when considering active gears in order to better coordinate with the standard PSPAP v. 1.0 description of effort. The basin- and gear-specific deployment efforts were simulated as

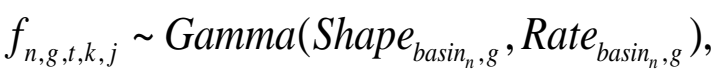

where

$f_{n, g, t, k, j}$

is the basin- and gear-specific effort, in minutes of deployment, for gear $\boldsymbol{g}$ and deployment $j$ within occasion $k$, year $t$, and bend $n$;

Shape $_{\text {basin }_{n}, g}$ is the estimated basin- and gear-specific shape parameter for a gamma distribution;

$\begin{aligned} \text { Rate }_{\text {basin }_{n}, g} & \text { is the estimated gear-specific rate parameter for a gamma distribution; } \\ \text { basin }_{n} & \text { is the basin associated with bend } n ; \\ g & \text { indexes gear; } \\ \boldsymbol{k} & \text { indexes deployment within sampling occasion; } \\ t & \text { indexes sampling occasion within year; } \\ n & \text { indexes year; and }\end{aligned}$


Gamma distributions provided a good fit to the effort data (fig. 6). See appendix 3 (table 3.2) for gear-specific shapes and rates.

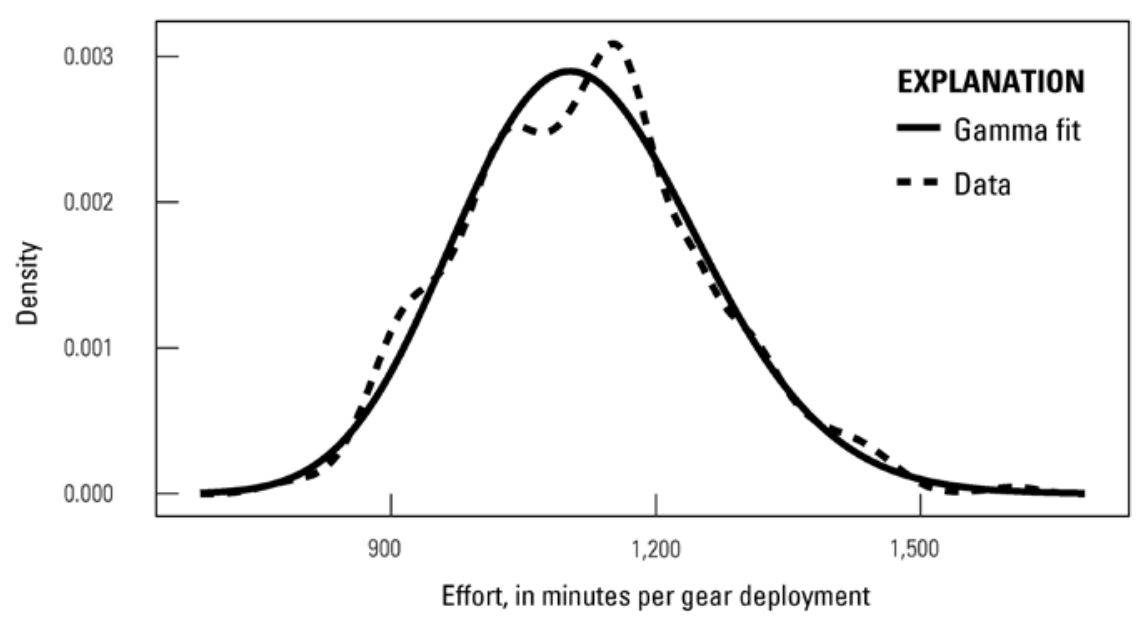

Figure 6. Example gamma distribution fit to effort data for trotline deployed in the upper basin, where effort is measured as minutes per gear deployment. Fitted distributions were used to randomly draw effort values for simulating pallid sturgeon capture.

Gear-specific catchability distributions were set up such that the log odds of catchability (q) was normally distributed as

$$
\operatorname{logit}\left(q_{n, g, t, k, j}\right) \sim \operatorname{Normal}\left(\mu_{g}, \sigma_{g}\right),
$$

where

$$
\begin{array}{cl}
q_{n, g, t, k, j} & \text { is the catchability for deployment } j \text { of gear } g \text { made within occasion } k, \\
\mu_{g} & \text { is the mean log-odds catchability of the gear; } \\
\sigma_{g} & \text { is the standard deviation of the log-odds catchability among deployments; } \\
g & \text { indexes gear; } \\
j & \text { indexes deployment within sampling occasion; } \\
k & \text { indexes sampling occasion within year; } \\
t & \text { indexes year; and } \\
n & \text { indexes the bend. }
\end{array}
$$

We allowed catchability to vary among deployments to account for variability in catch that could be attributed to habitat type or other environmental conditions. The inputs of $\mu_{g}$ and $\sigma_{g}$ are unknown and were therefore drawn from a uniform distribution to account for uncertainty in those values for each simulation.

Equation 20 is based on the assumption that capture probability $(p)$ is related to effort ( $f$ ) and catchability ( $q$ ) by $p=q \cdot f$ (Hubert and Fabrizio, 2007). When catchability ( $q$ ) is fixed, this is likely a good approximation for relatively small effort values $(f)$; however, as effort 
increases, $p$ may exceed 1 . In other words, the model $p=q \cdot f$ breaks down, and therefore, given our method of drawing effort values, we must be cautious of high capture probabilities. To indirectly account for this, we have flagged cases in our simulations where the occasion-level capture probability is higher than 0.4. There are alternative methods for generating occasionlevel capture probability distributions that can avoid this issue, and hence, we plan to alter the approach presented here in order to improve future simulations of catch data. Examples of occasion-level probability distributions produced under the current approach are available in appendix 3 (figs. 3.1-3.4). Additionally, equation 20 contains the assumption that gear deployments within sampling occasion are independent of one another and do not interact. This means both that there is a zero probability that the same fish will be caught by two separate deployments (within the same occasion) and that any particular deployment does not affect the probability that a fish is caught by any other deployment within the same sampling occasion. In cases where there is little fish movement within occasions or where gears are set sufficiently far apart, these assumptions are very likely met.

\section{Calculating Performance Metrics Given Catch Data and Associated Monitoring Design}

Monitoring design abundance and trend estimators are applied (see the "Population Abundance and Trend Estimators" section for details) to each catch-data replicate that was simulated under the monitoring design's sturgeon-season sampling protocols. The estimators provide abundance and trend estimates, as well as associated estimate standard errors. Precision (for both abundance and trend) is calculated directly from the estimator outputs as the relative standard error, or the estimate standard error divided by the estimate value.

Calculating the two bias performance metrics requires comparing the estimated abundance and trend values to the actual abundance and trend values; that is, the known abundance and trend of the reference population the catch data were simulated from. The bias performance metrics were calculated differently for trend and abundance. Trend bias was calculated as the difference in estimated trend over the 10-year period simulated and the actual 10-year trend. Abundance bias was calculated as the average relative bias over the 10 years, where relative bias is calculated as the difference between the estimated abundance and the actual abundance, all divided by the actual abundance.

For each of the 150 unique sturgeon-season design components of the alternative monitoring designs considered, the four performance metrics of abundance estimate bias, abundance estimate precision, trend estimate bias, and trend estimate precision were calculated for hundreds of catch-data replicates in order to account for all the uncertainties described in the previous two sections above.

\section{Fundamental Information Objective 3}

Fundamental information objective 3 relates to maintaining compatibility with legacy PSPAP v. 1.0 data. Designs analyzed thus far were developed to maintain some compatibility with legacy pallid sturgeon data by maintaining the bend-level sample unit and some level of randomization. The number of bends sampled within a segment, the minimum number of deployments per bend by gear, the effort per gear deployment, and the data collected and recorded for each sturgeon caught all remain the same under the alternative monitoring designs analyzed to date (March 2018) (table 4). Some loss of compatibility will be due to the simplification of only using gears that maximize catch, and therefore, the discontinued use of less-efficient gears will limit legacy compatibility for sturgeon season. Moreover, some 
monitoring designs take a new approach in how bends are selected, which will affect their compatibility with legacy data. The performance metric for fundamental objective 3 specifically takes into account compatibility issues that may arise from bend selection differences. In particular, the performance metric is the proportion of randomly selected bends (table 2). Under PSPAP v. 1.0, all bends were to be randomly selected each year for required sturgeon-season sampling. This was the protocol followed for all alternative monitoring designs using the random sampling approach, and hence, these monitoring designs received a performance metric of 1 . However, for alternative monitoring designs that used a fixed sampling approach, bends were chosen randomly the first year, and then those same bends were revisited during each of the following 9 years. In other words, random selection was done 1 out of 10 years for a performance metric of $1 / 10$. As discussed in earlier sections, data collected from fixed bends may not be representative of the entire segment, and therefore, it is meaningful that we discount the use of fixed bends with a much lower performance metric. Alternative survey designs considered as future work (for example, combination of random and fixed sampling, panel design) will likely have a performance metric somewhere in between these two extremes (1/10 and 1).

The performance metric for fundamental objective 3 strongly discounts a fixed bend selection design because the selected bends may not be representative of the segment being sampled; however, this does not mean sampling data with a fixed design will always be incompatible with legacy data. For all sampling designs, the CPUE of a single capture occasion can still be calculated, as was done with legacy data to obtain trend estimates. Under the conditions we have simulated thus far, the bias of single-occasion CPUE-based trend estimates for a fixed versus a random bend selection design are very similar, suggesting a high degree of compatibility (see the "Preliminary Design Outputs" section). Despite positive preliminary results, there are well-founded concerns that conditions not currently simulated could negatively affect compatibility when using fixed bends. Using the proportion of randomly selected bends as the performance metric for fundamental objective 3 decreases the value of fixed bend sampling in recognition of this risk.

The redesign efforts focus on sturgeon-season efforts to achieve fundamental objectives. The PSPAP v. 1.0 design also includes sampling during a fish-community season, with the intent of continuing collection of pallid sturgeon but adding in representation of the native fish community (Welker and others, 2017). Characterization of diversity and trends in the native fish community, and abundance of potential prey fish for pallid sturgeon, are ancillary subobjectives for the MRRP. We designated these as possibly coordinated with PSPAP v. 2.0 sampling, depending on their importance to decision making (table 3). Future simulations may evaluate monitoring designs with additional gear deployments that specifically target native fish community and forage fish subobjectives, sampling that can likely be linked with the proposed recruitment-detection sampling.

\section{Fundamental Information Objective 4}

Fundamental information objective 4 relates to providing relevant inputs to support population modeling. The proportion of relevant model inputs provided by each alternative monitoring design was the performance metric for this fundamental objective (table 2). Each model input (rows) and whether it can be estimated from the particular estimator component of the monitoring design (columns) are listed in table 7 . For inputs where only one parameter value is needed, each entry is a 1 if the particular monitoring design estimator can estimate the specific 
input and a 0 if it cannot. For inputs that require multiple parameter values, each entry receives a value of $1 /$ (number of parameters) if the particular monitoring design can estimate the given parameter and a 0 if it cannot. For example, the weight input relies on three parameter estimates, each of which receives a value of $1 / 3$ if it can be estimated. For each monitoring design, the performance metric for fundamental information objective 4 is then calculated as the sum of the particular estimator's column divided by the total number of model inputs. Additional sampling for model inputs (objective 4) is probably not necessary because implementation of the core metrics of PSPAP v. 2.0, effectiveness monitoring, and sampling for broodstock are likely to provide the needed data. The exception is establishing gender ratios, which may require shortterm (multiyear) efforts to sample blood and determine gender. In general, additional information for model inputs is not needed as annual time series; most of the additional demographic inputs can be established with some short-term sampling, for which coordination with PSPAP v. 2.0 sampling may be efficient and effective. Parameter values could be established during a window of a few years and then revisited in the future if there is concern that the values are drifting. 
Table 7. Collaborative population model inputs.

[Each monitoring design estimator receives a 1 if it can estimate the model input and a 0 if not. Entries of 0.75 for survival inputs are to account for the fact that apparent survival (survival + emigration) can be estimated from these estimators, but not actual survival as in the case of the closed robust design multistate model (CRDMS) estimator. Note some inputs (for example, hatchery inputs) with values of 0 cannot be determined from the estimators; however, they are being collected in other programs (for example, stocking, broodstock).]

\begin{tabular}{|c|c|c|c|c|c|}
\hline \multirow[b]{2}{*}{ Module } & \multirow[b]{2}{*}{ Input } & \multicolumn{4}{|c|}{ Monitoring design estimator } \\
\hline & & CPUE & MKA & $\mathbf{M}_{0} / \mathbf{M}_{\mathbf{t}}$ & CRDMS \\
\hline \multirow[t]{7}{*}{ Initialization data } & Maximum age & 0 & 0 & 0 & 0 \\
\hline & Sex ratio & 0 & 0 & 0 & 0 \\
\hline & $\begin{array}{l}\text { Abundance } \\
\text { wild }\end{array}$ & 0 & 1 & 1 & 1 \\
\hline & $\begin{array}{l}\text { Abundance } \\
\text { hatchery }\end{array}$ & 0 & 1 & 1 & 1 \\
\hline & $\begin{array}{l}\text { Abundance age } 0 \\
\text { wild }\end{array}$ & 0 & 0 & 0 & 0 \\
\hline & $\begin{array}{l}\text { Abundance age } 0 \\
\text { hatchery }\end{array}$ & 0 & 0 & 0 & 0 \\
\hline & Spatial distribution & 0 & 0 & 0 & 0 \\
\hline \multirow[t]{3}{*}{ Weight: weight $=\alpha \cdot$ length $^{\mathrm{b}}+\grave{\text { ò }}$} & $\alpha$ & $1 / 3$ & $1 / 3$ & $1 / 3$ & $1 / 3$ \\
\hline & $\mathrm{b}$ & $1 / 3$ & $1 / 3$ & $1 / 3$ & $1 / 3$ \\
\hline & ò & $1 / 3$ & $1 / 3$ & $1 / 3$ & $1 / 3$ \\
\hline \multirow[t]{3}{*}{ Fecundity: fecundity $=\alpha \cdot$ length $^{\mathrm{b}}+\grave{\mathrm{o}}$} & $\alpha$ & 0 & 0 & 0 & 0 \\
\hline & $\mathrm{b}$ & 0 & 0 & 0 & 0 \\
\hline & ò & 0 & 0 & 0 & 0 \\
\hline \multirow[t]{6}{*}{ Growth: $\mathrm{L}_{\infty} \cdot\left(1-\mathrm{e}^{-\mathrm{k} \cdot(\text { age }-\mathrm{t} 0)}\right) \cdot \mathrm{o}$} & $\mathrm{L}_{\infty}$ & $1 / 6$ & $1 / 6$ & $1 / 6$ & $1 / 6$ \\
\hline & $\mathrm{k}$ & $1 / 6$ & $1 / 6$ & $1 / 6$ & $1 / 6$ \\
\hline & $\operatorname{var}\left(\mathrm{L}_{\infty}\right)$ & $1 / 6$ & $1 / 6$ & $1 / 6$ & $1 / 6$ \\
\hline & $\operatorname{cov}\left(\mathrm{L}_{\infty}, \mathrm{k}\right)$ & $1 / 6$ & $1 / 6$ & $1 / 6$ & $1 / 6$ \\
\hline & $\operatorname{var}(\mathrm{k})$ & $1 / 6$ & $1 / 6$ & $1 / 6$ & $1 / 6$ \\
\hline & ò & $1 / 6$ & $1 / 6$ & $1 / 6$ & $1 / 6$ \\
\hline \multirow[t]{2}{*}{$\begin{array}{l}\text { Probability of being sexually mature: } \\
\operatorname{Pr}(\text { Mature })=-\mathrm{k} \cdot\left(\text { age }- \text { age } \mathrm{e}_{\text {mature }}\right)\end{array}$} & age $_{\text {mature }}$ & 0 & 0 & 0 & 0 \\
\hline & $\mathrm{k}$ & 0 & 0 & 0 & 0 \\
\hline \multirow[t]{2}{*}{$\begin{array}{l}\text { Probability of spawning: } \\
\text { logit }(Y)=\beta_{0}+\beta_{1} \cdot \text { YearsSinceLastSpawn }\end{array}$} & $\beta_{0}$ & 0 & 0 & 0 & 0 \\
\hline & $\beta_{1}$ & 0 & 0 & 0 & 0 \\
\hline Movement: $\operatorname{Pr}\left(\right.$ Bend $_{j} \mid$ Bend $\left._{i}\right)$ & $\beta$ & 0 & 0 & 0 & 0 \\
\hline \multirow[t]{6}{*}{ Survival probability } & Embryo & 0 & 0 & 0 & 0 \\
\hline & Free embryo & 0 & 0 & 0 & 0 \\
\hline & age 0 & 0 & 0 & 0 & 0 \\
\hline & age 1 & 0 & 0 & 0 & 0 \\
\hline & age 2 & 0 & 0 & 0 & 0 \\
\hline & age $3+$ & 0.75 & 0.75 & 0.75 & 1 \\
\hline \multirow[t]{2}{*}{ Stocking amount } & fingerling & 0 & 0 & 0 & 0 \\
\hline & yearling & 0 & 0 & 0 & 0 \\
\hline
\end{tabular}




\section{Fundamental Information Objective 5}

Cost constrains the amount of sampling effort and, therefore, the outcomes of alternative sampling designs. While more sampling may yield very precise and unbiased estimates of population assessment metrics, the cost may exceed the amount the USACE can budget annually to support population monitoring. Lastly, budgets may vary over time, and therefore, incorporating cost into analyses allows alternative monitoring designs to be examined in terms of estimated cost but also provides a method to evaluate future tradeoffs of decreased efforts or reduction of monitoring components in a transparent way if budgets are reduced. Annually, seven field offices have been used to carry out the PSPAP, although only six field offices currently receive contracts since segments 13 and 14 have not been sampled since 2015. We estimated the year- and field-crew-specific expected cost to sample a bend by calculating the number of bend days sampled in a field season for sturgeon, fish community, and high water. Bend days in this case represents unique date and bend combinations, such that if a bend was visited on more than 1 day, each day was counted.

The field-crew-specific contract amount was then divided by the total unique bend days sampled. There was some discrepancy between the fiscal year and sampling efforts. Specifically, the PSPAP v. 1.0 sampling year begins in the fall when water temperature is at or below 12.8 degrees Celsius and continues to October 31 of the following calendar year (Welker and others, 2017), whereas the Federal fiscal year begins on October 1 and ends on September 30. This results in a small incompatibility between annual contract schedules and actual work performed. Cost per bend day approximates the cost to sample a bend on a single occasion when using eight gear deployments and includes personnel costs, other personnel expenses, maintenance costs, and other expenses that occur within an annual period like data entry, report writing, and office work to support sampling. In some cases, the cost per bend day likely slightly overestimates the cost to sample a bend. For example, some crews, like the Nebraska field crew, also complete broodstock collection under their PSPAP contract, which is approximately 2 weeks of intensive sampling of multiple bends. These bend days were not included in this estimate. Also, there is likely a gear-dependent economy of sampling more than one bend per day that is not captured here but worth future examination. Since field crews are assigned specific segments and portions of segments, it was possible to estimate cost of a monitoring design by calculating how many bends were sampled with what frequency.

Recruitment-detection sampling designs for fundamental information objective 1 rely on sampling multiple trawls within a day, and therefore, based on costs to sample the number of bends specified in table 5, the estimated cost to perform this effort is approximately \$0.3 million. Performing the additional visits to a bend over time for sturgeon-season sampling results in a total cost (in millions) of $\$ 0.6, \$ 0.9, \$ 1.2$, and $\$ 1.5$ for 1,2 , 3, or 4 occasions, respectively. Costs may also be increased for scenarios that include sampling for the native fish community and forage fish (mostly the fish-community season deployments) or decreased if recruitmentdetection sampling is limited to a fewer number of segments (for example, lower one-third of basin). Costs related to altering or continuing this sampling to achieve ancillary subobjectives have not yet been evaluated. Cost calculations should be interpreted with caution and used only for relative comparisons because of departures from standard sampling protocols that may arise from weather conditions and setting extra nets. Such deviations cannot be accounted for in this exercise because costs are budgeted prior to work; however, this analysis provides a baseline to assess the benefit:cost of monitoring and additional monitoring components related to ancillary 
subobjectives in table 3. Additional efforts will be taken to further refine cost estimates accounting for effort within day, if possible.

\section{Synthesize Outputs and Develop a Decision-Support Tool to Compare Alternative Monitoring Designs}

\section{Valuing Fundamental Information Objectives}

Quantitative performance metrics were identified for each fundamental information objective (table 2). The simulation approach provided the outcomes of alternative monitoring designs, which in turn, were used to calculate the performance metrics that quantified each fundamental information objective. Performance metrics for fundamental information objectives 1, 3, 4, and 5 were straightforward to calculate for each alternative monitoring design; however, quantifying fundamental information objective 2 was more complicated because multiple performance metrics needed to be calculated for fundamental information objective 2 in order to compare each monitoring design.

For the second fundamental information objective, four performance metrics needed to be calculated to compare each design. The four metrics were the combination of bias and precision for estimates of population trend and abundance. Bias was calculated differently for trend and abundance. Trend bias was calculated as the difference in estimated trend over the 10-year period simulated and the actual 10-year trend. Abundance bias was calculated as the average relative bias over the 10 years, where relative bias is calculated as the difference between the estimated abundance and the actual abundance divided by the actual abundance. For both trend and abundance, estimate precision was calculated as the relative standard error. These performance metrics were calculated for each stochastic catch-data replicate and used to quantify the fundamental objectives and associated subobjectives.

\section{Linking Performance Metrics and Fundamental Information Objectives}

The outcomes of each monitoring design, quantified by performance metrics (table 2), needed to be combined to compare multiple designs. Each performance metric for fundamental information objectives 1,2 , and 4 were scaled to vary from 0 to 1 where 1 was desirable (that is, maximize or minimize a performance metric). Since the performance metrics for fundamental objective 3 were proportions, they were already on a 0 to 1 scale, where 0 was undesirable and 1 was desirable, and hence, no scaling was necessary. Performance metrics were scaled such that performance can be combined by additive weighting to create an overall utility value for each monitoring design that corresponds to the fundamental objectives of the PSPAP v. 2.0. Where maximizing a metric is desirable, proportional scaling was used to scale performance metrics as

$$
U(a)=\frac{a-\min _{\alpha \grave{A}}(\alpha)}{\max _{\alpha \grave{\alpha} A}(\alpha)-\min _{\alpha \grave{A}}(\alpha)}
$$

where

$U \quad$ is the scaled utility value varying from 0 to 1 ,

a is a realized performance metric value for one of the replicates simulated under one of the monitoring designs,

A is the set of all realized values of the performance metric across all monitoring designs and replicates, and 
This proportional scaling equation scales high performance metrics to high utilities (near 1) and is commonly used in decision making (Hammond and others, 1999; Clemen and others, 2001; Conroy and Peterson, 2013). Where minimizing a performance metric is desirable, a slight modification of equation 23 can be used to scale small metric values to high utility values. For example, for an objective quantified by bias, smaller performance metric values are desirable and will receive a higher utility that approaches 1 . Additionally, performance metrics can be scaled such that there is no improvement after a threshold is exceeded. We used utility functions for the four performance metrics associated with fundamental information objective 2 that return a value of 0 if performance metrics exceed specified values (fig. 7). For any replicates where an estimate for trend or abundance could not be made (for example, if an estimator did not converge due to lack of recapture data), the associated performance metrics were set beyond the specified cut-off values in figure 7 and, therefore, yielded a utility value of 0 .

Bias
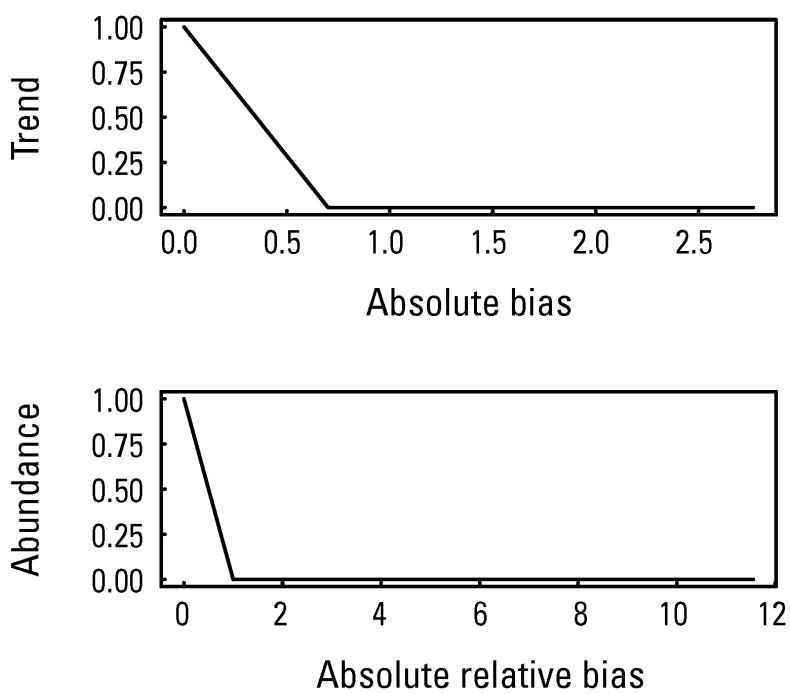

Precision
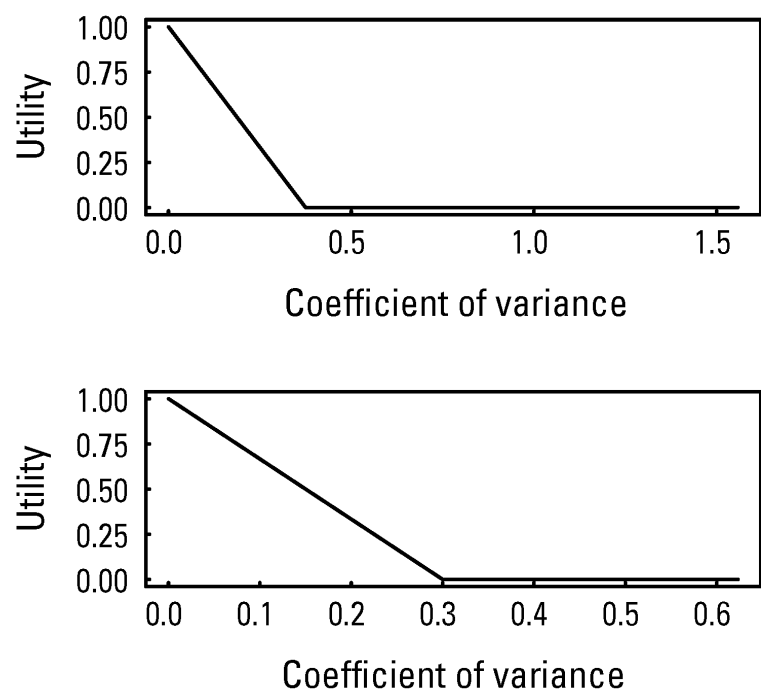

Figure 7. Utility functions used to scale the fundamental objective 2 performance metrics calculated for pallid sturgeon abundance and trend. In each plot, the utility of a performance metric will remain zero for all values above a particular threshold. These thresholds, starting with the upper left and moving counterclockwise, are: $0.7,1,0.3$, and 0.375 . Threshold values aided to provide preliminary results where extreme outcomes (for example, population size was estimated to be double that of what it actually was, the population was estimated to be growing at 70 percent when it was actually remaining constant, and so on) received a utility value of zero. However, these threshold values will not be used in future analyses that combine bias and precision into a single metric, the root square mean error. 
For preliminary estimates, scaled performance metrics for fundamental information objectives 1-4 were weighted and summed for each stochastic replicate as

$$
U_{\text {overall }}=\sum_{i=1}^{4} W_{i} \cdot U_{i}
$$

where

$U_{\text {overall }} \quad$ is the overall utility of a replicate simulated under a particular monitoring program,

$W_{i} \quad$ is the weight for fundamental information objective $i$,

$U_{i} \quad$ is the utility representing fundamental information objective $i$, and

$i \quad$ indexes the fundamental information objectives in table 2.

There were 2 information subobjectives and 4 performance metrics for fundamental information objective 2 that were aggregated to a single utility as

$$
\begin{aligned}
U_{2}= & W_{\text {trend }} \cdot\left(W_{\text {trend precision }} \cdot U_{\text {trend precision }}+W_{\text {trend bias }} \cdot U_{\text {trend bias }}\right) \\
& +W_{\text {abundance }} \cdot\left(W_{\text {abundance precision }} \cdot U_{\text {abundance precision }}+W_{\text {abundancebias }} \cdot U_{\text {abundancebias }}\right)
\end{aligned}
$$

where

$U_{2} \quad$ is the utility representing fundamental information objective 2; that is, the weighted utility of the abundance and trend performance metrics,

$W_{\text {trend }}$
$W_{\text {trend precision }}$
$U_{\text {trend precision }}$
$W_{\text {trend bias }}$
$U_{\text {trend bias }}$
$W_{\text {abundance }}$
$W_{\text {abundance precision }}$
$U_{\text {abundance precision }}$
$W_{\text {abundance bias }}$
$U_{\text {abundance bias }}$
is the weight for the trend information subobjective, is the weight for the scaled trend precision performance value, is the scaled trend precision performance value, is the weight for the scaled trend bias performance value, is the scaled trend bias performance value, is the weight for the abundance information subobjective, is the weight for the scaled abundance precision performance value, is the scaled abundance precision performance value, is the weight for the scaled abundance bias performance value, and is the scaled abundance bias performance value.

Note, however, in future analyses, the need for weighting bias versus precision may be eliminated by combining the bias and precision of abundance/trend estimates presented here into a single performance metric (root square mean error).

Benefit:cost analyses can then be performed by using the expected cost of the monitoring design (performance metric for fundamental information objective 5) and the overall monitoring design utility (benefits) calculated by equation 24 . For preliminary analyses, all weighting values were assumed to be equal among components. The section below details a possible process being 
developed to eliciting stakeholder weights to inform decisions rather than assuming equal weighting among objectives and associated subobjectives.

\section{Weighting Fundamental Information Objectives and Subobjectives}

The challenge in combining utilities is determining how each performance metric utility should be weighted. To understand some of the complications, assume that most stakeholders find trend precision to be generally more important than trend bias. Choosing a weight of 0.75 for precision and 0.25 for bias to represent this general preference is a subjective approach that did not take into account variation in the metrics - something that should affect the weighting. For example, if all monitoring designs had trend estimates with relative standard error values that ranged from 0.001 to 0.002 (that is, great precision), then many stakeholders would be happy with the precision of any of the available choices, and therefore, its importance in decision making is low. Hence, if trend bias values varied greatly when making a decision, one would focus on which choice of monitoring design also led to a small bias. In this case, the bias metric should be weighted higher than the precision metric (even though, in general, precision was thought to be more important than bias) because the bias values should have a greater effect on the choice of monitoring design given the small variation in precision values. As part of the ongoing efforts of the PSPAP v. 2.0 redesign, we will use swing weighting, a method that addresses some of the complications just described, to determine the weights, $W_{(\cdot)}$, used in equations 24 and 25 above. We also plan to eliminate the need for some weights by combining bias and precision into a single performance metric (root square mean error).

Swing weighting is a structured approach, is less subjective, and takes into account variation among performance metrics (Clemen and others, 2001). The process involves comparing the worst case to the best case scenario for each metric (or objective) while holding each of the other metrics constant at their worst case. In other words, swing weighting forces respondents to think about how a decision is affected when each metric "swings" from worst to best. These swings are first ranked and then valued. The swing that has the most influence on the decision process (relative to the other swings) would be given a rank of 1 (most important), the swing with the second greatest influence on the decision is given a rank of 2 , and so on. The baseline scenario, where all metrics are set to their worst case, always gets the highest (worst) rank. The scenario with a rank of 1 is assigned a value of 100 , and the baseline scenario is assigned a value of 0 . All other cases are then given a value from 0 to 100 , representing the impact they have on the decision-making process relative to the highest and lowest ranked scenarios. After values are assigned, the weights are calculated as the value divided by the sum of all values.

As a consistent, structured process, swing weighting provides an excellent approach for comparing and compiling stakeholder weights. We are currently developing an exercise that uses swing weighting as a way to understand what differences and similarities exist in stakeholder values on the importance of objective metrics, as well as to analyze the consequences of these differences on valuing various monitoring designs. While the authors of PSPAP v. 2.0 will not be making any decisions based on these weights, this analysis will provide valuable information on stakeholder preferences and will be a useful tool for decision makers. For swing weighting to be used consistently amongst stakeholders, it is important for each stakeholder to have a good understanding of the swing weighting process. We created YouTube videos that describe the swing weighting process and its role in the PSPAP v. 2.0 and explain the meaning and variation in the abundance and trend metrics. We plan to post a downloadable swing weighting form, 
hyperlinks to the YouTube videos described above, and instructions on how to fill in the swing weighting form on the PSPAP v. 2.0 blog (https://mcolvin.github.io/PSPAP-Reboot ). Once finalized, an email will be sent out to PSPAP stakeholders inviting them to visit the blog to fill in and submit a swing weighting form. After swing weighting data have been collected, valuation of monitoring designs will be considered across the range of stakeholder weighting schemes. Additionally, variation in swing weights among stakeholders may provide a useful basis for further discussion.

\section{Preliminary Design Outputs}

The analysis of sampling alternative designs is in progress, and results may change if additional monitoring designs are developed and as weightings are added. Therefore, the following results are preliminary; however, the process used to generate the results will not change.

\section{Fundamental Information Objective 1}

The power to detect age- 0 recruitment given the presence of naturally produced age- 0 pallid sturgeon within the basin varied depending on capture probability (fig. 8). Power was also influenced by where recruits were intercepted, albeit the effect was weak. Scenarios in figure 8 show where recruitment level was low, varying between 5 and 30 recruits, but there still was power to detect a recruit at the basin level given a high enough capture probability and enough otter trawl deployments per sampled bend (for example, fig. 8, panels $C, E, F$ ). However, if capture probability is low, the number of trawls required within a bend to achieve a reasonable level of power may not be achievable given cost constraints (for example, fig. 8, panels $A, B$ ). If sampling is not feasible to address this objective, decisions relating to recruitment will need to rely more heavily on indirect metrics, such as back calculating from the population model.

\section{Fundamental Information Objective 2}

Increasing the number of sturgeon-season sampling occasions within a bend generally improved the outcomes of all performance metrics (fig. 9). For example, in the top left plot of figure 9, notice how the boxplots for the MKA estimator aggregated by the weighted mean (MKA_WM) show the median bias getting closer and closer to zero as the number of occasions changes from one to four. This pattern was similar for gill nets and trammel nets. Patterns remained the same when the precision and bias metrics were scaled using proportional weighting (fig. 10). Also highlighted in figure 10 is the tradeoff of being very precise but biased for the monitoring designs using an MKA estimator. Although ranges were overlapping, once abundance and trend performance metrics were weighted and combined to represent fundamental objective 2, there was a benefit (increased likelihood of a higher utility) of using capturerecapture $\left(\mathrm{M}_{0}, \mathrm{M}_{\mathrm{t}}\right.$, and CRDMS) approaches relative to catch and catch-effort (MKA, CPUE) approaches (fig. 11). 

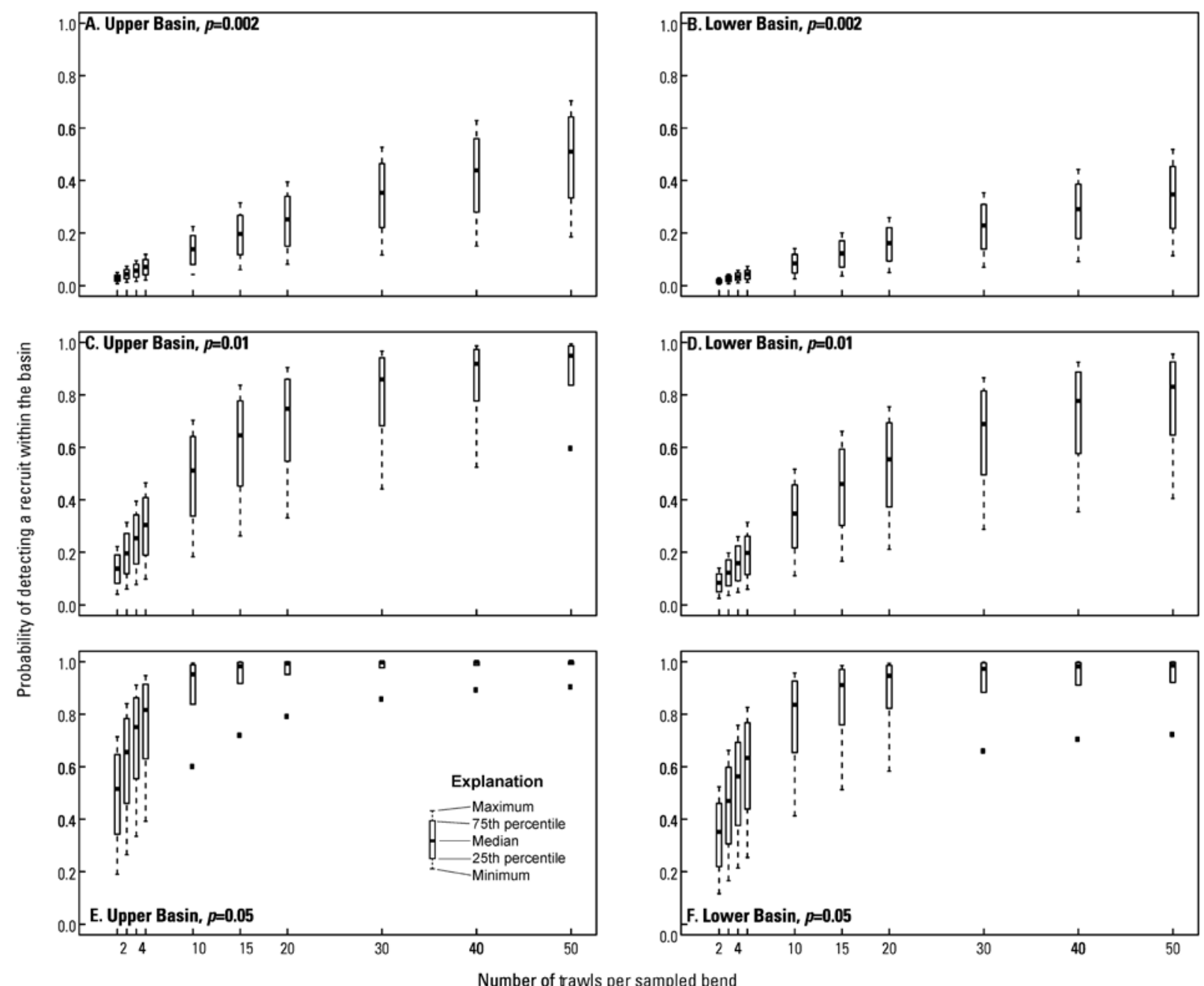

Figure 8. Boxplots of the probability of detecting a recruit at the basin level with increasing number of trawls within a bend. Values simulated are for trawl-level capture probabilities of 0.001 (panels $A$ and $B$ for the upper and lower basin, respectively), 0.005 (panels $C$ and $D$ for the upper and lower basin, respectively), and 0.02 (panels $E$ and $F$ for the upper and lower basin, respectively). In this scenario, recruitment-detection trawls were performed throughout the basin, recruitment level ranged from 5 to 30 age-0 pallid sturgeon (specifically, $5,10,15,20,25$ or 30 ), and all age-0 recruits were intercepted in the lower one-third of the basin. 

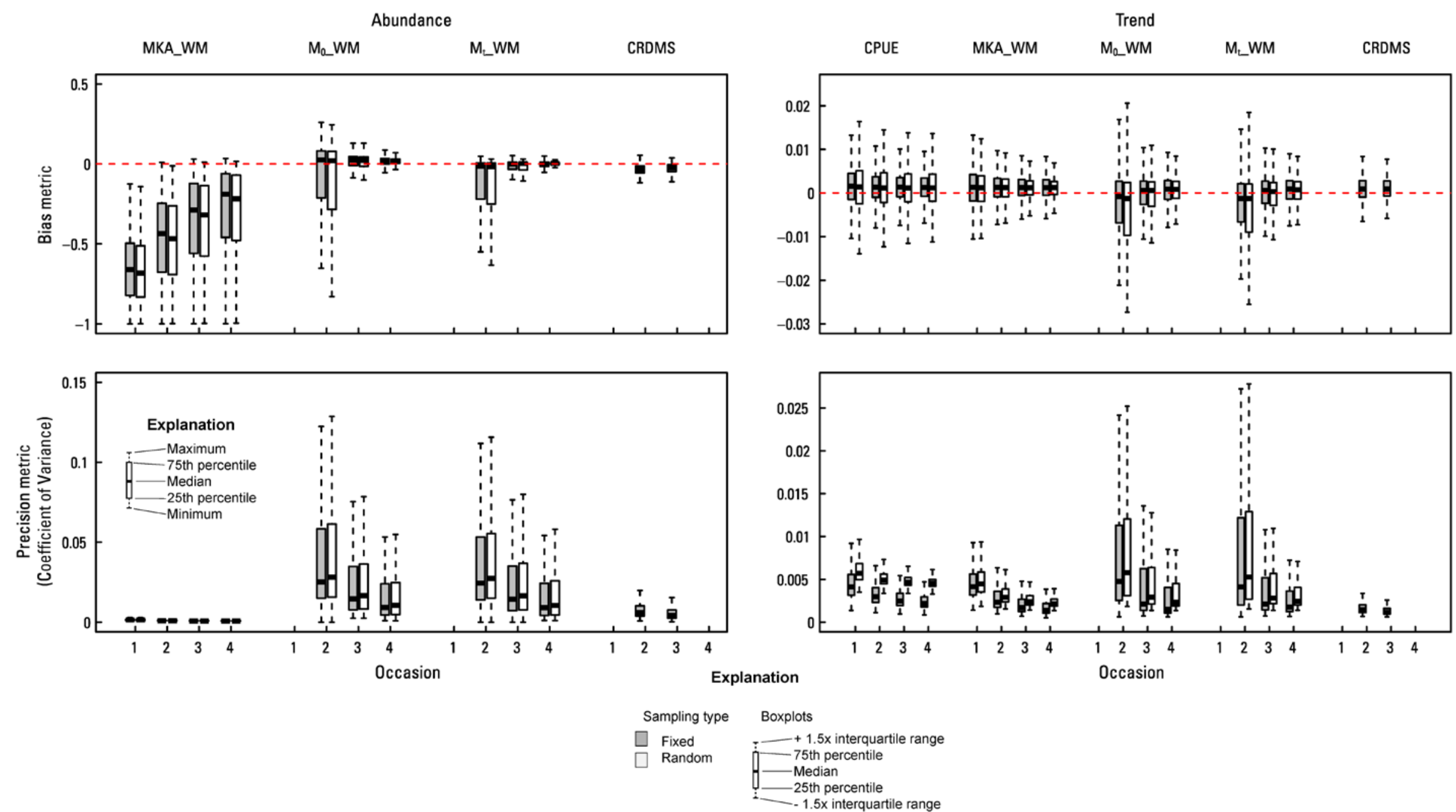

Figure 9. Boxplots of the performance metrics associated with fundamental objective 2 for varying sturgeon-season designs. Estimators include CPUE, catch per unit effort; MKA_WM, minimum know alive bend-level abundance estimator aggregated to the segment and basin levels using the weighted mean approach;

MO_WM, closed population bend-level abundance estimator assuming constant capture probability aggregated to the segment and basin levels using the weighted mean approach; Mt_WM, closed population bend-level abundance estimator assuming heterogeneity in capture probability in time, aggregated to the segment and basin levels using the weighted mean approach; and CRDMS, a multistate robust design segment-level abundance estimator aggregated to the basin level using the weighted mean approach. Each boxplot represents outcomes from the 1,600 catch-data replicates, or 800 catch-data replicates in cases using the CRDMS estimator. Boxplot whiskers extend out 1.5 times the interquartile range. Outliers were not plotted for clarity; however, several outliers were present, especially in the case of the MO_WM and Mt_WM estimators. Results are from simulating trotlines. 

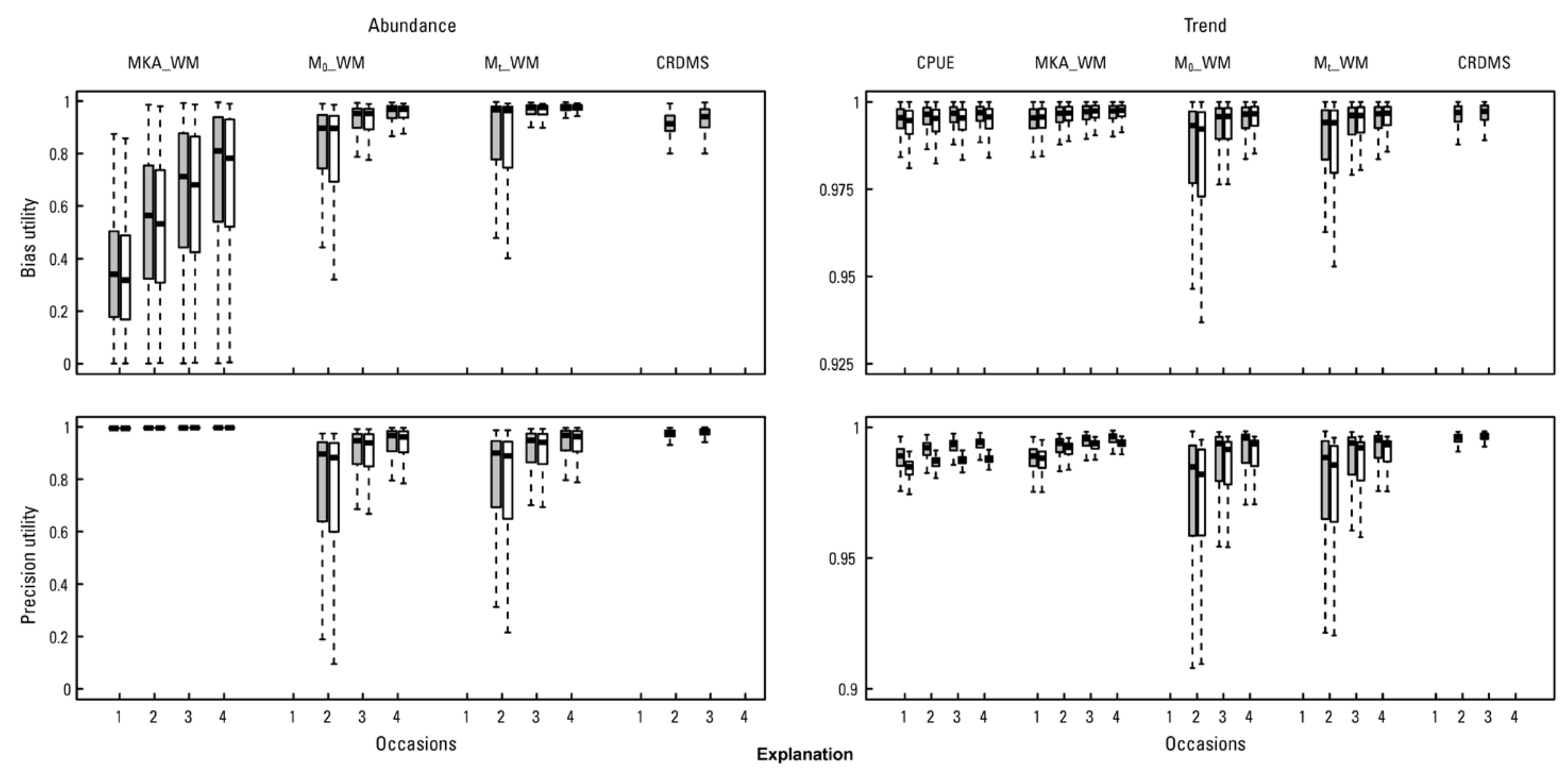

Sampling type Boxplots
$\square$ Fixed
$\square$ Random

Figure 10. Boxplots of scaled utility values for each of the performance metrics in figure 9 relating to fundamental objective 2 . For each sturgeon-season design, results are calculated from the 1,600 catch-data replicates (or 800 catch-data replicates in cases using the CRDMS estimator). Boxplot whiskers extend out 1.5 times the interquartile range. Outliers were not plotted for clarity; however, several outliers were present, especially in the case of the $M_{0} W_{1}$ and $M_{t}$ WM estimators. Results are from simulating trotlines. Estimators include CPUE, catch per unit effort; MKA_WM, minimum know alive bend-level abundance estimator aggregated to the segment and basin levels using the weighted mean approach; $M_{0}$ WM, closed population bend-level abundance estimator assuming constant capture probability aggregated to the segment and basin levels using the weighted mean approach; $M_{\mathrm{t}} \mathrm{WM}$, closed population bend-level abundance estimator assuming heterogeneity in capture probability in time, aggregated to the segment and basin levels using the weighted mean approach; and CRDMS, a multistate robust design segment-level abundance estimator aggregated to the basin level using the weighted mean approach. 


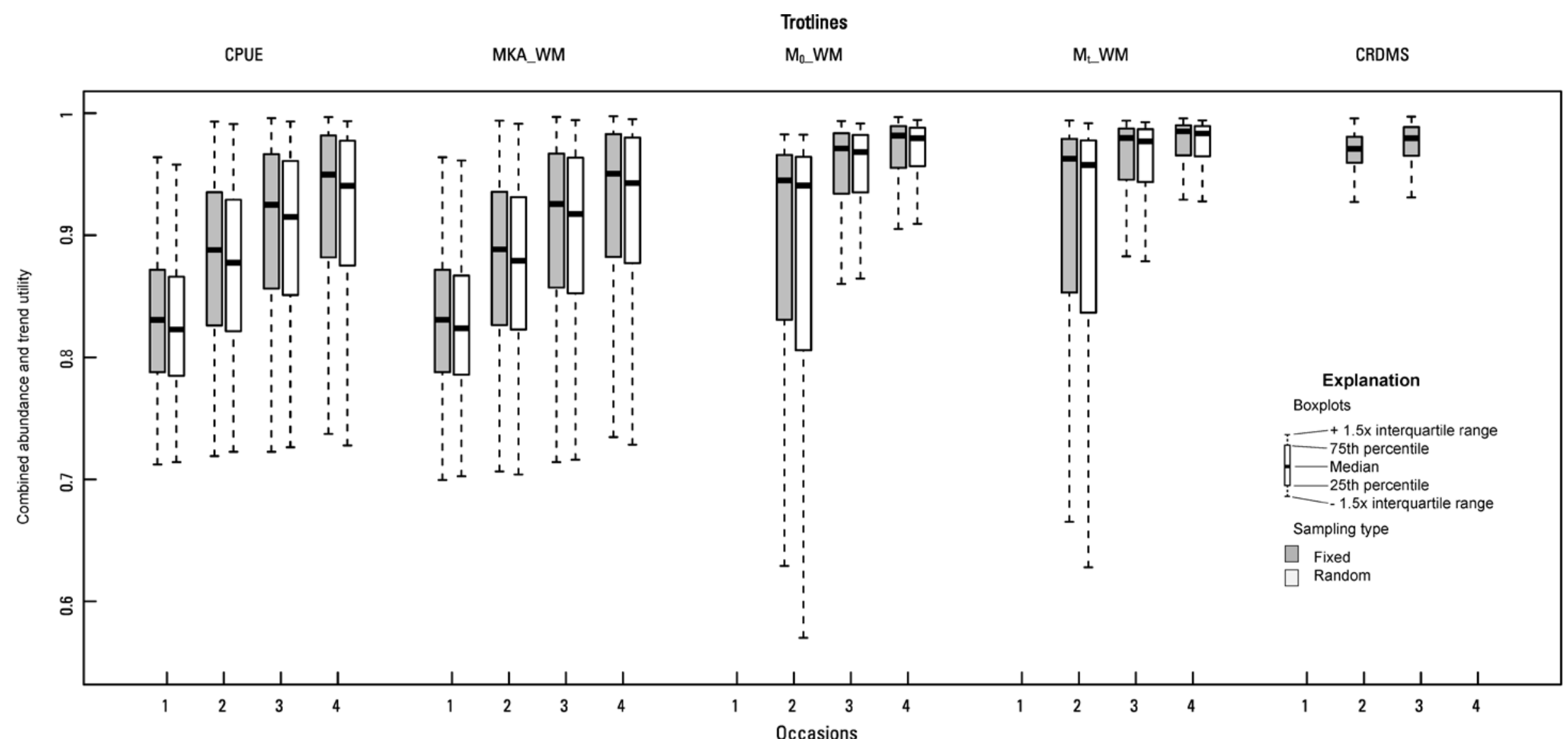

Figure 11. Boxplots of the overall utility value for fundamental objective 2, calculated as the combined utility for trend and abundance estimates assuming equal weighting of subobjectives. For each sturgeon-season design, results are simulated for trotlines and calculated from the 1,600 catch-data replicates (or 800 catchdata replicates in cases using the CRDMS estimator). Boxplot whiskers extend out 1.5 times the interquartile range. Outliers were not plotted for clarity; however, several outliers were present, especially in the case of the $M_{0}$ WM and Mt_WM estimators. Estimators include CPUE, catch per unit effort; MKA_WM, minimum know alive bend-level abundance estimator aggregated to the segment and basin levels using the weighted mean approach; Mo_WM, closed population bend-level abundance estimator assuming constant capture probability aggregated to the segment and basin levels using the weighted mean approach; $\mathrm{M}_{\mathrm{t}}$ WM, closed population bend-level abundance estimator assuming heterogeneity in capture probability in time, aggregated to the segment and basin levels using the weighted mean approach; and CRDMS, a multistate robust design segment-level abundance estimator aggregated to the basin level using the weighted mean approach. 


\section{Overall Monitoring Design Utility}

For each monitoring design replicate, we calculated the weighted utility of fundamental objectives 1-4 using equation 24 . To obtain preliminary results, an equal weighting of each objective was used; that is, $W_{1}=W_{2}=W_{3}=W_{4}=1 / 4$. Plotting the median utility, taken across all analyzed catch data and recruitment-detection replicates for each monitoring design (table 4), against expected cost (fig. 12) indicates that high monitoring design utilities can be obtained under a wide range of cost. Ideally, stakeholders would like a monitoring design with a high utility and a lower cost. For example, the monitoring design using random sampling with two sturgeon-season occasions, the $\mathrm{M}_{\mathrm{t}}$ estimator, and 40-49 recruitment-detection trawls has a high utility but only costs $\$ 0.9$ million (fig. 13 ), which is better, in terms of benefit:cost, than the monitoring designs that achieve similar utilities but cost \$1.2 or \$1.5 million.

These results are only illustrative of the output of the process and the decision-support tool because additional simulation analyses, including those with added variation, are still a work in progress. In figures 9-13, the weightings among utilities were assumed to be equal and do not reflect stakeholder input on weights. Moreover, not all alternative monitoring designs have been analyzed. For example, we have yet to analyze monitoring designs that use the robust design abundance and trend estimator on catch data from sampled bends chosen by the random approach. Since random bend selection has a much higher fundamental information objective 3 utility than fixed bend selection (1 versus 0.1 ) and the robust design estimator has a high fundamental objective 2 utility (fig. 11), monitoring designs that use the robust design on data from random bends may surpass many of the previously analyzed designs in overall utility. Similarly, results from future analyses based on reference populations with added complexity (for example, greater movement) may affect monitoring design outcomes. Additionally, there is uncertainty around capture and detection probability. The results presented represent the expected utility given the uncertainty in capture probability and may change in light of new knowledge concerning such uncertainties. Capture and detection probabilities are critical uncertainties and require further efforts to reduce that uncertainty.

\section{Developing a Decision-Support Tool}

A flexible tool to support PSPAP decision making will be an ongoing need in the context of adaptive management and uncertainty in funding. The fundamental objectives and performance metrics can be developed into a decision model to compare alternative PSPAP monitoring designs accounting for uncertainty (Marcot and others, 2001; Nyberg and others, 2006; Conroy and Peterson, 2013). Specifically, there is potential for monitoring budgets to change over time. Variable budgets would motivate a need to potentially modify the PSPAP on an annual basis and provide the necessary information to generate contracts with field crews to conduct sampling. The decision tool also may be used to design a "must have" sampling regime, a "good to have" sampling regime, and an "if extra money is available" sampling regime. Additionally, as the adaptive management process continues, new information may become available that can increase the efficiency of the PSPAP and reduce uncertainty around estimates of recruitment to age 1, population abundance, and population trend. Therefore, we are developing a decision model to support this initial redesign effort and provide a flexible framework to inform and support future PSPAP decisions. The process to develop the decision model will synthesize the outputs of simulations presented in this report and additional analyses. 


\section{Trotlines}

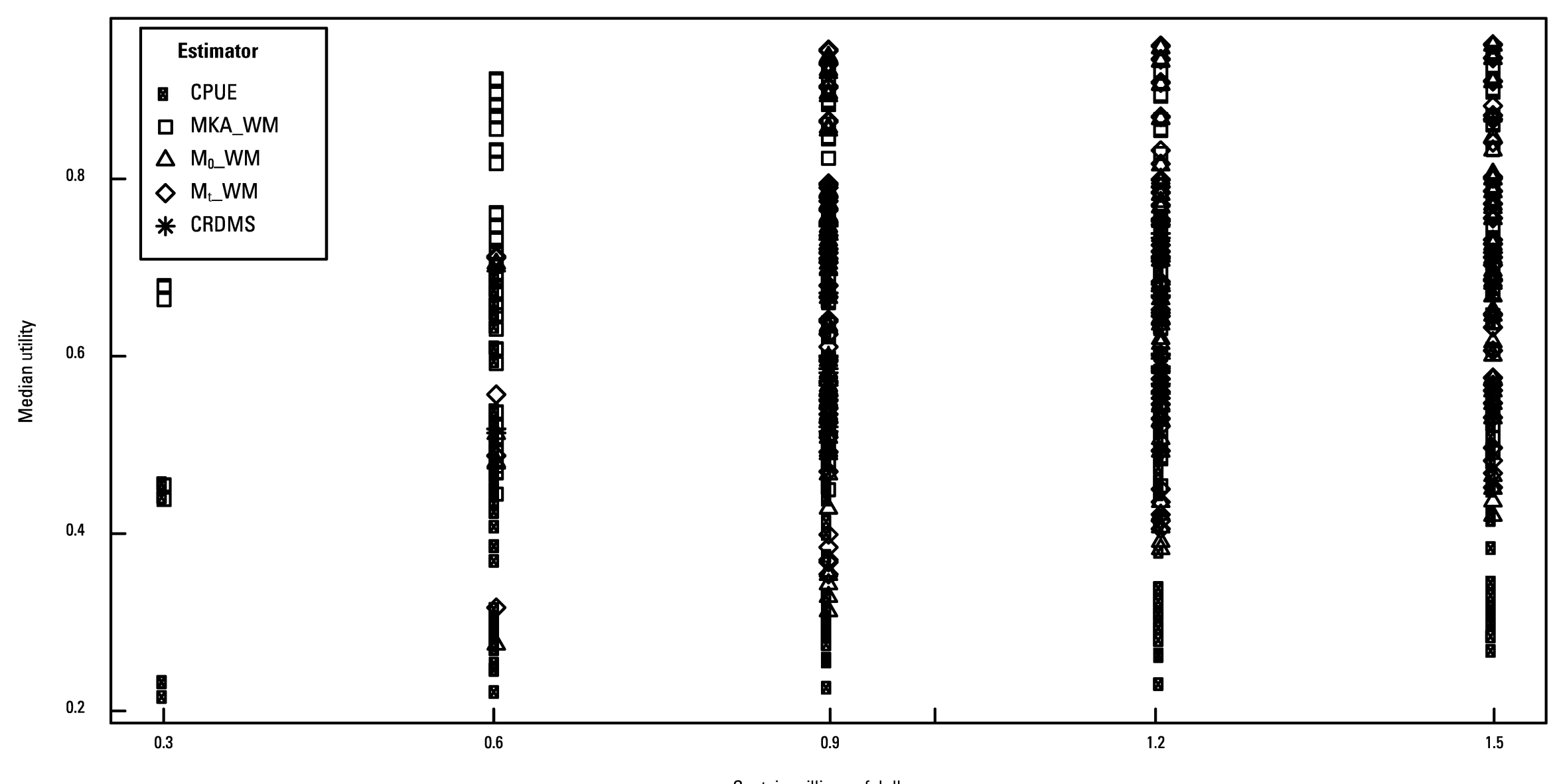

Cost, in millions of dollars

Figure 12. Plots of median monitoring design utility versus cost for each of the 270 analyzed alternative monitoring designs (the sturgeon-season sampling designs illustrated by boxplots in figure 11 plus recruitment-detection sampling design) that were simulated for trotlines and the given estimators. As a preliminary analysis, median utility (taken across all catch-data replicates analyzed for the given monitoring design) quantifies a value for each of the monitoring designs when fundamental objectives 1-4 are weighted equally (and subobjectives within fundamental objective 2 are also weighted equally). Outcomes were simulated using trotline specific catchability and effort values. Of note is that there are alternatives that score highly (that is, close to 1 ) for a range of varying costs. Estimators include CPUE, catch per unit effort; MKA_WM, minimum know alive bend-level abundance estimator aggregated to the segment and basin levels using the weighted mean approach; Mo_WM, closed population bend-level abundance estimator assuming constant capture probability aggregated to the segment and basin levels using the weighted mean approach; $M_{t}$ WM, closed population bend-level abundance estimator assuming heterogeneity in capture probability in time, aggregated to the segment and basin levels using the weighted mean approach; and CRDMS, a multistate robust design segment-level abundance estimator aggregated to the basin level using the weighted mean approach. 


\section{Trotlines}

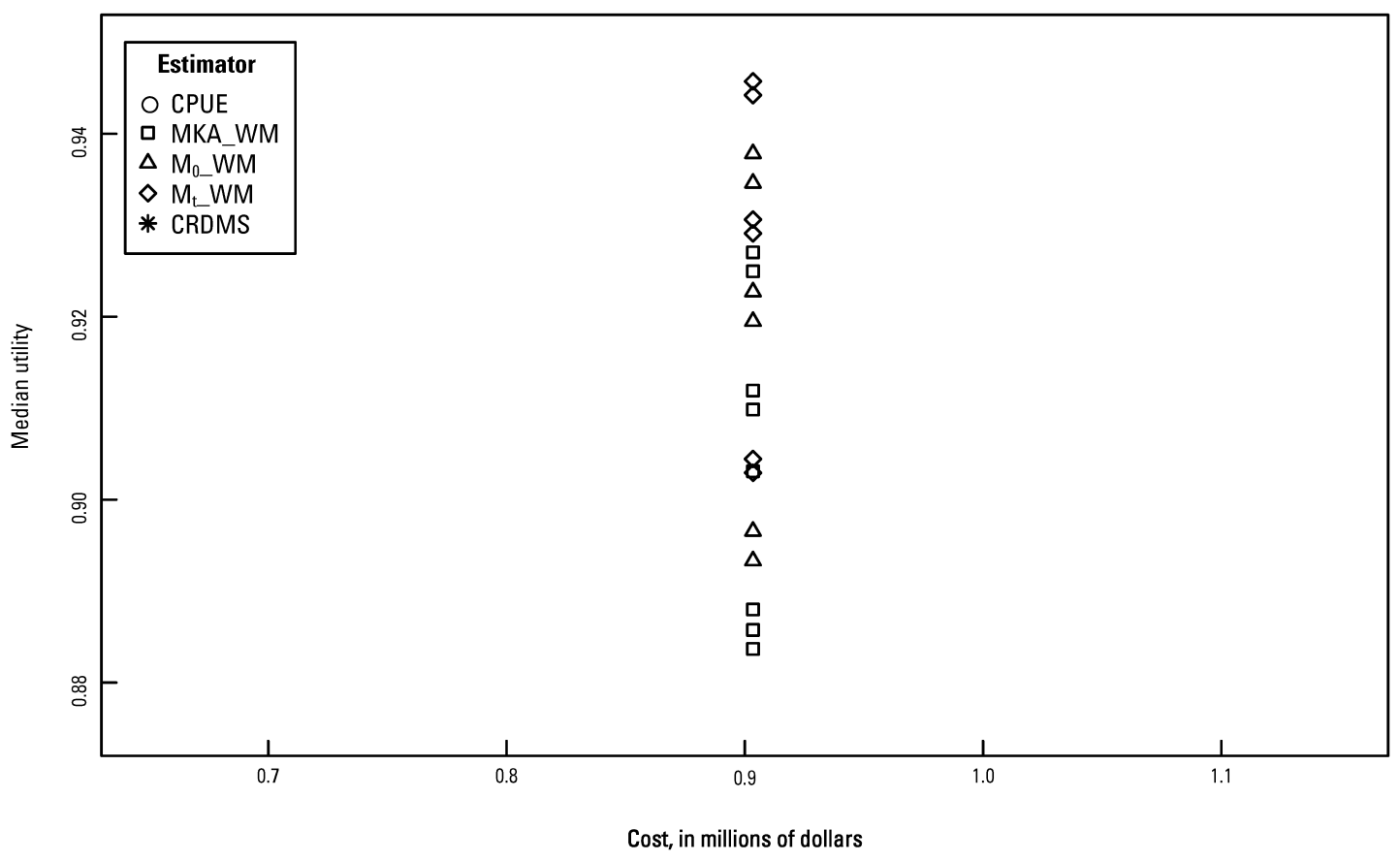

Figure 13. Zoomed in version of figure 12 to show the estimators associated with the highest utilities that cost approximately $\$ 0.9$ million. All points in the plot above represent monitoring designs that use random bend selection, use 2 sturgeon-season sampling occasions, and deploy at least 20 trawls per bend for recruitment-detection sampling. The monitoring design with the highest utility uses the $\mathrm{M}_{\mathrm{t}}$ trend and abundance estimator aggregated by the weighted mean approach and the largest number of trawls (40-49) for recruitment-detection sampling. Estimators include CPUE, catch per unit effort; MKA_WM, minimum know alive bend-level abundance estimator aggregated to the segment and basin levels using the weighted mean approach; Mo_WM, closed population bend-level abundance estimator assuming constant capture probability aggregated to the segment and basin levels using the weighted mean approach; $\mathrm{M}_{\mathrm{t}} \mathrm{WM}$, closed population bend-level abundance estimator assuming heterogeneity in capture probability in time, aggregated to the segment and basin levels using the weighted mean approach; and CRDMS, a multistate robust design segment-level abundance estimator aggregated to the basin level using the weighted mean approach.

The submodel for fundamental objective 1 has been developed into a Bayesian Decision network representing the outcomes of the scenarios examined (fig. 14). The scenarios simulated address biological uncertainties in the systems, such as recruits being exported from the system and, therefore, unavailable to detect in a monitoring program. As science components provide information that reduces these uncertainties (that is, learning if and where pallid sturgeon recruits are intercepted and located), this new information can be incorporated into the decision model and the monitoring program can adapt. For example, the box representing location in figure 13 can be updated if it is learned that all recruits are being exported outside the system and the corresponding power to detect recruitment becomes 0 , which, in turn, will have consequences for allocating monitoring effort to support fundamental objective 1 . Efforts are ongoing to parameterize the Bayesian Decision network for fundamental objective 2 and then couple to the decision model for fundamental objectives. 


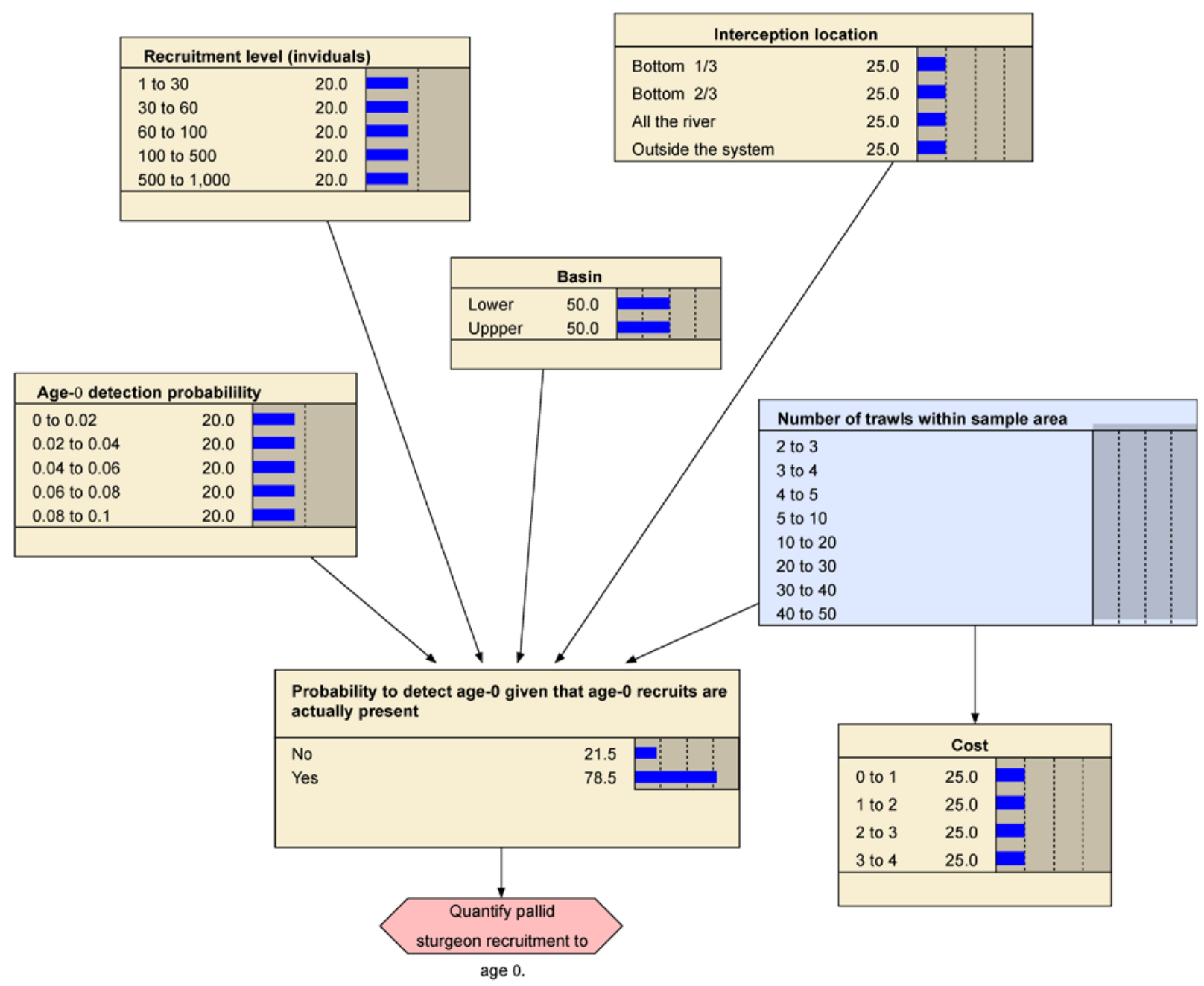

Figure 14. Illustration of a decision-support model developed for fundamental objective 1. The model can be used to rapidly assess the tradeoff of varying levels of sampling on the probability of detecting recruitment, given it occurred, accounting for uncertainty in recruitment levels. Additionally, information from pilot studies estimating detection probability can be used to reduce uncertainty and update potential tradeoffs of cost and probability to detect recruitment.

\section{Refine Preliminary Outputs with Pilot Studies}

\section{Informing Capture and Detection Probabilities}

Two phase 1 pilot efforts are being designed to address the uncertainties in capture and detection probability prior to any basin-scale pilot implementation. First, an experimental release of hatchery-origin age-0 pallid sturgeon into the lower basin will be used as part of a two-part study. In the first part, an increasing number of fish will be stocked into an interdike area over a period of 5 days and sampled continuously using a standard trawl. The increasing number of fish each day will allow estimates of detection and capture probability at varying densities. Once preliminary capture and detection probabilities are estimated, several interdike areas will be stocked with a known density of hatchery-origin age-0 pallid sturgeon and trawled, where trawling effort is informed by the preliminary capture and detection probability estimates. The 
results of this sampling will provide spatial replication and allow quantification of parameter variability. From these estimates, we can evaluate catch scenarios and refine the optimal sampling design as it relates to fundamental objective 1 . This work is scheduled to be conducted in early summer 2018 but is pending the availability of genetic unique age-0 (70-109 mm) pallid sturgeon. This and the following study will inform the expected values for capture and detection probability, but there will be uncertainty in extrapolating results to segment and basin scales. Caution will be warranted in extrapolation and attendant uncertainties will need to be calculated.

Capture probability of age-1+ pallid sturgeon is also uncertain. Therefore, a pilot effort to estimate gear-specific capture probabilities began March 12, 2018, for bends in segment 14. The effort repeatedly samples randomly selected bends in segments 13 and 14 over three occasions (that is, 3 days) using combinations of trotlines and gill nets. All randomly selected bends within segments will be completed before sampling bends in another segment to minimize potential for violating closure assumptions at the bend and segment levels. Four possible gear combinations will be evaluated: gill net only, trotline only, gill nets first two occasions and trotline last, and trotlines first two occasions and gill net last. Gear combinations will be randomly assigned to a bend prior to sampling. Eight gear deployments will be used for each occasion, and gear will be deployed in locations believed to maximize the probability of capturing a pallid sturgeon. To further inform capture probabilities while accounting for an effect of sturgeon species, all shovelnose sturgeon captured will be floy tagged, length measured, and released. Floy tagging is limited to the first two occasions. Floy tagging is not necessary on the last occasion.

From these efforts, bend- and occasion-specific capture probabilities may be estimated contingent on sufficient recaptures. Because pallid sturgeon are rare and there may be a behavioral component to capture probability, additional effort may be needed to improve capture probability estimates. Specifically, there are approaches to allow capture probability to be shared between the two species and, assuming the species respond to capture similarly, to fit a closed population estimator that accounts for a behavioral response (that is, Mb; Otis and others, 1978). This calculation would allow capture probability to vary depending on previous capture such that "trap happy" or "trap shy" behaviors can be accounted. Additionally, these efforts may provide sufficient information to estimate a size-dependent capture probability function. This function, in turn, would potentially allow estimates of varying size- and age-related metrics and inform sizeselective functions.

\section{Additional Design Challenges and Ongoing Refinement}

We anticipate that monitoring design improvements to PSPAP v. 2.0 will be an ongoing process, similar to the history of iterative changes to PSPAP v. 1.0 documented in Welker and others (2016). Changes and modification should be expected as part of any large-scale monitoring program (Reynolds and others, 2016). Additional work will be needed to refine further and optimize the monitoring designs, even as there is a need to deploy PSPAP v. 2.0 in fall 2019. We recognize that stakeholder input is an important aspect of this iterative process, and in particular, field-crew input during the pilot season (beginning fall 2018) is expected to play a significant role in this refinement and optimization process. Additionally, population monitoring ancillary subobjectives (table 3) will require stand-alone optimizations that are dependent on the overall design. Many of the subobjectives have been satisfied under the current PSPAP v. 1.0 design and will continue to be satisfied regardless of the new design (for example, size structure, age structure); however, aspects will benefit from evaluation of metric performance. For example, for a given monitoring design, estimated size structure can be 
compared to true size structure to analyze whether efforts are sufficient to characterize size subobjectives.

The pilot season beginning in fall 2018 will be especially helpful in the refinement and learning process. Work on the exact details of the timing of implementing various monitoring components during the 2018 pilot season is underway. Typical weather conditions, as mined from the PSPAP database, and updated handling protocols will need to be considered in construction of a sampling schedule as these may constrain the number of secondary sampling occasions that are feasible within particular segments. Such constraints will need to be taken into account within the optimization process. Furthermore, the inclusion of monitoring components related to ancillary subobjectives (for example, telemetry, fish community, broodstock) will be dependent on budget negotiations between field crews and the USACE. Resulting budgets may constrain both what ancillary monitoring is feasible as well as the number of feasible secondary sampling occasions during sturgeon season.

Quantifying effects of management actions is also a potential role of a population assessment program. The monitoring designs compared were developed to potentially incorporate this application. Parameters in capture-recapture models can be related to covariates that provide the potential to quantify the population response to management actions (such as channel reconfigurations for IRCs) over long time intervals. Additionally, environmental covariates could quantify short-term responses, however, the effect size would likely need to be large for detection, and all analyses would need to be complementary to effectiveness monitoring. For example, changes in an environmental variable modified by a management action can be related to survival or migration parameters using a logit linear model as $\operatorname{logit}(\theta)=\beta_{0}+\beta_{1} \cdot X+$ ò, where $\theta$ is an estimated parameter (for example, $\phi, \gamma^{\prime}, \gamma^{\prime \prime}$ ), $\beta_{0}$ is the intercept, $\beta_{1}$ is the effect of the covariate $X$, and ò is a residual error. This will require a stand-alone optimization to evaluate whether captures are sufficient to detect an effect. Lastly, with some modification to estimators, auxiliary information can be used to inform parameter estimates. For example, complementary telemetry can be used to determine whether a pallid sturgeon is in the study area or not and thereby inform movement parameter estimates, as well as capture probability and survival for capture-recapture estimators.

The capture-recapture estimators implemented were developed using existing software and $\mathrm{R}$ packages. Therefore, there was constrained flexibility in some simulations; flexibility is a necessity when performing mark-recapture on a linear system. One shortcoming discovered was the limitations of using a multistate capture-recapture model to implement a robust design; specifically, in cases with little to no movement, estimates for a random bend selection design are not as straightforward to interpret and may prove difficult to obtain due to lack of recaptures. In light of this, we have only analyzed monitoring designs that combine the multistate robust design estimator with fixed sampling; however, closer examination of this estimator with random sampling is now underway. Additionally, since the robust design requires multiple years to estimate movement parameters, it not a viable estimator until the second year of data is collected. Bayesian capture-recapture models may provide the additional flexibility needed to implement capture-recapture models through application of auxiliary telemetry data and through borrowing of information from shovelnose sturgeon recapture. Such models are likely to be computationally intensive and require expansion into cloud-based or parallelized computing. We plan to develop these types of estimators when existing software cannot estimate the metrics of interest. 


\section{Summary}

This report documents the framework and process used to compare alternative monitoring designs for Scaphirhynchus albus (pallid sturgeon) populations of the Upper and Lower Missouri River given multiple stakeholders and decision-maker objectives. Decisions among alternative monitoring programs are complex because of the multiple fundamental information objectives associated with the population assessment program, and a simple power analysis will not suffice, especially when multiple ancillary subobjectives are present. The process used to compare alternative monitoring programs will allow decision makers to evaluate the tradeoff of varying monitoring design components with cost and fundamental objectives. Additionally, the process will facilitate the incorporation of new information as it becomes available.

\section{References Cited}

Braaten, P.J., Campana, S.E., Fuller, D.B., Lott, R.D., Bruch, R.M., and Jordan, G.R., 2015, Age estimations of wild pallid sturgeon (Scaphirhynchus albus, Forbes and Richardson 1905) based on pectoral fin spines, otoliths and bomb radiocarbon-Inferences on recruitment in the damfragmented Missouri River: Journal of Applied Ichthyology, v. 31, no. 5, p. 821-829. [Also available at https://doi.org/10.1111/jai.12873.]

Braaten, P.J., Fuller, D.B., Lott, R.D., and Jordan, G.R., 2009, An estimate of the historic population size of adult pallid sturgeon in the upper Missouri River Basin, Montana and North Dakota: Journal of Applied Ichthyology, v. 25, no. S2, p. 2-7. [Also available at https://doi.org/10.1111/j.1439-0426.2009.01195.x.]

Clemen, R.T., Reilly, T., and Clemen, R.T., 2001, Making hard decisions-An introduction to decision analysis (2d ed.): Pacific Grove, Calif. Duxbury/Thomson Learning, 664 p.

Cochran, W.G., 1977, Sampling techniques (3d ed.): New York, John Wiley \& Sons, Ltd., 399 p.

Conroy, M.J., and Peterson, J.T., 2013, Decision making in natural resource management-A structured, adaptive approach: West Sussex, U.K., John Wiley \& Sons, Ltd., 306 p. [Also available at https://doi.org/10.1002/9781118506196.]

DeLonay, A.J., Chojnacki, K.A., Jacobson, R.B., Albers, J.L., Braaten, P.J., Bulliner, E.A., Elliott, C.M., Erwin, S.O., Fuller, D.B., Haas, J.D., Ladd, H.L.A., Mestl, G.E., Papoulias, D.M., and Wildhaber, M.L., 2016a, Ecological requirements for pallid sturgeon reproduction and recruitment in the Missouri River-A synthesis of science, 2005 to 2012: U.S. Geological Survey Scientific Investigations Report 2015-5145, 224 p. [Also available at https://doi.org/10.3133/sir20155145.]

DeLonay, A.J., Chojnacki, K.A., Jacobson, R.B., Braaten, P.J., Buhl, K.J., Elliott, C.M., Erwin, S.O., Faulkner, J.D.A., Candrl, J.S., Fuller, D.B., Backes, K.M., Haddix, T.M., Rugg, M.L., Wesolek, C.J., Eder, B.L., and Mestl, G.E., 2016b, Ecological requirements for pallid sturgeon reproduction and recruitment in the Missouri River-Annual report 2014: U.S. Geological Survey Open-File Report 2016-1013, 131 p. [Also available at https://doi.org/10.3133/ofr20161013.]

Fischenich, J.C., Buenau, K.E., Bonneau, J.L., Fleming, C.A., Marmorek, D.R., Nelitz, M.A., Pickard, D., Ma, B.O., and Gemeinhardt, T.R., 2018, Science and Adaptive Management Plan Appendices and Attachments: Missouri River Recovery Program, U.S. Army Corps of Engineers ERDC/EL TR-18-XX, 792 p. [Also available at http://www.nwo.usace.army.mil/mrrp/mgmt-plan/.] 
Fischenich, J.C., Marmorek, D.R., Nelitz, M.A., Murray, C.L., Ma, B.O., Buenau, K.E., Long, G., Bonneau, J.L., Fleming, C.A., and Schwarz, C.J., 2018, Science and Adaptive Management Plan: Missouri River Recovery Program, U.S. Army Corps of Engineers ERDC/EL TR-18XX, 502 p. . [Also available at http://www.nwo.usace.army.mil/mrrp/mgmt-plan/.]

Frissell, C.A., Liss, W.J., Warren, C.E., and Hurley, M.D., 1986, A hierarchical framework for stream habitat classification-Viewing streams in a watershed context: Environmental Management, v. 10, no. 2, p. 199-214. [Also available at https://doi.org/10.1007/BF01867358.]

Gutreuter, S., Burkhardt, R., and Lubinski, K., 1995, Long Term Monitoring Program procedures-Fish monitoring: Onalaska, Wis., National Biological Service, Environmental Management Technical Center Program Report 95-P002-1, 39 p.

Hadley, G.L., and Rotella, J.J., 2009, Upper basin pallid sturgeon survival estimation project final report: U.S. Fish and Wildlife Service, 35 p.

Hamel, M.J., Koch, J.D., Steffensen, K.D., Pegg, M.A., Hammen, J.J., and Rugg, M.L., 2014, Using mark-recapture information to validate and assess age and growth of long-lived fish species: Canadian Journal of Fisheries and Aquatic Sciences, v. 71, no. 4, p. 559-566. [Also available at https://doi.org/10.1139/cjfas-2013-0393.]

Hammond, J.S., Keeney, R.L., and Raiffa, H., 1999, Smart choices-A practical guide to making better decisions: Boston, Mass., Harvard Business Review Press, 242 p.

Hubert, W.A., and Fabrizio, M.C., 2007, Relative abundance and catch per unit effort, chap. 7 of Guy, C.S., and Brown, M.L., eds., Analysis and interpretation of freshwater fisheries data: Bethesda, Md., American Fisheries Society, p. 279-326.

Jacobson, R.B., Annis, M.L., Colvin, M.E., James, D., Welker, T.L., and Parsley, M.J., 2016, Missouri River Scaphirhynchus albus (pallid sturgeon) effects analysis-Integrative report 2016: U.S. Geological Survey Scientific Investigations Report 2016-5064, 154 p., accessed June 2018 at https://doi.org/10.3133/sir20165064.

Jacobson, R.B., Parsley, M.J., Annis, M.L., Colvin, M.E., Welker, T.L., and James, D.A., 2015, Science information to support Missouri River Scaphirhynchus albus (pallid sturgeon) effects analysis: U.S. Geological Survey Open-File Report 2015-1226, 78 p., accessed June 2018 at https://doi.org/10.3133/ofr20151226.

Jaeger, M., Ankrum, A., Watson, T.M., Hadley, G.L., Rotella, J., Jordan, G., Wilson, R., Camp, S.L., Thatcher, T., and Boyd, K., 2009, Pallid sturgeon management and recovery in the Yellowstone River, in Upper Basin pallid sturgeon recovery workgroup, 2008 annual report: Glendive, Mont., Montana Fish, Wildlife, and Parks, 311 p.

Jordan, G.R., Heist, E.J., Braaten, P.J., DeLonay, A.J., Hartfield, P., Herzog, D.P., Kappenman, K.M., and Webb, M.A.H., 2016, Status of knowledge of the pallid sturgeon (Scaphirhynchus albus Forbes and Richardson, 1905): Journal of Applied Ichthyology, v. 32, no. S1, p. 191207. [Also available at https://doi.org/10.1111/jai.13239.]

Killgore, K.J., Hoover, J.J., Kirk, J.P., George, S.G., Lewis, B.R., and Murphy, C.E., 2007, Age and growth of pallid sturgeon in the free-flowing Mississippi River: Journal of Applied Ichthyology, v. 23, no. 4, p. 452-456. [Also available at https://doi.org/10.1111/j.14390426.2007.00892.x.]

Koch, J.D., Steffensen, K.D., and Pegg, M.A., 2011, Validation of age estimates obtained from juvenile pallid sturgeon Scaphirhynchus albus pectoral fin spines: Journal of Applied Ichthyology, v. 27, no. 2, p. 209-212. [Also available at https://doi.org/10.1111/j.14390426.2010.01656.x.] 
MacKenzie, D.I., Nichols, J.D., Lachman, G.B., Droege, S., Royle, J.A., and Langtimm, C.A., 2002, Estimating site occupancy rates when detection probabilities are less than one: Ecology, v. 83, no. 8, p. 2248-2255. [Also available at https://doi.org/10.1890/00129658(2002)083[2248:ESORWD]2.0.CO;2.]

Marcot, B.G., Holthausen, R.S., Raphael, M.G., Rowland, M.M., and Wisdom, M.J., 2001, Using Bayesian belief networks to evaluate fish and wildlife population viability under land management alternatives from an environmental impact statement: Forest Ecology and Management, v. 153, no. 1-3, p. 29-42. [Also available at https://doi.org/10.1016/S03781127(01)00452-2.]

Nyberg, J.B., Marcot, B.G., and Sulyma, R., 2006, Using Bayesian belief networks in adaptive management: Canadian Journal of Forest Research, v. 36, no. 12, p. 3104-3116. [Also available at https://doi.org/10.1139/x06-108.]

Otis, D.L., Burnham, K.P., White, G.C., and Anderson, D.R., 1978, Statistical inference from capture data on closed animal populations: Wildlife Monographs, no. 62, p. 3-135. [Also available at https://www.jstor.org/stable/3830650.]

Pollock, K.H., 1982, A capture-recapture design robust to unequal probability of capture: The Wildlife Society, v. 46, no. 3, p. 752-757. [Also available at https://www.jstor.org/stable/3808568.]

Powell, L.A., 2007, Approximating variance of demographic parameters using the delta method-A reference for avian biologists: The Condor, v. 109, no. 4, p. 949-954. [Also available at https://doi.org/10.1650/0010-5422(2007)109[949:AVODPU]2.0.CO;2.]

Powell, L.A., and Gale, G.A., 2015, Variance and the delta method, chap. 5 of Estimation of Parameters for Animal Populations, A primer for the rest of us: Lincoln, Nebr., Caught Napping Publications, p. 61-70.

R Development Core Team, 2010, R-A language and environment for statistical computing: Vienne, Austria, R Foundation for Statistical Computing, 3424 p. [Also available at https://cran.r-project.org/doc/manuals/fullrefman.pdf.]

Reynolds, J.H., Knutson, M.G., Newman, K.B., Silverman, E.D., and Thompson, W.L., 2016, A road map for designing and implementing a biological monitoring program: Environmental Monitoring and Assessment, v. 188, no. 7, p. 399. [Also available at https://doi.org/10.1007/s10661-016-5397-x.]

Rotella, J., 2015, Upper basin pallid sturgeon survival estimation project-2015 update: U.S. Fish and Wildlife Service, 105 p.

Rotella, J., 2017, Upper basin pallid sturgeon survival estimation project-2017 update: U.S. Fish and Wildlife Service, $121 \mathrm{p}$.

Schapaugh, A.W., and Tyre, A.J., 2011, Power analysis for the Pallid Sturgeon Population Assessment Program: Lincoln, Nebr., University of Nebraska-Lincoln, 42 p.

Schloesser, J.T., Paukert, C.P., Doyle, W.J., Hill, T.D., Steffensen, K.D., and Travnichek, V.H., 2012, Heterogeneous detection probabilities for imperiled Missouri River fishes-Implications for large-river monitoring programs: Endangered Species Research, v. 16, no. 3, p. 211-224. [Also available at https://doi.org/10.3354/esr00399.]

Schwarz, C.J., and Seber, G.A.F., 1999, Estimating animal abundance-Review III: Statistical Science, v. 14, no. 4, p. 427-456. [Also available at https://doi.org/10.1214/ss/1009212521.] Shuman, D.A., Klumb, R.A., Wilson, R.H., Jaeger, M.E., Haddix, T., Gardner, W.M., Doyle, W.J., Horner, P.T., Ruggles, M., Steffensen, K.D., Stukel, S., and Wanner, G.A., 2011, Pallid sturgeon size structure, condition, and growth in the Missouri River Basin: Journal of Applied 
Ichthyology, v. 27, no. 2, p. 269-281. [Also available at https://doi.org/10.1111/j.14390426.2010.01645.x.]

Steffensen, K.D., Pegg, M.A., and Mestl, G., 2013a, Population prediction and viability model for pallid sturgeon (Scaphirhynchus albus, Forbes and Richardson) in the lower Missouri River: Journal of Applied Ichthyology, v. 29, no. 5, p. 984-989. [Also available at https://doi.org/10.1111/jai.12277.]

Steffensen, K.D., Pegg, M.A., and Mestl, G.E., 2013b, Population characteristics of pallid sturgeon (Scaphirhynchus albus, Forbes and Richardson) in thelower Missouri River: Journal of Applied Ichthyology, v. 29, no. 4, p. 687-695. [Also available at https://doi.org/10.1111/jai.12196.]

Steffensen, K.D., Powell, L.A., and Koch, J.D., 2010, Assessment of hatchery-reared pallid sturgeon survival in the lower Missouri River: North American Journal of Fisheries Management, v. 30, no. 3, p. 671-678. [Also available at https://doi.org/10.1577/M09-151.1.]

Steffensen, K.D., Powell, L., and Pegg, M.A., 2012, Population Size of Hatchery-Reared and Wild Pallid Sturgeon in the Lower Missouri River: North American Journal of Fisheries Management, v. 32, no. 1, p. 159-166. https://doi.org/10.1080/02755947.2012.661388.]

Steffensen, K.D., Powell, L.A., and Pegg, M.A., 2017, Using the robust design framework and relative abundance to predict the population size of pallid sturgeon Scaphirhynchus albus in the lower Missouri River: Journal of Fish Biology, v. 91, no. 5, p. 1378-1391. [Also available at https://doi.org/10.1111/jfb.13457.]

Steffensen, K.D., Powell, L.A., Stukel, S.M., Winders, K.R., and Doyle, W.J., 2015, Updated assessment of hatchery-reared pallid sturgeon (Forbes and Richardson, 1905) survival in the lower Missouri River: Journal of Applied Ichthyology, v. 32, no. 1, p. 1-8. [Also available at https://doi.org/10.1111/jai.12929.]

Tyre, A.J., Tenhumberg, B., Field, S.A., Niejalke, D., Parris, K., and Possingham, H.P., 2003, Improving precision and reducing bias in biological surveys-Estimating false-negative error rates: Ecological Applications, v. 13, no. 6, p. 1790-1801. [Also available at https://doi.org/10.1890/02-5078.]

Welker, T.L., and Drobish, M.R., 2017, Missouri River standard operating procedures for fish sampling and data collection, v. 1.8: Yankton, S.D., U.S. Army Corps of Engineers, 195 p.

Welker, T.L., Drobish, M.R., and Williams, G.A., 2017, Pallid Sturgeon Population Assessment Project, guiding document, v. 1.8: Yankton, S.D., U.S. Army Corps of Engineers, 67 p.

Wildhaber, M.L., Albers, J.L., Green, N.S., and Moran, E.H., 2017, A fully-stochasticized, agestructured population model for population viability analysis of fish-Lower Missouri River endangered pallid sturgeon example: Ecological Modelling, v. 359, p. 434-448. [Also available at https://doi.org/10.1016/j.ecolmodel.2015.07.019.]

Wildhaber, M.L., Gladish, D.W., and Arab, A., 2012, Distribution and habitat use of the Missouri River and Lower Yellowstone River benthic fishes from 1996 to 1998-A baseline for fish community recovery: River Research and Applications, v. 28, no. 10, p. 1780-1803. [Also available at https://doi.org/10.1002/rra.1559.]

Wildhaber, M.L., Holan, S.H., Bryan, J.L., Gladish, D.W., and Ellersieck, M., 2011, Assessing power of large river fish monitoring programs to detect population changes-The Missouri River sturgeon example: Journal of Applied Ichthyology, v. 27, no. 2, p. 282-290. [Also available at https://doi.org/10.1111/j.1439-0426.2010.01635.x.]

Wildhaber, M.L., Yang, W.H., and Arab, A., 2016, Population trends, bend use relative to available habitat and within-river-bend habitat use of eight indicator species of Missouri and 
lower Kansas River benthic fishes_-15 years after baseline assessment: River Research and Applications, v. 32, no. 1, p. 36-65. [Also available at https://doi.org/10.1002/rra.2846.] Williams, B.K., Szzaro, R.C., and Shapiro, C.D., 2009, Adaptive Management-The U.S. Department of the Interior technical guide: Adaptive Management Working Group: Washington, D.C., U.S. Department of the Interior, 72 p.

Winders, K.R., and Steffensen, K.D., 2014, Population size of pallid sturgeon, Scaphirhynchus albus (Forbes and Richardson, 1905), in the lower Missouri River near Kansas City, Missouri, USA: Journal of Applied Ichthyology, v. 30, no. 6, p. 1356-1361. [Also available at https://doi.org/10.1111/jai.12558.]

Wu, G., and Holan, S.H., 2017, Bayesian hierarchical multi-population multistate Jolly-Seber models with covariates-Application to the Pallid Sturgeon Population Assessment Program: Journal of the American Statistical Association, v. 112, no. 518, p. 471-483.

https://doi.org/10.1080/01621459.2016.1211531.] 


\section{Appendix 1. Recruitment-Detection Simulation Parameters}

The recruitment-detection simulations described in the "Fundamental Information Objective 1" section, under the "Calculate Performance Metrics Given Alternative Monitoring Designs” section, utilized the parameter values listed in table 1.1.

Table 1.1. Recruitment-detection simulations: currently simulated parameter values and the full distributions under analysis (proposed future work).

\begin{tabular}{|c|c|c|c|c|}
\hline Parameter & Description & Values currently simulated & $\begin{array}{c}\text { Future } \\
\text { distribution }\end{array}$ & Explanation \\
\hline Recruits $_{\text {basin }}$ & $\begin{array}{l}\text { Total number of } \\
\text { naturally produced } \\
\text { age-0 fish in the } \\
\text { basin }\end{array}$ & $\begin{array}{c}5 ; 10 ; 15 ; 20 ; 25 ; 30 ; 40 ; 50 ; 60 ; 100 ; 500 ; \\
\text { or } 1,000\end{array}$ & $\begin{array}{l}\text { Discrete- } \\
\text { Uniform(1; } \\
\text { 1,000) }\end{array}$ & $\begin{array}{l}\text { Level of age- } 0 \text { pallid sturgeon } \\
\text { recruited to each basin is } \\
\text { unknown. }\end{array}$ \\
\hline$\pi_{\text {basin }}$ & $\begin{array}{l}\text { Probability vector } \\
\text { of bend-specific } \\
\text { interception } \\
\text { probabilities (sums } \\
\text { to 1) }\end{array}$ & $\begin{array}{l}\text { Varied among three scenarios: }(1) \\
\text { Anywhere (probabilities were given by } \\
\text { bend length divided by basin length). ( } 2) \\
\text { Lower two-thirds (probabilities for all } \\
\text { bends in upper one-third of the basin's } \\
\text { length were } 0 \text { and probabilities for all other } \\
\text { bends were bend length divided by the } \\
\text { interception region length). (3) Lower one- } \\
\text { third (probabilities were calculated } \\
\text { similarly to the previous scenario). }\end{array}$ & $\begin{array}{l}\text { Uniform } \\
\text { among the } 3 \\
\text { scenarios } \\
\text { currently } \\
\text { simulated }\end{array}$ & $\begin{array}{l}\text { Interception probabilities are } \\
\text { unknown and will likely } \\
\text { change with IRC modifications } \\
\text { to the river. }\end{array}$ \\
\hline $\mathrm{P}_{\text {basin }}$ & $\begin{array}{c}\text { Basin-specific } \\
\text { median age-0 } \\
\text { capture probability } \\
\text { of an otter trawl } \\
\text { (OT04) }\end{array}$ & $\begin{array}{c}0.00001,0.001,0.002,0.005,0.01,0.02 \\
0.05 \text {, or } 0.1\end{array}$ & $\begin{array}{l}\text { Uniform }(0, \\
\text { 0.1) }\end{array}$ & $\begin{array}{l}\text { Otter trawl (OT04) age-0 } \\
\text { capture probabilities are } \\
\text { unknown; otter trawl (OT16) } \\
\text { detection probabilities were } \\
\text { less than 0.1 for juvenile } \\
\text { sturgeon (Schloesser and } \\
\text { others, 2012). }\end{array}$ \\
\hline K & $\begin{array}{l}\text { Number of trawls } \\
\text { per sampled bend }\end{array}$ & $2,3,4,5,10,15,20,30,40$, or 50 & $\begin{array}{l}\text { Discrete- } \\
\text { Uniform }(1, \\
50)\end{array}$ & $\begin{array}{l}\text { Proposed recruitment-detection } \\
\text { effort. }\end{array}$ \\
\hline
\end{tabular}




\section{Appendix 2. Arithmetic Mean Compared to Weighted Mean Aggregation Approaches}

For aggregating bend-level estimates to the segment level using the arithmetic mean approach, we calculate the estimated densities of each sampled bend and then take the typical average (add up the densities and divide by the total number of bends sampled). This averaged density is used as an estimate of the segment density. The segment abundance is then calculated from the segment density estimate and segment length. Mathematically, the arithmetic mean segment abundance estimate was calculated as

$$
\hat{N}_{s}=\frac{\sum_{j \mathrm{~d} J}\left(\frac{\hat{N}_{s, j}}{L_{s, j}}\right)}{\text { bends }_{s}} \cdot L_{s},
$$

where

$\begin{aligned} \hat{N}_{s} & \text { is the estimated segment abundance of segment } s, \\ L_{s} & \text { is the total length (in river kilometers) of segment } S, \\ \hat{N}_{s, j} & \text { is the estimated abundance of sampled bend } j \text { in segment } S, \\ L_{s, j} & \text { is the length (in river kilometers) of bend } j \text { in segment } S, \\ \text { bends } s_{s} & \text { is the number of sampled bends in segment } S, \\ J & \text { is the set of indices for all sampled bends in segment } S, \\ j & \text { indexes sampled bends within a segment, and } \\ S & \text { indexes segment. }\end{aligned}$

Although standard error may be estimated using the variance estimates for the ratio estimator (see the "Estimating Minimum Known Alive, $\mathrm{M}_{0}$, and $\mathrm{M}_{\mathrm{t}}$ Segment-Level Abundance" section), currently, the standard error of the estimate was calculated as the square root of the variance, which was calculated as

$$
\operatorname{Var}\left(N_{s}\right)=L_{s}^{2} \cdot \operatorname{Var}\left(d_{s}\right)=\frac{L_{s}^{2}}{\text { bends }_{s}} \cdot \sum_{j \grave{\jmath} J}\left(\hat{d}_{s, j}-\hat{d}_{s}\right)^{2},
$$

where

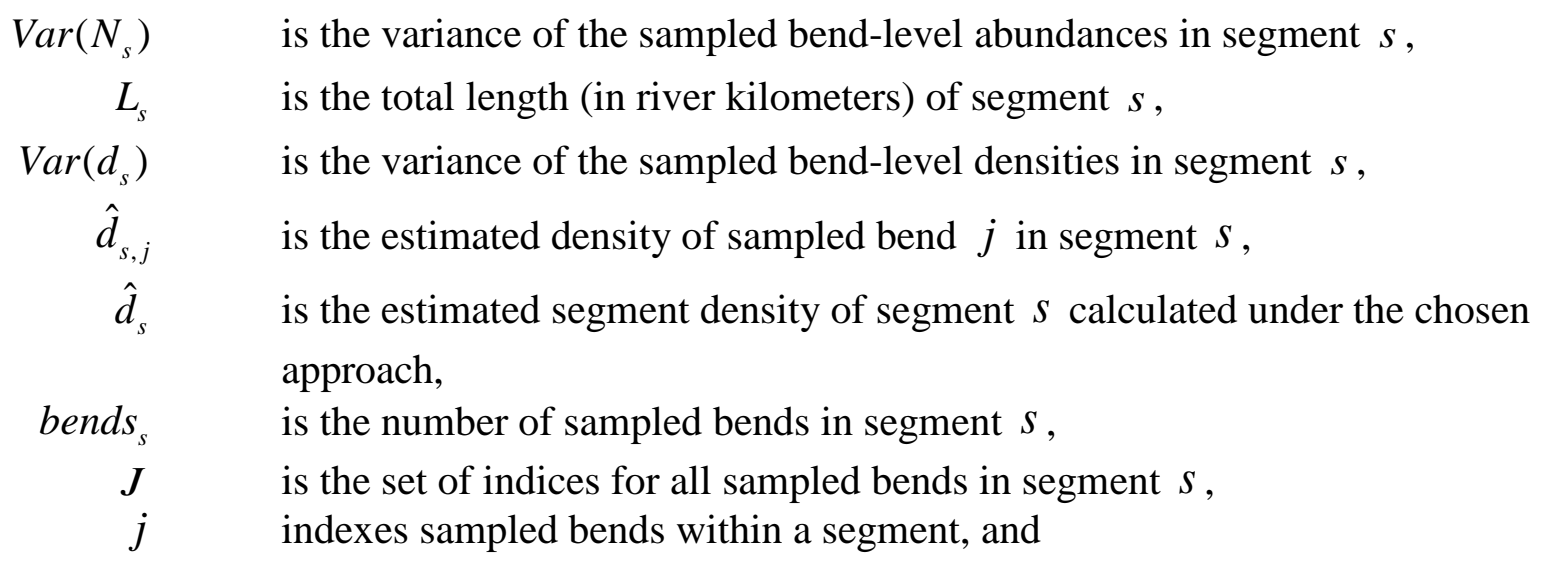




\section{$S \quad$ indexes segment.}

A potential issue with aggregating bend-level density to segment-level density using the arithmetic mean approach is that it treats each bend as equivalent to any other bend, despite the fact that bends are of different sizes (see also chapter 6 of Cochran [1977]). To get a good understanding of how this can affect an estimate, let us look at a simplified example with known abundances (that is, perfect estimates). Assume that a certain segment consists of four bends with the abundances and lengths of each bend given in table 2.1. To find the average segment density, add all bend abundances together to get a segment abundance of 125 and divide by the total of the bend lengths, or 27 river kilometers (rkm), giving a segment density of approximately 4.63 fish per river kilometer.

\begin{tabular}{lcc}
$\begin{array}{l}\text { Table 2.1. Known bend abundance, length, and density for } \\
\text { each of the four bends within the segment of interest. } \\
\text { [rkm, river kilometer] }\end{array}$ \\
$\begin{array}{ccc}\text { Bend } \\
\text { abundance }\end{array}$ & $\begin{array}{c}\text { Bend length } \\
\text { (rkm) }\end{array}$ & Bend density (fish/rkm) \\
\hline 30 & 3 & 10 \\
45 & 5 & 9 \\
14 & 7 & 2 \\
36 & 12 & 3 \\
\hline
\end{tabular}

This process is different from calculating the density of each bend and taking the mean of these bend densities to obtain an estimated segment density of 6 fish per river kilometer, as the arithmetic mean approach would do. Moreover, (by multiplying the estimated segment density by the segment length), the arithmetic mean aggregation approach estimates that there are 162 fish in the segment even though there are 125. While a difference of 37 fish may not seem large, keep in mind the example presented uses small bend abundances and a relatively small length of river (27 rkm). Larger bend abundances, like those simulated in the reference populations, and larger segment stretches can easily lead to larger differences in this calculation.

Even with perfect bend abundance knowledge, the arithmetic mean approach fails to calculate the segment abundance perfectly, because the bends are of different lengths but treated the same (had they all been the same length, say $5 \mathrm{rkm}$, this approach would have worked). A density of 3 fish per river kilometer means a lot more in terms of abundance when the bend length is $12 \mathrm{rkm}$ (36 fish) versus $2 \mathrm{rkm}$ (6 fish).

The weighted mean aggregation estimator attempts to remedy this issue by weighting each bend density by the ratio of the bend's length to the total of the sampled bend lengths. For the example of the segment described in table 2.1, the weighted mean density is calculated as the sum of each bend density multiplied by its weight:

Notice that this simplifies to

$$
\hat{d_{s}}=10 \frac{3}{27}+9 \frac{5}{27}+2 \frac{7}{27}+3 \frac{12}{27}
$$

$$
\hat{d}_{s}=\frac{30}{27}+\frac{45}{27}+\frac{14}{27}+\frac{36}{27}=\frac{30+45+14+36}{27},
$$


which is the sum of the bend abundances divided by the sum of the bend lengths (that is, the segment abundance divided by the segment length), which calculates the exact segment density of approximately 4.63 fish per river kilometer. Since the segment density is correct, the segment abundance estimated from it will be correct as well, $\hat{d}_{s} \cdot L_{s} \approx(4.63)(27) \approx 125$ fish. Since, unlike the arithmetic mean approach, the weighted mean produces a correct abundance estimate given perfect knowledge, it is highly likely to produce a better abundance estimate than those derived by the arithmetic mean approach when given imperfect knowledge.

For comparative purposes, the four fundamental information objective 2 performance metrics (abundance estimate bias, abundance estimate precision, trend estimate bias, and trend estimate precision) were calculated for both the arithmetic mean and weighted mean aggregation methods. A noticeable difference occurs in the trend bias metric for each estimator type (minimum known alive [MKA], $\mathrm{M}_{0}$, and $\mathrm{M}_{\mathrm{t}}$ ), with the weighted mean approach typically having bias values much closer to zero than the arithmetic mean approach (fig. 2.1). The remaining three metrics did not show clear differences for the simulation conditions currently analyzed; however, it is possible differences would arise with the inclusion of simulation variations not analyzed here (for example, varying pallid sturgeon spatial distributions). Because the weighted mean aggregation approach provides exact estimates, given perfect knowledge, and performs better in the current calculations of trend estimate bias, we will continue to focus on this aggregation approach in future report updates. 

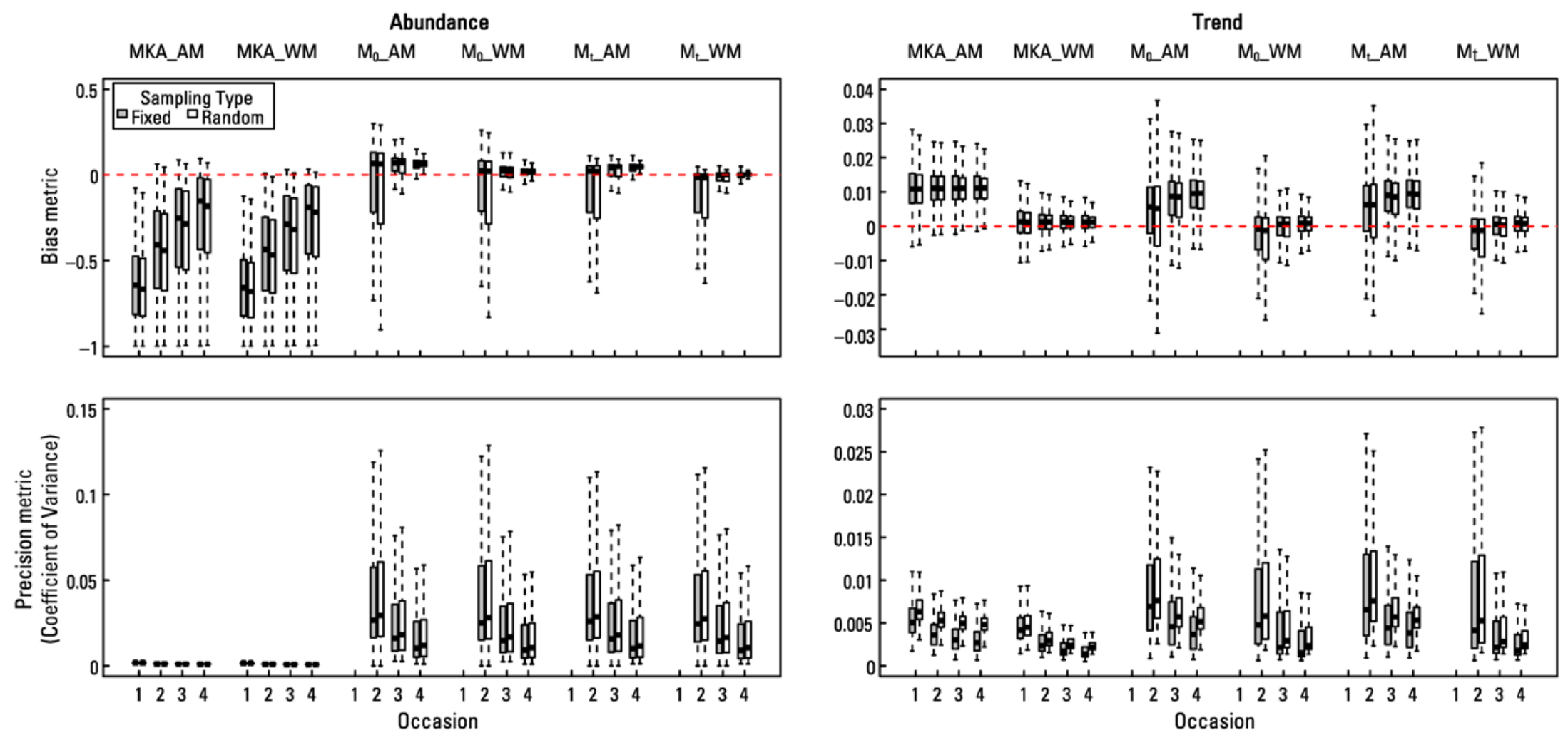

Explanation

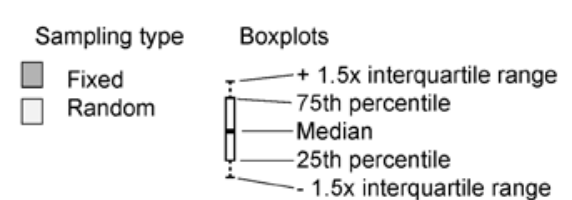

Figure 2.1. Plots comparing the outcomes of the performance metrics associated with fundamental objective 2 (as calculated for the 1,600 catch-data replicates) of the arithmetic mean (AM) aggregation method and the weighted mean (WM) aggregation method. Boxplot whiskers extend out 1.5 times the interquartile range. Outliers were omitted for clarity; however, several outliers were present, especially in the case of the $M_{0}$ and $M_{t}$ estimators under both aggregation approaches.

Results are from simulating trotlines. Estimators include MKA_AM, minimum know alive bend-level abundance estimator aggregated to the segment level using the arithmetic mean approach; MKA_WM, minimum know alive bend-level abundance estimator aggregated to the segment level using the weighted mean approach; Mo_AM, closed population bend-level abundance estimator assuming constant capture probability aggregated to the segment level using the arithmetic mean approach; $\mathrm{M}_{0}$ WM, closed population bend-level abundance estimator assuming constant capture probability aggregated to the segment level using the weighted mean approach; $\mathrm{M}_{\mathrm{t}} \mathrm{AM}$, closed population bend-level abundance estimator assuming heterogeneity in capture probability in time, aggregated to the segment level using the arithmetic mean approach; and $\mathrm{M}_{\mathrm{t}} \mathrm{WM}$, closed population bend-level abundance estimator assuming heterogeneity in capture probability in time, aggregated to the segment level using the weighted mean approach. 


\section{Appendix 3: Reference Population and Catch-Data Simulation Parameters}

This appendix contains further details of the reference population and catch-data simulations described in the "Fundamental Information Objective 2" section, under the "Calculate Performance Metrics Given Alternative Monitoring Designs” section. Table 3.1 describes the parameters utilized to construct the 400 replicate reference populations, while tables 3.2 and 3.3describe the parameters utilized to construct the 4 catch datasets per population per monitoring design, for a total of 1,600 catch-data replicates per monitoring design. Additionally, figures 3.1-3.4 show example probability densities of the occasion-level capture probabilities (resulting from the effort and catchability distributions described in tables 3.2 and 3.3) used in the catch-data simulations. 
Table 3.1. Reference population parameter inputs and distributions.

\begin{tabular}{|c|c|c|c|}
\hline Parameter & Description & Distribution or Value & Explanation \\
\hline$\lambda_{\text {segment,origin }}$ & $\begin{array}{l}\text { Average pallid sturgeon density } \\
\text { (fish/rkm) }\end{array}$ & $\begin{array}{l}\text { Segment and origin specific constants; } \\
\text { see table } 6\end{array}$ & $\begin{array}{l}\text { Values derived from the literature; see } \\
\text { table } 6 .\end{array}$ \\
\hline$\gamma_{\text {basin }}$ & $\begin{array}{l}\text { Basin-specific number of males per } \\
\text { females }\end{array}$ & Uniform $(1,3)$ & $\begin{array}{l}\text { Encompass the range of sex ratios } \\
\text { reported by Jaeger and others ( } 2009) \text {, } \\
\text { Steffensen and others ( } 2013 a) \text {, Jordan and } \\
\text { others (2016), and Wildhaber and others } \\
\text { (2017). }\end{array}$ \\
\hline$L_{\infty}$ & $\begin{array}{l}\text { Asymptotic length } \\
\text { Brody-growth coefficient }\end{array}$ & $\begin{array}{l}\qquad\left(L_{\infty}, k\right) \sim \exp \left(N\left(\mu_{\text {basin }}, \Sigma_{\text {basin }}\right)\right), \\
\text { truncated to the } 80 \% \text { confidence ellipse }\end{array}$ & $\begin{array}{l}\text { von Bertalanffy growth parameters fit to } \\
\text { PSPAP length data; truncated to eliminate } \\
\text { extreme values. }\end{array}$ \\
\hline$\mu_{\text {basin }}$ & $\begin{array}{l}\text { Mean values for } \\
\left(\log L_{\infty}, \log k\right)\end{array}$ & $\begin{array}{c}\mu_{\text {upperbasin }}=(7.136028770,-3.003764445) \\
\mu_{\text {lowerbasin }}=(6.982160,-2.382711)\end{array}$ & PSPAP database fit \\
\hline$\Sigma_{\text {basin }}$ & $\begin{array}{l}\text { Variance-covariance matrix for } \\
\qquad\left(\log L_{\infty}, \log k\right)\end{array}$ & $\begin{aligned} \Sigma_{\text {upperbasin }} & =\left[\begin{array}{cc}0.2768 & -0.364 \\
-0.364 & 0.6342\end{array}\right] \\
\Sigma_{\text {lowerbasin }} & =\left[\begin{array}{cc}0.0894 & -0.1327 \\
-0.1327 & 0.3179\end{array}\right]\end{aligned}$ & PSPAP database fit \\
\hline$\Phi$ & Average annual survival & 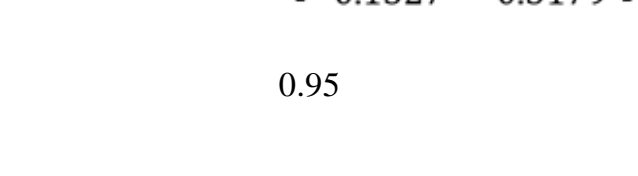 & $\begin{array}{l}\text { Approximation for age-2+ survival; used } \\
\text { for all fish in order to analyze estimator } \\
\text { performance under constant trend in the } \\
\text { absence of recruitment. }\end{array}$ \\
\hline$\beta$ & Site fidelity parameter & 1 & $\begin{array}{l}\text { Gives high site fidelity; will vary in future } \\
\text { simulations to examine the effects of } \\
\text { movement. }\end{array}$ \\
\hline$\Psi_{\text {basin,recruitment }}$ & $\begin{array}{l}\text { Basin-specific frequency of } \\
\text { recruitment }\end{array}$ & $\begin{array}{l}\text { Discrete-Uniform }(1 / 5,1 / 4,1 / 3,1 / 2,1) \text { for } \\
\text { half the populations and } 0 \text { (that is, no } \\
\text { recruitment) for the other half }\end{array}$ & $\begin{array}{l}\text { Recruitment frequencies are unknown; } \\
\text { compare recruitment outcomes to no } \\
\text { recruitment outcomes. }\end{array}$ \\
\hline$\lambda_{\text {recruits,basin }}$ & $\begin{array}{l}\text { Basin-specific average number of age- } \\
0 \text { naturally produced pallid sturgeon, } \\
\text { given recruitment has occurrerd and } \\
\text { age } 0 \text { s are present in the study area }\end{array}$ & 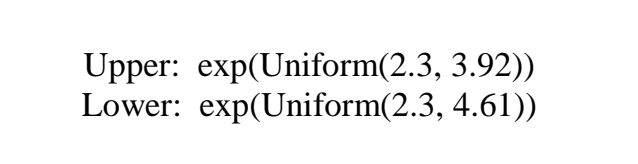 & $\begin{array}{l}\text { Average number of age 0s naturally } \\
\text { produced is unknown but assumed low. }\end{array}$ \\
\hline
\end{tabular}


Upper basin trotlines
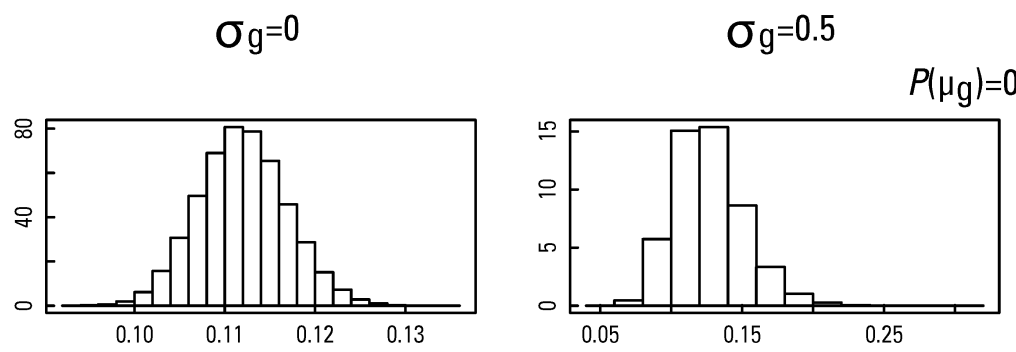

$\sigma_{g}=1$

$\sigma_{g}=1.5$

$P\left(\mu_{\mathrm{g}}\right)=0.000025$
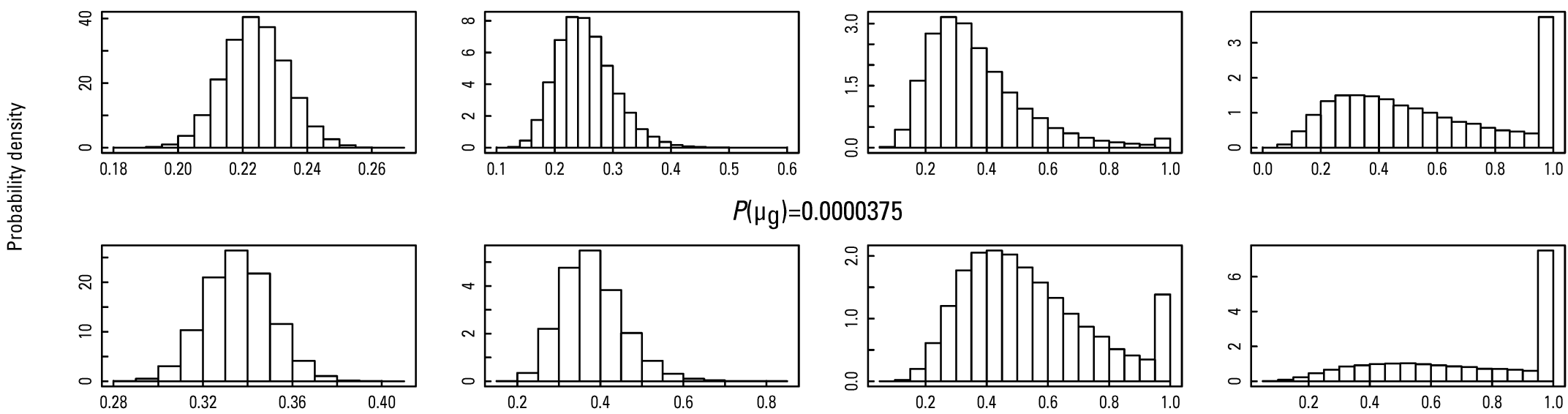

$P(\mu \mathrm{g})=0.0000375$
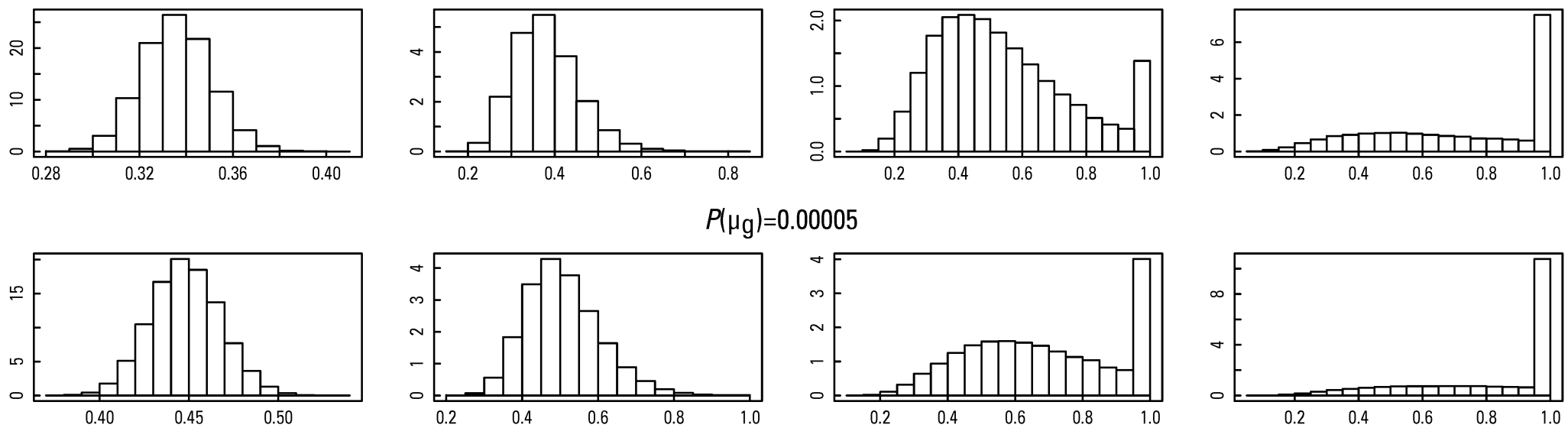

$P\left(\mu_{\mathrm{g}}\right)=0.00005$
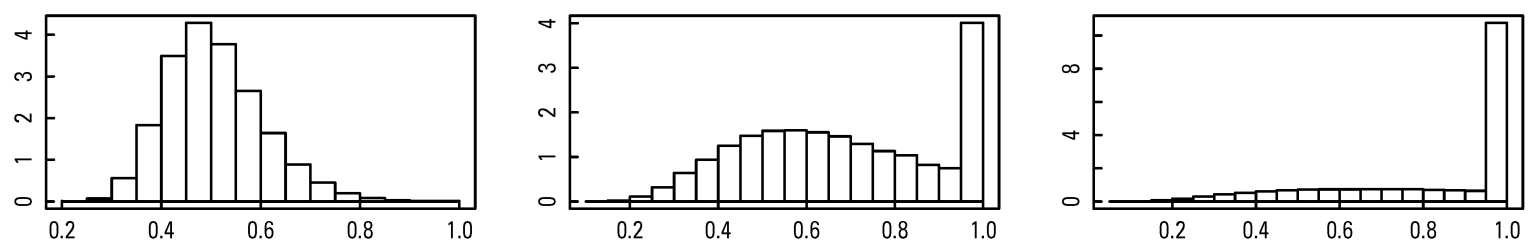

Occasion level capture probability, pk

Figure 3.1. Occasion-level capture probability distributions resulting from various mean and standard deviation inputs to the logit-normal distribution defining deployment-level catchability in the catch-data simulations. Each row has a fixed mean value, $P\left(\mu_{g}\right)=P\left(\mu_{T L C 1}\right)=0.0000125,0.000025,0.0000375,0$ or 0.00005 , and each column has a fixed standard deviation, $\sigma_{g}=\sigma_{T L C 1}=0,0.5,1$, or 1.5 . The function $P$ is the logistic function, $P(x)=\frac{1}{1+e^{-x}}$. For all plots, 50,000 occasion-level capture probabilities were calculated with deployment-level effort values drawn from the gamma distribution for trotlines in the upper basin described in table 3.2 . 
Upper basin trammel nets
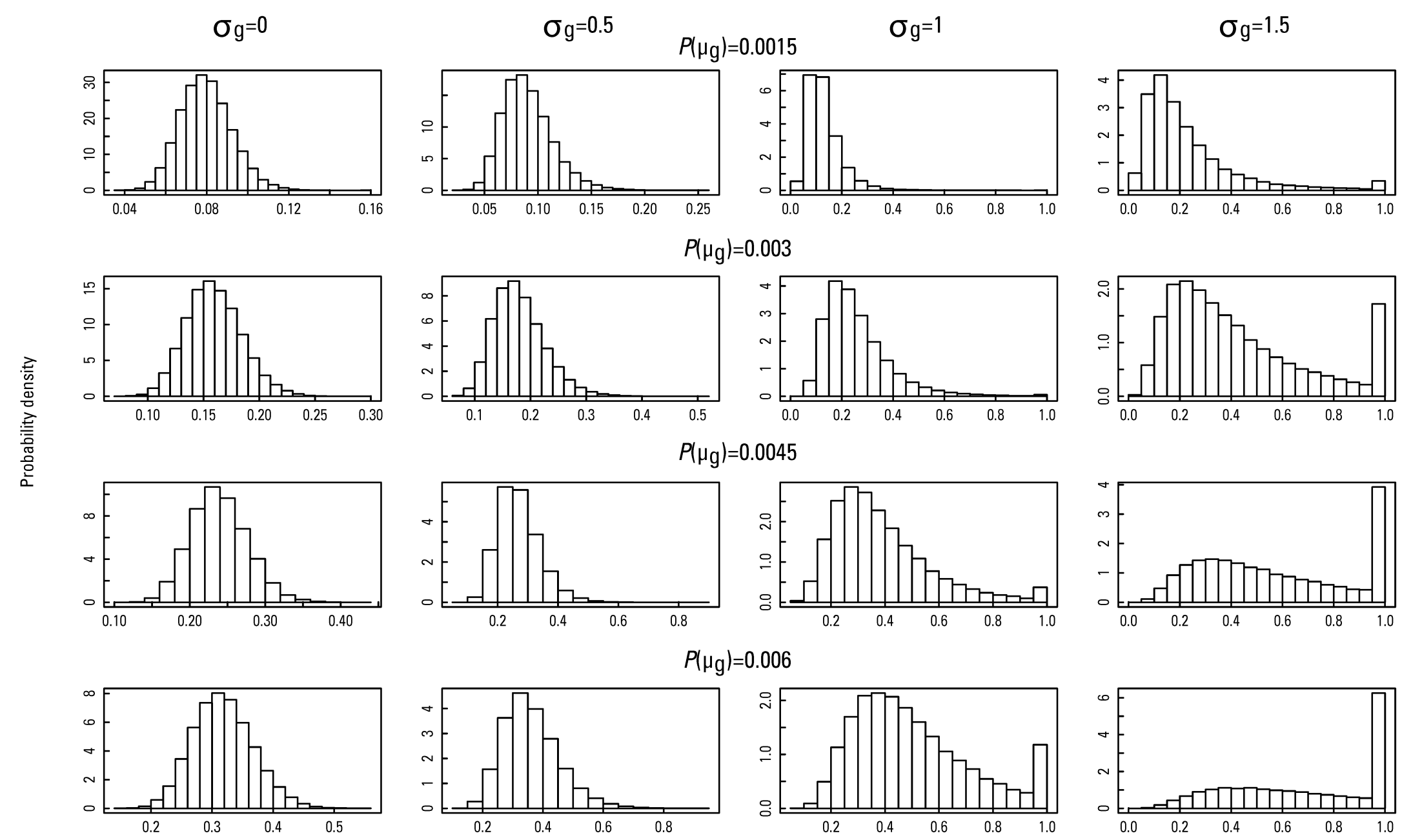

Occasion level capture probability, pk

Figure 3.2. Occasion-level capture probability distributions resulting from various mean and standard deviation inputs to the logit-normal distribution defining deployment-level catchability in the catch-data simulations. Each row has a fixed mean value $P\left(\mu_{g}\right)=P\left(\mu_{T N}\right)=0.0015,0.003,0.0045$, or 0.006 , and each column has a fixed standard deviation $\sigma_{g}=\sigma_{T N}=0,0.5,1$, or 1.5 . The function $P$ is the logistic function, $P(x)=\frac{1}{1+e^{-x}}$. For all plots, 50,000 occasion-level capture probabilities were calculated with deployment-level effort values drawn from the gamma distribution for trammel nets in the upper basin described in table 3.2 . 


\section{Lower basin trotlines}

$\sigma_{g}=0$
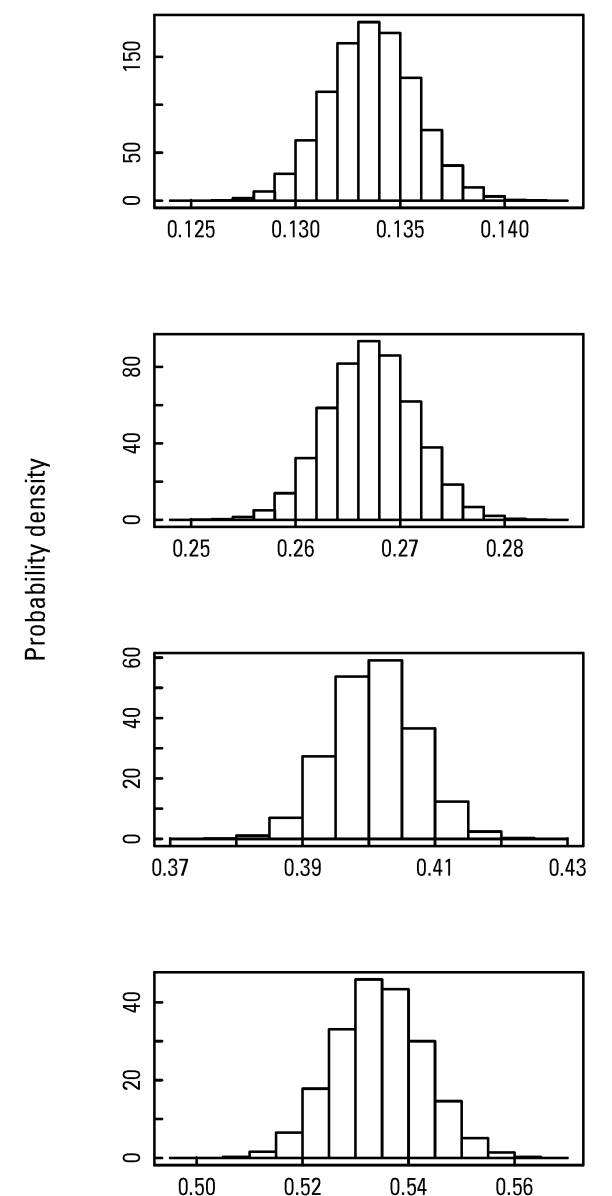

$\sigma_{g}=0.5$

$P(\mu \mathrm{g})=0.0000125$
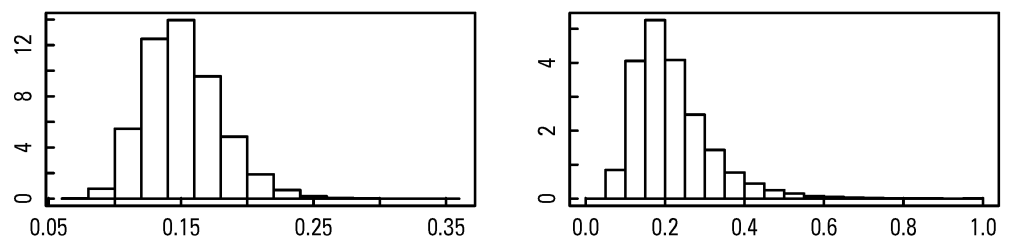

$P(\mu \mathrm{g})=0.000025$
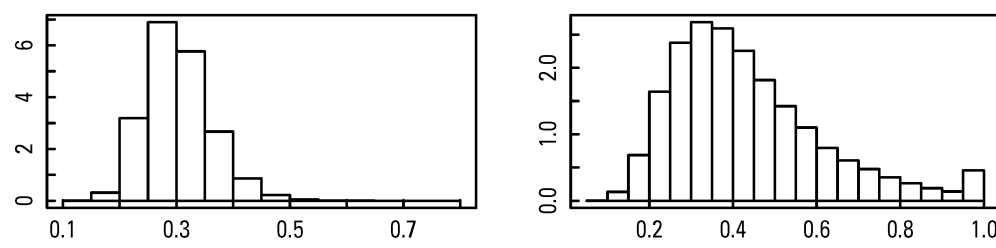

$P(\mu \mathrm{g})=0.0000375$
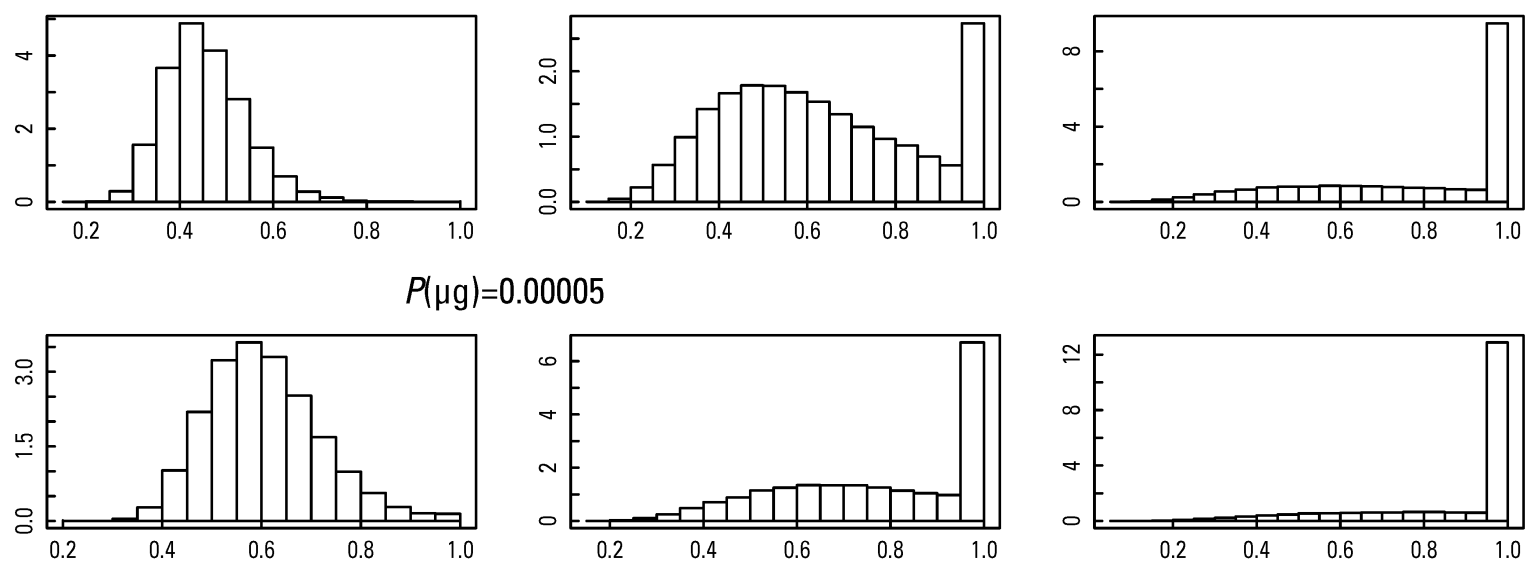

Occasion level capture probability, $\mathrm{pk}_{\mathrm{k}}$

Figure 3.3. Occasion-level capture probability distributions resulting from various mean and standard deviation inputs to the logit-normal distribution defining deployment-level catchability in the catch-data simulations. Each row has a fixed mean value, $P\left(\mu_{g}\right)=P\left(\mu_{T L C 1}\right)=0.0000125,0.000025,0.0000375,0$ or 0.000051 , and each column has a fixed standard deviation, $\sigma_{g}=\sigma_{T L C 1}=0,0.5,1$, or 1.5. The function $P$ is the logistic function, $P(x)=\frac{1}{1+e^{-x}}$. For all plots, 50,000 occasion-level capture probabilities were calculated with deployment-level effort values drawn from the gamma distribution for trotlines in the lower basin described in table 3.2 . 
Lower basin gill nets

$\sigma_{g}=0$
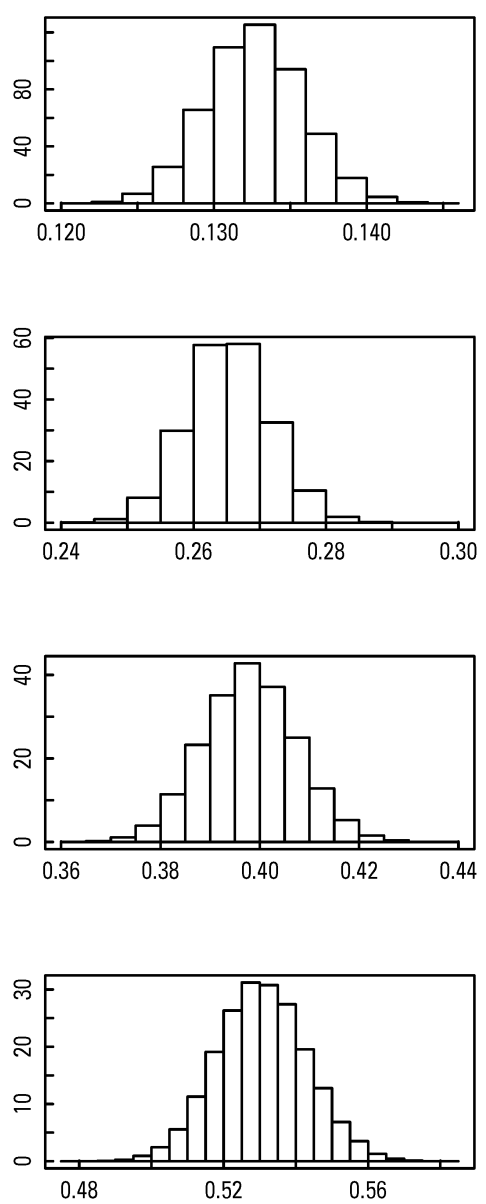

$\sigma_{g}=0.5$

$P(\mu \mathrm{g})=0.0000125$
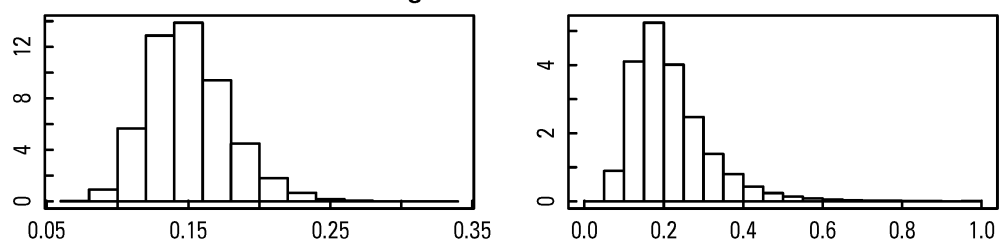

$P\left(\mu_{\mathrm{g}}\right)=0.000025$
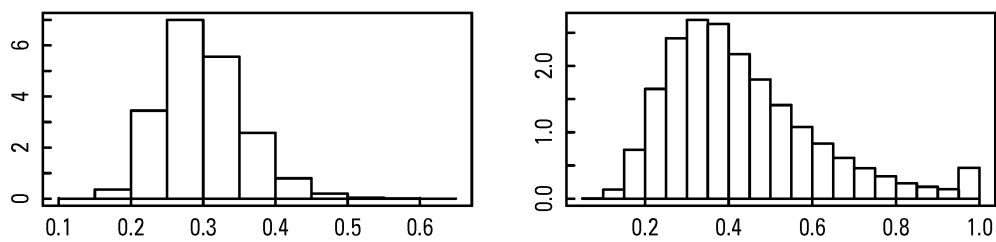

$P(\mu \mathrm{g})=0.0000375$
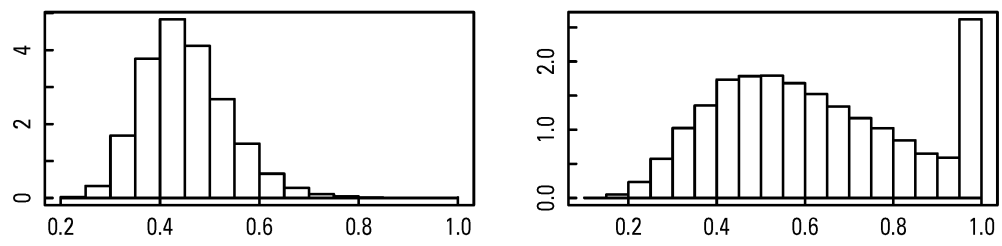

$P(\mu \mathrm{g})=0.00005$

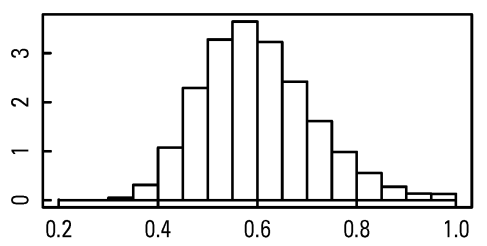

$\sigma_{g}=1$

$\sigma_{g}=1.5$
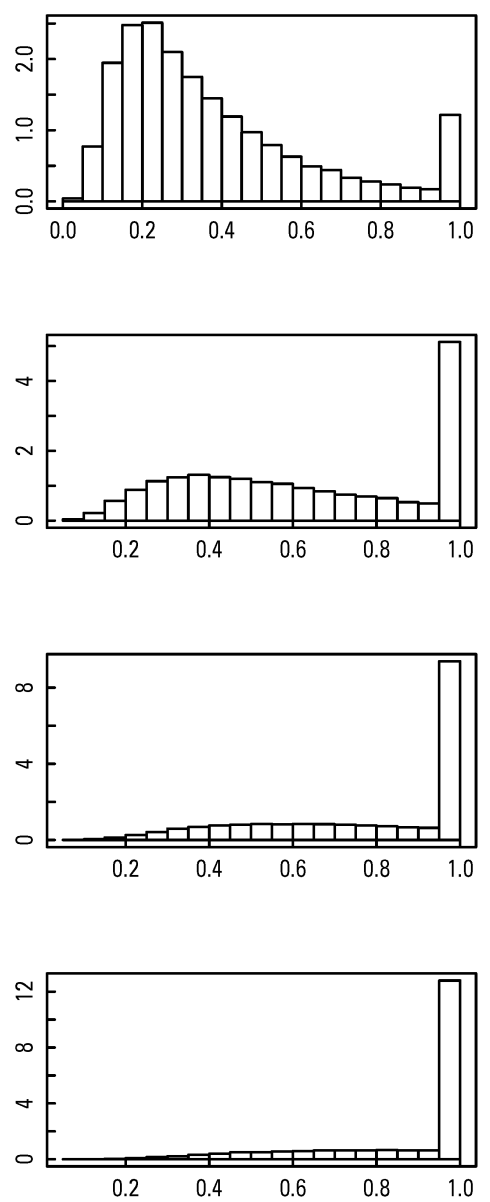

Occasion level capture probability, pk

Figure 3.4. Occasion-level capture probability distributions resulting from various mean and standard deviation inputs to the logit-normal distribution defining deployment-level catchability in the catch-decision data simulations. Each row has a fixed mean value, $P\left(\mu_{g}\right)=P\left(\mu_{G N 14}\right)=0.0000125,0.000025,0.0000375,0 \mathrm{r}$ 0.00005 , and each column has a fixed standard deviation, $\sigma_{g}=\sigma_{G N 14}=0,0.5,1$, or 1.5 . The function $P$ is the logistic function, $P(x)=\frac{1}{1+e^{-x}}$. For all plots, 50,000 occasion-level capture probabilities were calculated with deployment-level effort values drawn from the gamma distribution for gill nets in the lower basin described in table 3.2 . 
Table 3.2. Summary of effort data by gear and basin, where effort is measured in minutes of gear use per deployment.

[The shape and rate columns are the results of fitting a gamma distribution to the data. Gears include gill nets (GN14, GN18, GN41, GN81), otter trawls (OT16), trotlines (TLC1, TLC2), and trammel nets (TN). PSPAP, pallid sturgeon population assessment program; Std. Dev., standard deviation]

\begin{tabular}{|c|c|c|c|c|c|c|c|c|}
\hline \multirow[b]{2}{*}{$\begin{array}{c}\text { PSPAP } \\
\text { gear } \\
\text { code } \\
\end{array}$} & \multirow[b]{2}{*}{$\begin{array}{l}\text { Sample } \\
\text { size }\end{array}$} & \multicolumn{5}{|c|}{ Effort, in minutes } & \multicolumn{2}{|c|}{$\begin{array}{c}\text { Gamma } \\
\text { parameters }\end{array}$} \\
\hline & & Mean & $\begin{array}{l}\text { Std. } \\
\text { Dev. }\end{array}$ & Minimum & Maximum & Median & Shape & Rate \\
\hline \multicolumn{9}{|c|}{ Lower Basin } \\
\hline GN14 & 1,523 & 1,326 & 89 & 1,002 & 1,633 & 1,333 & 224.49 & 0.17 \\
\hline GN18 & 4,698 & 1,221 & 123 & 750 & 1,695 & 1,221 & 98.54 & 0.08 \\
\hline GN41 & 1,118 & 1,327 & 91 & 969 & 1,563 & 1,340 & 210.67 & 0.16 \\
\hline GN81 & 4,094 & 1,219 & 117 & 750 & 1,678 & 1,222 & 109.46 & 0.09 \\
\hline OT16 & 606 & 3 & 7 & 1 & 178 & 2 & 1.99 & 0.71 \\
\hline TLC1 & 2,164 & 1,336 & 60 & 1,067 & 1,542 & 1,341 & 500.66 & 0.37 \\
\hline TLC2 & 5,219 & 1,206 & 109 & 859 & 1,591 & 1,210 & 122.77 & 0.1 \\
\hline $\mathrm{TN}$ & 1,072 & 4 & 3 & 1 & 69 & 3 & 2.57 & 0.68 \\
\hline \multicolumn{9}{|c|}{ Upper Basin } \\
\hline GN14 & 700 & 1,130 & 183 & 310 & 1,751 & 1,151 & 29.74 & 0.03 \\
\hline GN41 & 716 & 1,134 & 183 & 295 & 1,762 & 1,138 & 30.63 & 0.03 \\
\hline OT16 & 9,081 & 4 & 7 & 1 & 511 & 4 & 6.79 & 1.67 \\
\hline TLC1 & 3,616 & 1,120 & 139 & 755 & 1,615 & 1,119 & 65.33 & 0.06 \\
\hline TLC2 & 80 & 1,025 & 150 & 694 & 1,416 & 994 & 49.93 & 0.05 \\
\hline $\mathrm{TN}$ & 10,915 & 7 & 7 & 1 & 610 & 6 & 5.13 & 0.77 \\
\hline
\end{tabular}


Table 3.3. Catch data simulation parameter inputs and distributions.

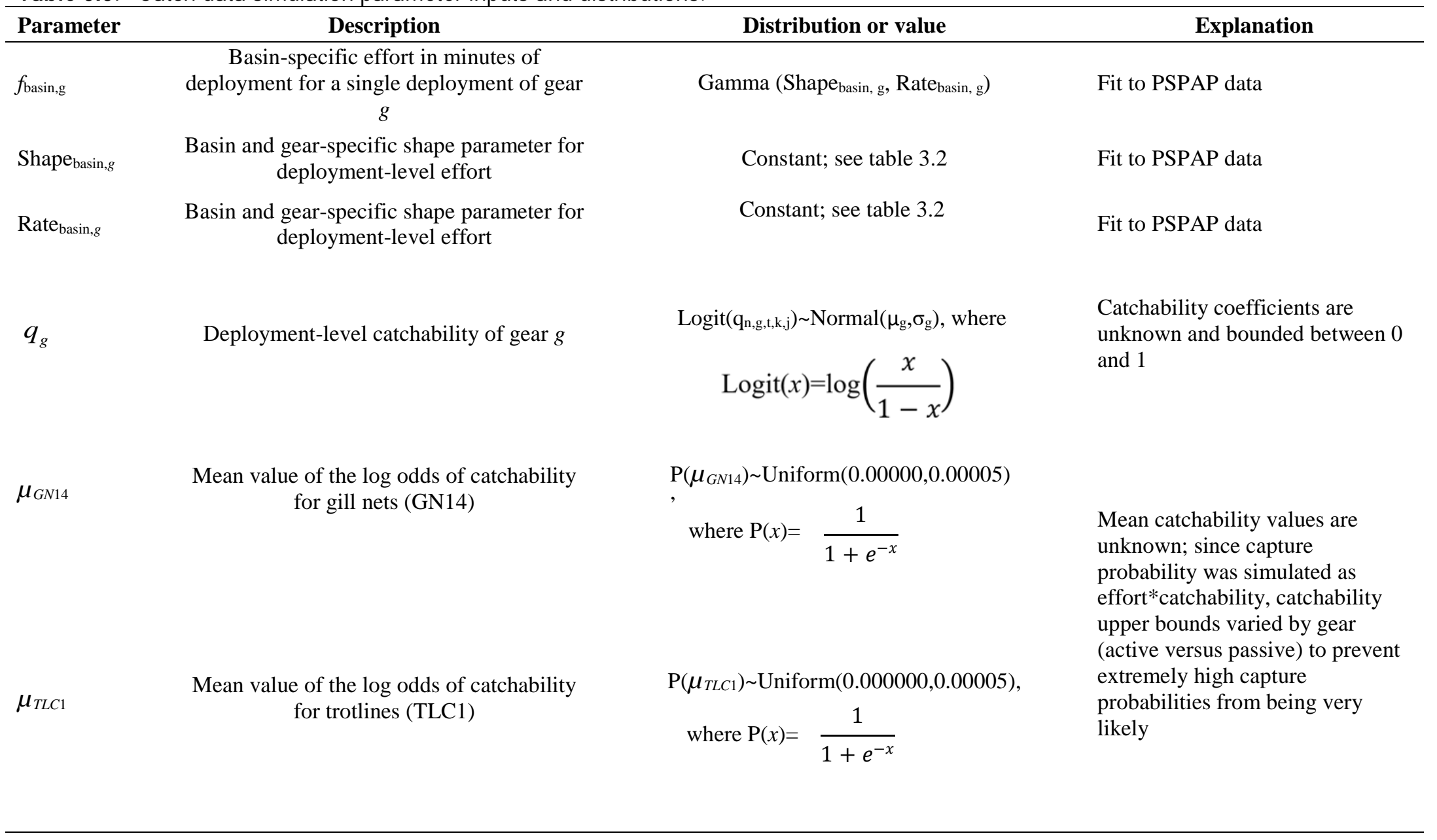

